IFAS Extension

\title{
Field Observations During the Ninth Microwave Water and Energy Balance Experiment (MicroWEX-9): from March 24, 2010 through January 6, 2011'
}

\author{
Tara Bongiovanni, Pang-Wei Liu, Karthik Nagarajan, Robert Terwilleger, Alejandro Monsivais- \\ Huertero, Jasmeet Judge, Juan Fernandez-Diaz, Daniel Preston, Tyler Cheney, and \\ Jason Motsinger ${ }^{2}$
}

1. This document is AE494, one of a series of the Department of Agricultural and Biological Engineering, Florida Cooperative Extension Service, Institute of Food and Agricultural Sciences, University of Florida. First published January 2013. Please visit the EDIS website at http://edis.ifas.ufl.edu.

2. Tara Bongiovanni and Pang-Wei Liu are graduate research assistants of the Center for Remote Sensing (CRS) at the University of Florida (UF); Karthik Nagarajan is a post-doctoral researcher of CRS at UF; Robert Terwilleger is an undergraduate research assistant of the CRS at UF; Alejandro Monsivais-Huertero is an assistant professor at ESIME Unidad Ticomán, Instituto Politécnico Nacional, Mexico; Jasmeet Judge is an assistant professor and director of CRS at UF (email: jasmeet@ufledu); Juan Fernandez-Diaz is a graduate research assistant of the National Center for Airborne Laser Mapping (NCALM) at the University of Houston (UH); Daniel Preston is an engineering technician of CRS at UF; Tyler Cheney and Jason Motsinger are affiliated with UF's Research Experience for Undergraduates; Tara Bongiovanni, Pang-Wei Liu, Karthik Nagarajan, Robert Terwilleger, Alejandro Monsivais-Huertero, Jasmeet Judge, and Daniel Preston are affiliated with the Department of Agricultural and Biological Engineering Department, Institute of Food and Agricultural Sciences, University of Florida, Gainesville, FL 32611. Juan Fernandez-Diaz is affiliated with the Civil Engineering Department, University of Houston. 
1. Introduction

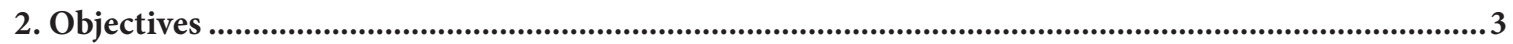

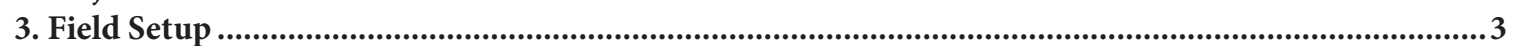

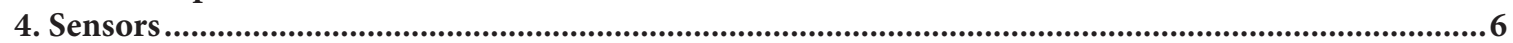

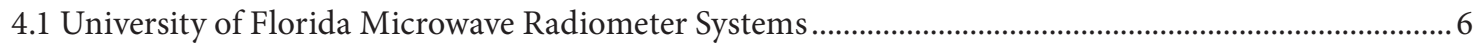

4.1.1 University of Florida C-band Microwave Radiometer (UFCMR)......................................................... 6

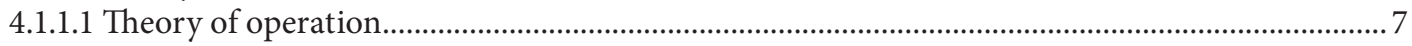

4.1.2 University of Florida L-band Microwave Radiometer (UFLMR) ....................................................... 8

4.1.2.1 Theory of Operation .................................................................................................................. 10

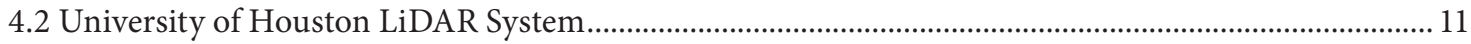

4.2.1 University of Houston Mobile Terrestrial Laser Scanning (M-TLS) ................................................ 11

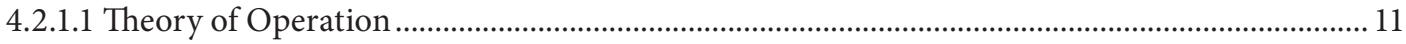

4.2.2 University of Houston Optech Gemini Airborne LiDAR Terrain Mapper........................................ 12

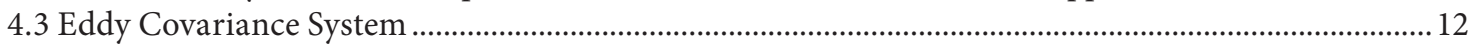

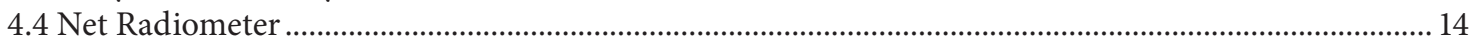

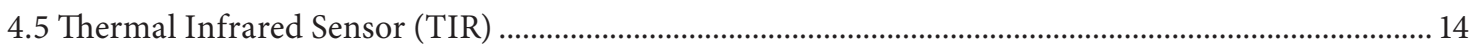

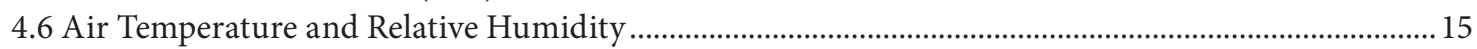

4.7 Soil Moisture and Temperature Probes............................................................................................. 15

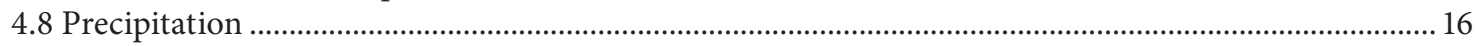

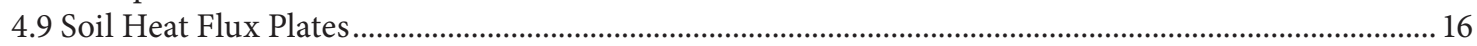

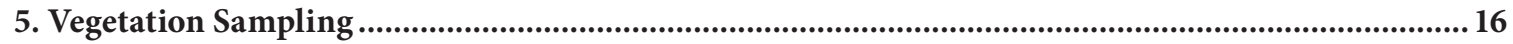

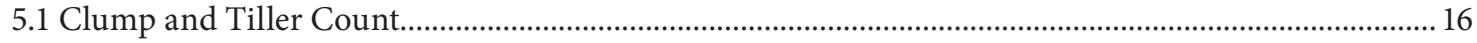

5.2 Clump Height and Width................................................................................................................. 16

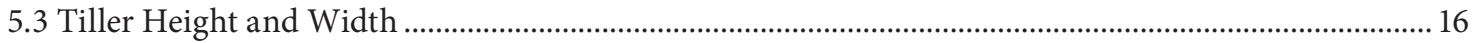

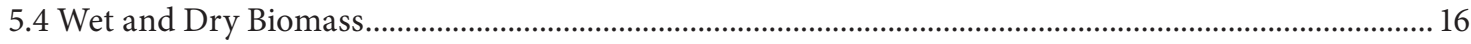

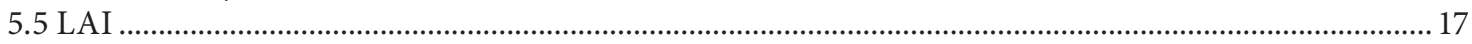

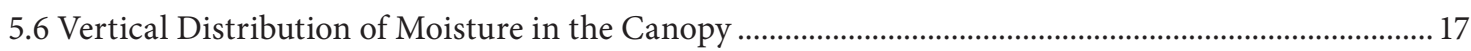

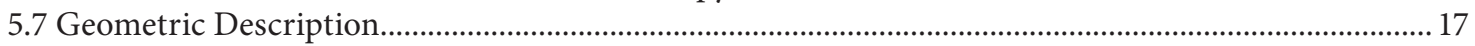

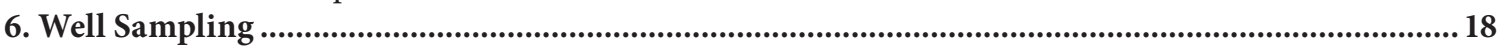

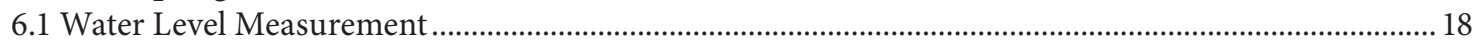

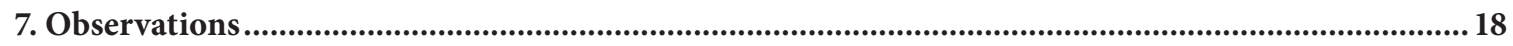

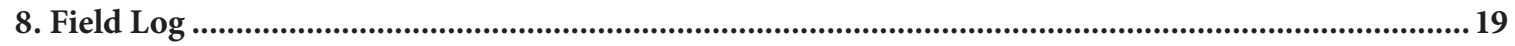

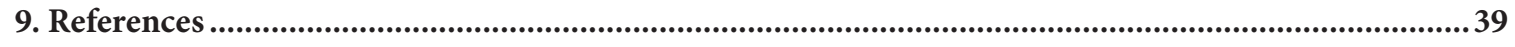

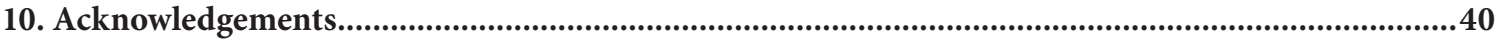

A. Field Observations.........................................................................................................................

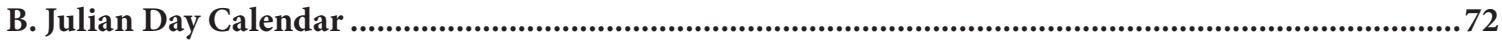




\section{Introduction}

For accurate prediction of weather and near-term climate, root-zone soil moisture is one of the most crucial components driving surface hydrological processes. Soil moisture in the top meter governs moisture and energy fluxes at the landatmosphere interface, and it plays a significant role in the partitioning of precipitation into runoff and infiltration.

Energy and moisture fluxes at the land surface can be estimated by Soil-Vegetation-Atmosphere-Transfer (SVAT) models. These models are typically used in conjunction with numerical weather and near-term climate prediction models and surface-subsurface hydrological models. Even though the biophysics of moisture and energy transport is well-captured in most current SVAT models, the errors in initialization, forcings, and computation accumulate over time, and the model estimates of soil moisture in the root zone diverge from reality. Remotely sensed microwave observations can be assimilated in these models to improve root-zone soil moisture estimates.

The microwave signatures at low frequencies, particularly at $1.4 \mathrm{GHz}$ (L-band), are very sensitive to soil moisture in the top few centimeters in most vegetated surfaces. Many studies have been conducted in agricultural areas, such as bare soil, grass, soybean, wheat, pasture, and corn, to understand the relationship between soil moisture and microwave remote sensing. It is important to know how microwave signatures vary with soil moisture, evapotranspiration (ET), and biomass during the growing season for a dynamic agricultural canopy with a significant wet biomass of $10-12 \mathrm{~kg} / \mathrm{m}^{2}$.

\section{Objectives}

The goal of MicroWEX-9 was to conduct a season-long experiment that incorporated passive microwave observations as well as Light Detection and Ranging (LiDAR) observations for a growing season of elephant grass. The variety of sensors would allow for further understanding of the land-atmosphere interactions during the growing season, and their effect on observed passive microwave signatures at $6.7 \mathrm{GHz}$ and $1.4 \mathrm{GHz}$, as well as LiDAR scans. These observations match that of the satellite-based passive microwave radiometers, Advanced Microwave Scanning Radiometer (AMSR), and the Soil Moisture and Ocean Salinity (SMOS) mission, respectively, and the upcoming NASA Soil Moisture Active Passive (SMAP) mission. Specific objectives of MicroWEX-9 included the following:

1. To understand the growth and development of elephant grass and establish vegetation sampling methodologies accepted by agronomists that can be used in calibrating crop-growth models and are relevant to microwave remote sensing observations.

2. To re-design the installation structures to meet the demands of a dense, high elephant grass canopy.

3. To collect passive microwave, LiDAR, and other ancillary data to develop preliminary algorithms to estimate microwave signatures for elephant grass.

4. To evaluate feasibility of soil moisture retrievals using passive microwave data at $6.7 \mathrm{GHz}$ and $1.4 \mathrm{GHz}$ for the growing elephant grass canopy.

\section{Field Setup}

MicroWEX-9 was conducted by the Center for Remote Sensing, Department of Agricultural and Biological Engineering at the Plant Science Research and Education Unit (PSREU) $\left(29.4^{\circ} \mathrm{N}, 82.17^{\circ} \mathrm{W}\right)$, Institute of Food and Agricultural Sciences (IFAS), Citra, FL. Figure 1 shows the location of the PSREU, and Figure 2 shows the study site for the MicroWEX-9. The study site was located at the west side of the PSREU. The dimensions of the study site were $183 \mathrm{~m} \mathrm{x} 183 \mathrm{~m}$. The elephant grass (Pennisetum purpureum) varieties Merkeron, N-13, N-43, and N-51 were planted on December 7 [Day of Year (DoY) 341 in 2009 , at an orientation $0^{\circ}$ from the east (See Table B-1 on page 72 for corresponding months and dates to the DOY mentioned in this document). The planting technique used was a double-stalk planting rate cut into $91 \mathrm{~cm}$ (36 inches) pieces, and the row spacing was $182.9 \mathrm{~cm}$ (72 inches). A linear move system was used for irrigation in the beginning of the season with gun irrigation starting on DoY 102 in 2010. The instruments consisted of a ground-based microwave radiometer system, a mobile LiDAR system, and micrometeorological stations. The ground-based microwave radiometer system 
was installed facing south to avoid the radiometer shadow interfering with the field of view. The ground-based LiDAR system was mounted in a truck bed that would be consecutively positioned near the west and east corners of the north edge of the field. The airborne LiDAR system flew over the field to gather data. The ground-based microwave radiometer system installation began on DoY 50 in 2010 with micrometeorological stations installed on DoY 83 in 2010.

A micrometeorological station was installed at the center of the field and included soil heat flux plates and the eddy covariance system. Four rain gauges were installed at different heights in line with the outer edge of the radiometer footprint. Two micrometeorological stations with soil moisture, soil heat flux, and soil temperature sensors were installed at the locations shown in Figure 3. A relative humidity $(\mathrm{RH})$ sensor, temperature sensor, and net radiometer were installed at the West Station. This report provides detailed information regarding sensors deployed and data collected during the MicroWEX-9.

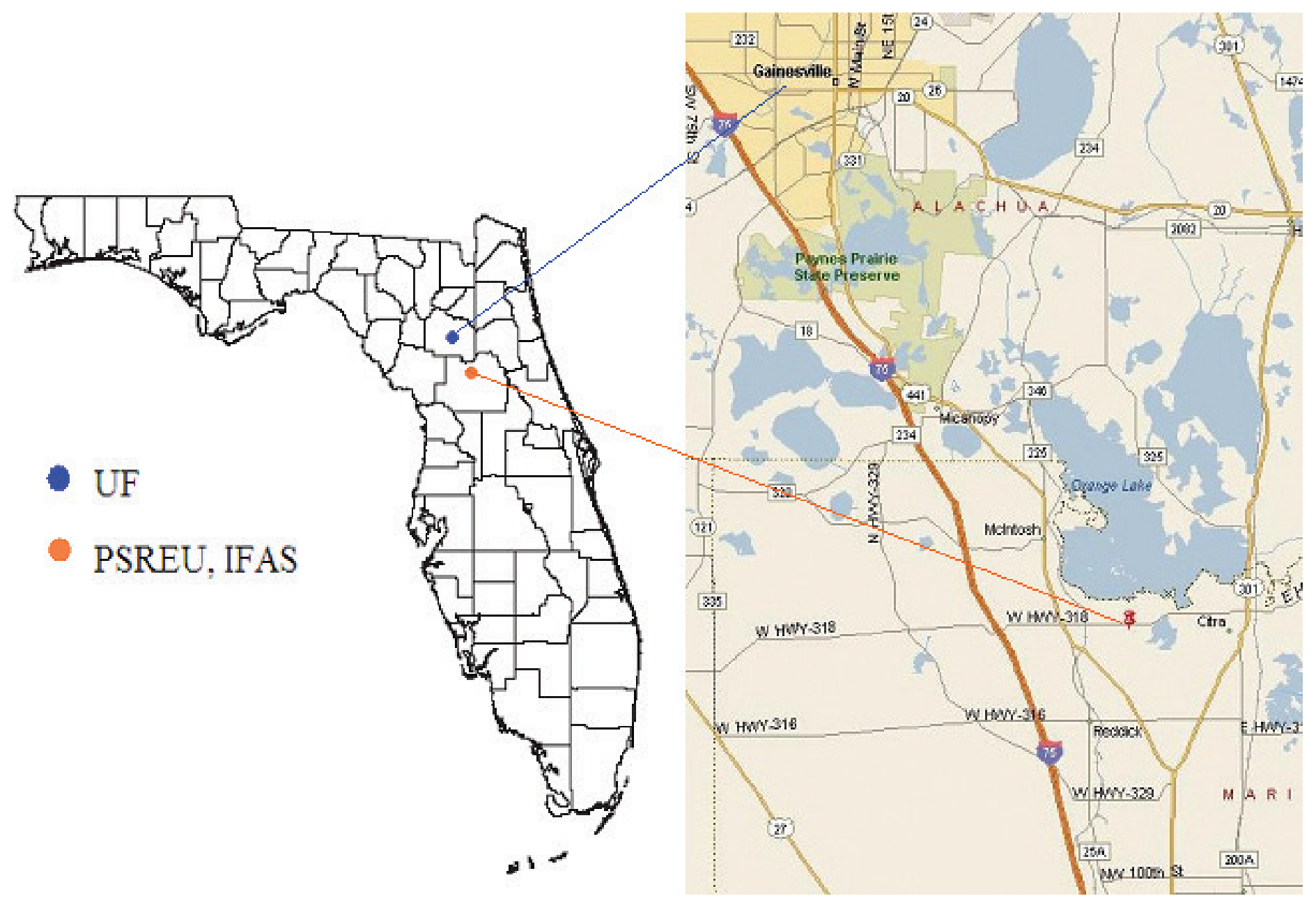

Figure 1. Location of PSREU/IFAS (from http://plantscienceunit.ifas.ufl.edu/directions.shtml) 


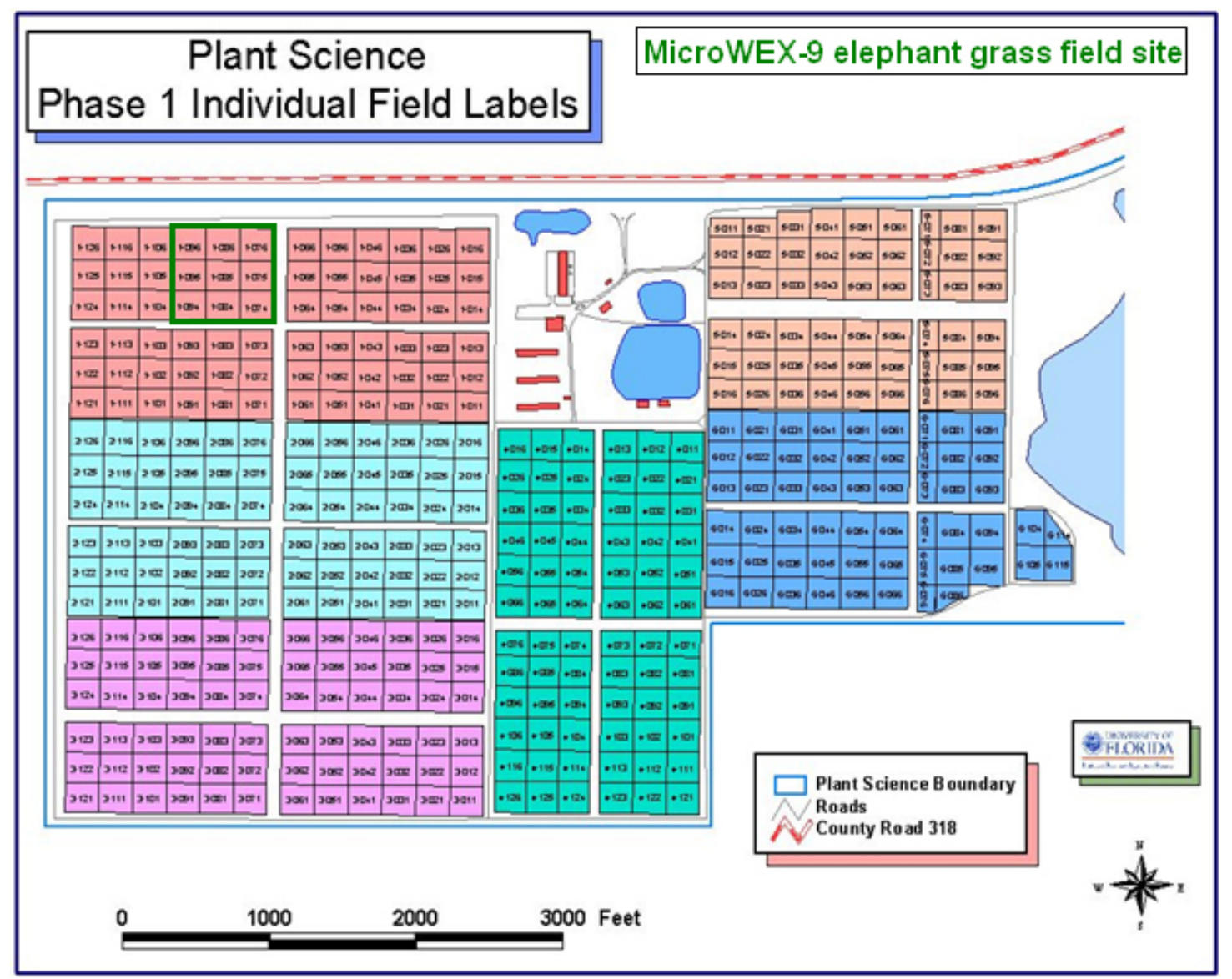

Figure 2. Location of the field site for MicroWEX-9 at the UF/IFAS PSREU (from http://plantscienceunit.ifas.ufl.edu/images/location/p1.jpg)

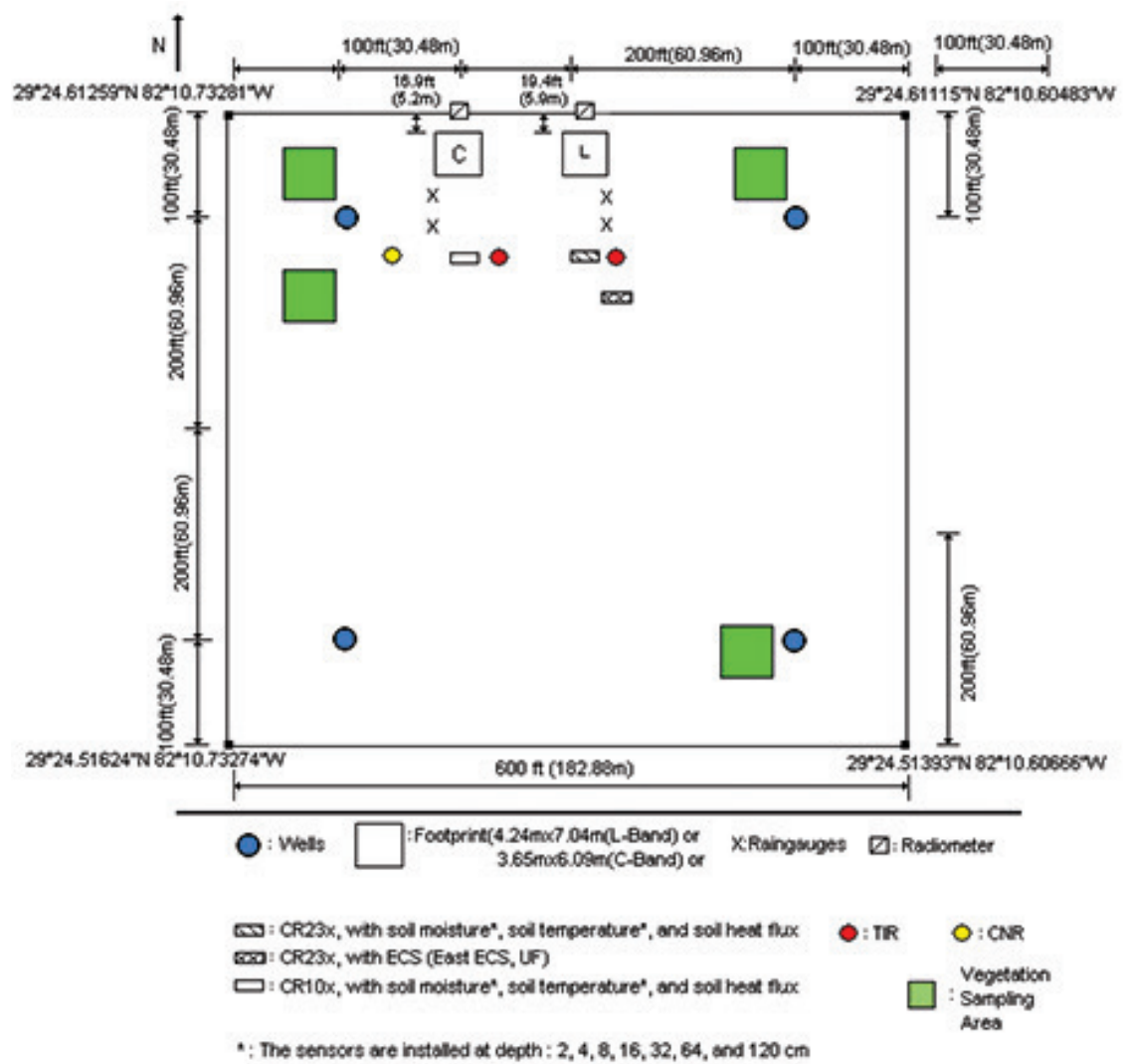

Figure 3. Layout of the sensors during MicroWEX-9. 


\section{Sensors}

MicroWEX-9 had four major types of instrument subsystems: 1) the ground-based University of Florida L-band and C-band Radiometers, 2) the mobile University of Houston LiDAR, 3) the micrometeorological, and 4) the soil subsystem.

\subsection{University of Florida Microwave Radiometer Systems}

\subsubsection{UNIVERSITY OF FLORIDA C-BAND MICROWAVE RADIOMETER (UFCMR)}

Microwave brightness temperatures at $6.7 \mathrm{GHz}(\lambda=4.48 \mathrm{~cm})$ were measured every 15 minutes using the University of Florida's C-band Microwave Radiometer system (UFCMR) (Figure 4a). The radiometer system consisted of a dual polarization total power radiometer operating at the center frequency of $6.7 \mathrm{GHz}$ housed atop a $10 \mathrm{~m}$ tower installed on a 16' trailer bed. The UFCMR was designed and built by the Microwave Geophysics Group at the University of Michigan. It operates at the center frequency at $6.7 \mathrm{GHz}$, which is identical to one of the center frequencies on the space-borne AMSR aboard the NASA Aqua Satellite Program. The UFCMR observed the $5.721 \mathrm{~m}$ x $7.707 \mathrm{~m}$ footprint from a height of 7.365 $\mathrm{m}$. A rotary system was used to rotate the look-angle of the UFCMR both for field observations and sky measurements. The brightness temperatures were observed at an incidence angle of 50. The radiometer was calibrated at least once every week with a microwave absorber as warm load and measurement of sky as cold load. Figure $4 \mathrm{~b}$ shows a close-up of the rotary system, and Figure 4c shows a close-up of the UFCMR antenna. Table 1 lists the UFCMR specifications. Figure A-1 shows the V- and H-pol brightness temperatures observed at C-band during MicroWEX-9.

Table 1. UFCMR specifications

\begin{tabular}{|c|c|c|}
\hline Parameter & Qualifier & Value \\
\hline Frequency & Center & $6.7 \mathrm{GHz}$ \\
\hline Bandwidth & $3 \mathrm{~dB}$ & $20 \mathrm{MHz}$ \\
\hline \multirow[t]{4}{*}{ Beamwidth } & 3 dB V-pol elevation ${ }^{a}$ & $23^{\circ}$ \\
\hline & 3 dB V-pol azimuth ${ }^{b}$ & $21^{\circ}$ \\
\hline & $3 \mathrm{~dB} \mathrm{H}-$ pol elevation ${ }^{\mathrm{c}}$ & $21^{\circ}$ \\
\hline & $3 \mathrm{~dB} H$-pol azimuth ${ }^{d}$ & $23^{\circ}$ \\
\hline Isolation & & $>27 \mathrm{~dB}$ \\
\hline Polarizations & Sequential & $\mathrm{V} / \mathrm{H}$ \\
\hline Receiver temp $\left(\mathrm{T}_{\text {rec }}\right)$ & & $437 \mathrm{~K}$ \\
\hline Noise Figure & From $\mathrm{T}_{\text {rec }}$ & $3.99 \mathrm{~dB}$ \\
\hline RF gain & & $85 \mathrm{~dB}$ \\
\hline \multirow[t]{2}{*}{ NEDT } & $1 \mathrm{sec}$ & $0.71 \mathrm{~K}$ \\
\hline & $8 \mathrm{sec}$ & $0.25 \mathrm{~K}$ \\
\hline \multicolumn{3}{|c|}{ 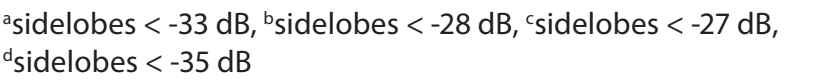 } \\
\hline
\end{tabular}




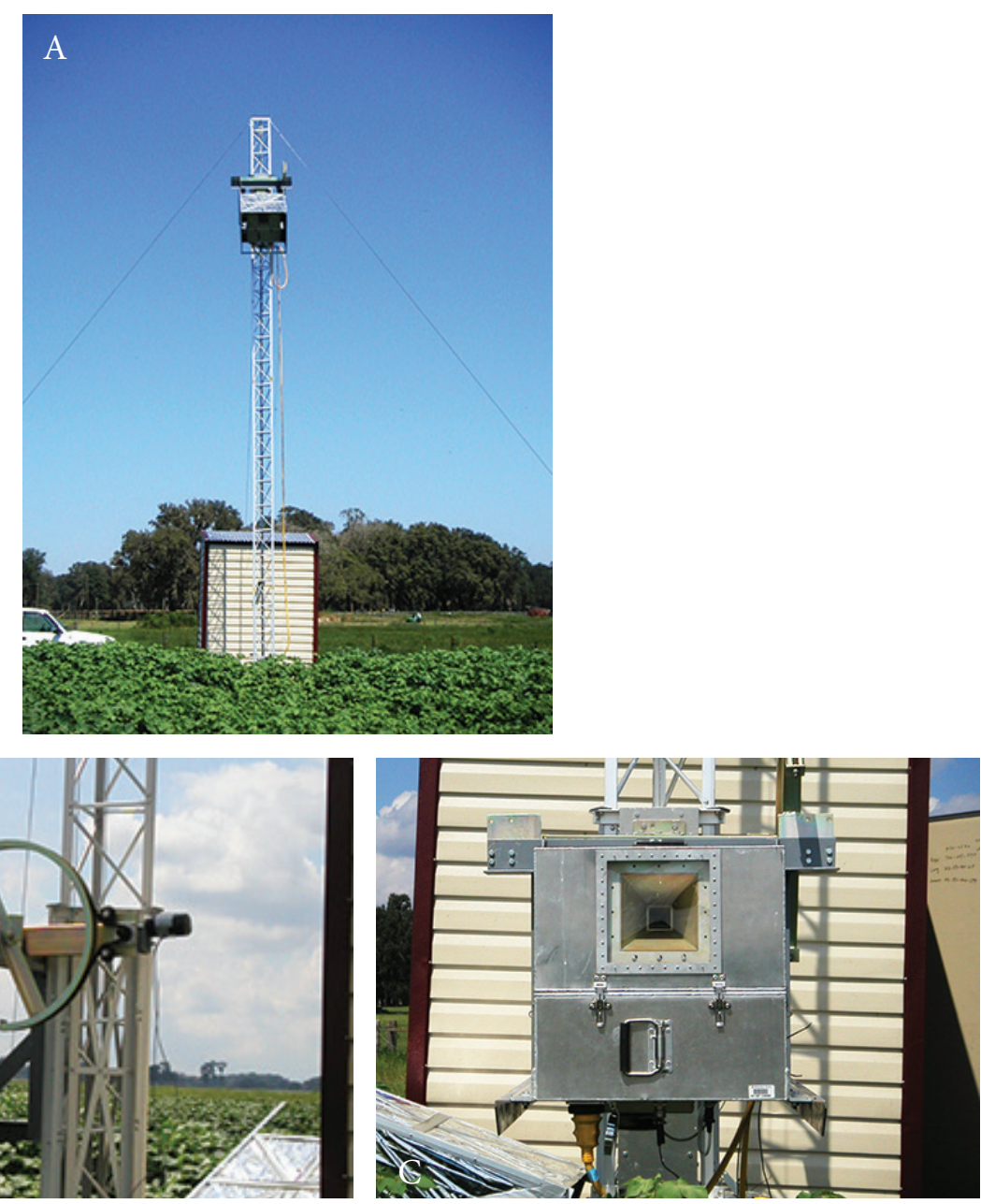

Figure 4. (a) The UFCMR system, (b) the side view of the UFCMR showing the rotary system, and (c) the front view of the UFCMR showing the receiver antenna.

\subsubsection{THEORY OF OPERATION}

The UFCMR uses a thermoelectric cooler (TEC) for thermal control of the Radio Frequency (RF) stages for the UFCMR. This is accomplished by the Oven Industries "McShane" thermal controller. McShane is used to cool or heat by the Proportional-Integral-Derivative (PID) algorithm with a high degree of precision at $0.01^{\circ} \mathrm{C}$. The RF components are all attached to an aluminum plate that must have sufficient thermal mass to eliminate short-term thermal drifts. All components attached to this thermal plate, including the TEC, use thermal paste to minimize thermal gradients across junctions.

The majority of the gain in the system is provided by a gain and filtering block designed by the University of Michigan for the STAR-Light instrument (De Roo 2003). The main advantage of this gain block is the close proximity of all the amplifiers, simplifying the task of thermal control. This gain block was designed for a radiometer working at the radio astronomy window of 1400-1427 MHz, and so the receiver is a heterodyne type with downconversion from the C-band RF to L-band. To minimize the receiver noise figure, a C-band low-noise amplifier (LNA) is used just prior to downconversion. To protect the amplifier from saturation due to out-of-band interference, a bandpass filter with relatively wide bandwidth but low insertion loss is used just prior to the amplifier. Three components are between the filter and antenna: a switch for choosing polarization, a switch for monitoring a reference load, and an isolator to minimize changes in the apparent system gain due to differences in the reflections looking upstream from the LNA.

The electrical penetrations use commercially available weatherproof bulkhead connections (Deutsch connectors or equivalent). The heat sinks have been carefully located employing RTV (silicone sealant) to seal the bolt holes. The radome uses 15 mil polycarbonate for radiometric signal penetration. It is sealed to the case using a rubber gasket held down by a square retainer. 
The first SubMiniature version A (SMA) connection is an electromechanical latching, driven by the Z-World control board switches between V-and H-polarization sequentially. The SMA second latching that switches between the analog signal from the first switch and the reference load signal from a reference load resistor sends the analog signal to an isolator, where the signals within $6.4-7.2 \mathrm{GHz}$ in radiofrequency are isolated. Then the central frequency is picked up by a $6.7 \mathrm{GHz}$ bandpass filter, which also protects the amplifier from saturation. A low-noise amplifier (LNA) is used to eliminate the noise figure and adjust gain. A mixer takes the input from the LNA and a local oscillator to output a 1.4 GHz signal to STAR-Light. After the Power Amplifier and Filtering Block (Star-Light back-end), the signal is passed through a Square Law Detector and a Post-Detection Amplifier (PDA). The UFCMR is equipped with a microcontroller that is responsible for taking measurements, monitoring the thermal environment, and storing data until a download is requested. A laptop computer is used for running the user interface named FluxMon to communicate with the radiometer through Radiometer Control Language (RadiCL). The radiometer is configured to maintain a particular thermal set point, and make periodic measurements of the brightness at both polarizations sequentially and the reference load. The data collected by the radiometer are not calibrated within the instrument, since calibration errors could corrupt an otherwise useful dataset. Figure 5 shows the block diagram of the UFCMR.

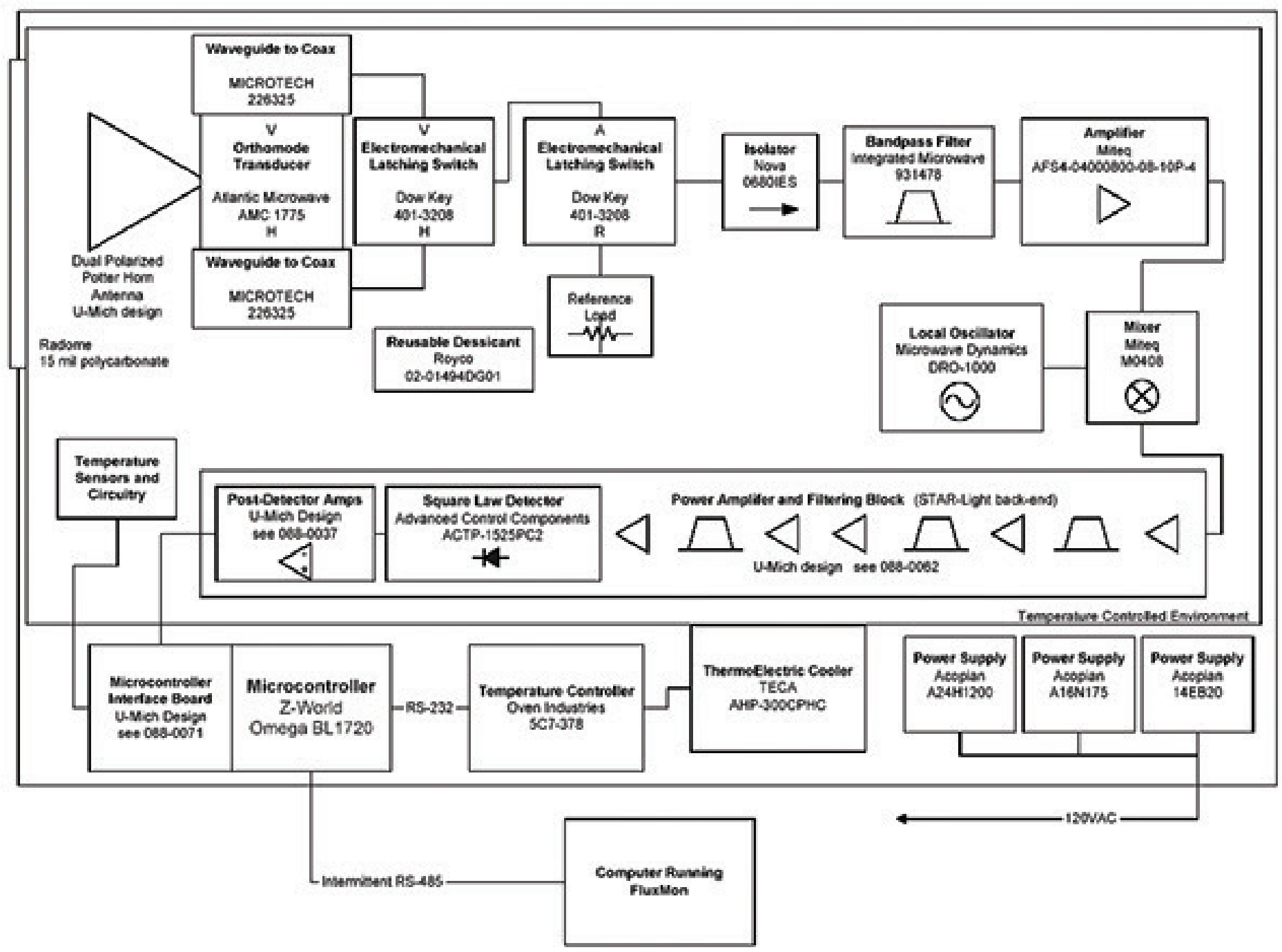

Figure 5. Block diagram of the University of Florida C-band Microwave Radiometer (De Roo 2002).

\subsubsection{UNIVERSITY OF FLORIDA L-BAND MICROWAVE RADIOMETER (UFLMR)}

Microwave brightness temperatures at $1.4 \mathrm{GHz}(\lambda=21.0 \mathrm{~cm})$ were measured every 15 minutes using the University of Florida's L-band Microwave Radiometer system (UFLMR) (Figure 6a). The radiometer system consisted of a single polarization total power radiometer operating at the center frequency of $1.4 \mathrm{GHz}$ housed atop a $9.14 \mathrm{~m}$ tower installed on a 16 ' trailer bed. UFLMR was designed and built by the Microwave Geophysics Group at the University of Michigan. It operates at the center frequency at $1.4 \mathrm{GHz}$, which is identical to one of the center frequencies on the space-borne SMOS 
mission. The UFLMR observed the $6.044 \mathrm{~m}$ x $8.931 \mathrm{~m}$ footprint from a height of $7.175 \mathrm{~m}$. A rotary system was used to rotate the look-angle of the UFLMR for both field observations and sky measurements. The brightness temperatures were observed at an incidence angle of $54^{\circ}$. The radiometer was calibrated at least every week with a measurement of sky as cold load. Every other week the radiometer calibration included a microwave absorber as warm load. Figure $6 \mathrm{~b}$ shows a closeup of the rotary system, and Figure $6 \mathrm{c}$ shows the antenna of the UFLMR. Table 2 lists the UFLMR specifications. Figure A-1 shows the horizontally polarized brightness temperatures observed by the UFLMR during MicroWEX-9.
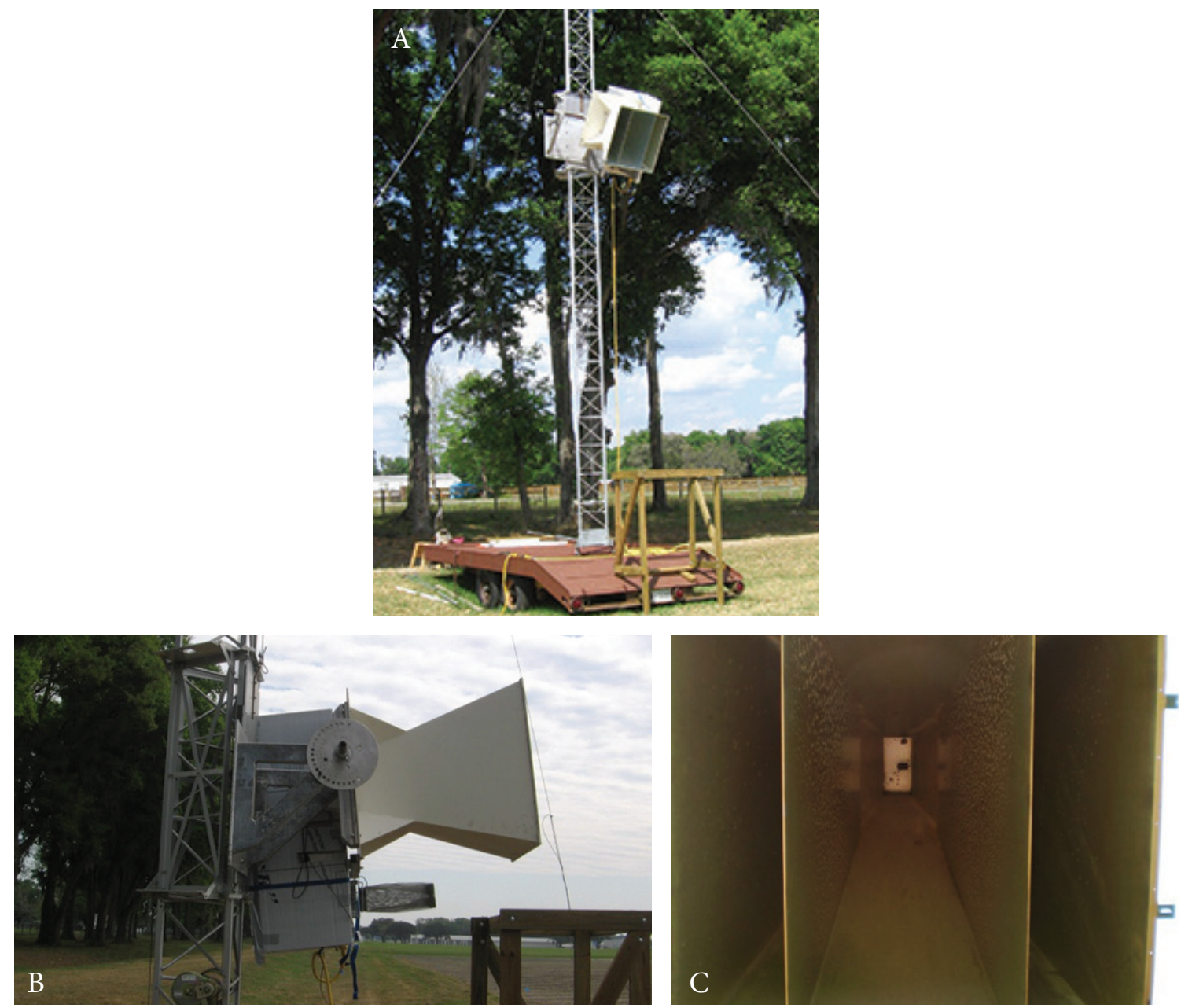

Figure 6. (a) The UFLMR system, (b) the side view of the UFLMR showing the rotary system, and (c) the front view of the UFLMR showing the receiver antenna.

Table 2. UFLMR specifications

\begin{tabular}{|l|l|l|}
\hline \multicolumn{1}{|c|}{ Parameter } & \multicolumn{1}{|c|}{ Qualifier } & \multicolumn{1}{c|}{ Value } \\
\hline Frequency & Center & $1.4 \mathrm{GHz}$ \\
\hline Bandwidth & $3 \mathrm{~dB}$ & $20 \mathrm{MHz}$ \\
\hline Beamwidth & $3 \mathrm{~dB} \mathrm{H-pol} \mathrm{elevation}{ }^{\mathrm{a}}$ & $22.5^{\circ}$ \\
\cline { 2 - 3 } & $3 \mathrm{~dB} \mathrm{H-pol} \mathrm{azimuth}{ }^{\mathrm{b}}$ & $20.0^{\circ}$ \\
\hline Polarizations & Single & $\mathrm{H}$ \\
\hline Receiver temp (Trec) & & $179 \mathrm{~K}$ \\
\hline Noise Figure & From Trec & $2.1 \mathrm{~dB}$ \\
\hline RF gain & & $79 \mathrm{~dB}$ \\
\hline NE $\Delta \mathrm{T}$ & & $0.5 \mathrm{~K}$ \\
\hline asidelobes $<-20 \mathrm{~dB}^{\mathrm{b}}{ }^{\mathrm{b}}$ sidelobes $<-30 \mathrm{~dB}$ & \\
\hline
\end{tabular}




\subsubsection{THEORY OF OPERATION}

The UFLMR is similar to the UFCMR in many respects, using a thermoelectric cooler (TEC) for thermal control, a similar electromechanical switching mechanism, and a Z-World controller. The PDA is the same, and the software is a newer version of RadiCL. The RF block is designed for V-and H-pol switching. However, the UFLMR's septum horn antenna is single-polarized. As a result, only the $\mathrm{H}$-pol signal is guided from antenna to coax to the RF block, and the V-pol input to the RF block is a cold load (ColdFet).

In the RF block, the first switch alternates between V-and H-pol, and the second alternates between the reference load and the signal from the first switch. An isolator prevents reflections of the input signal. After the isolator, the signal goes through a bandpass filter and then an LNA, followed by a series of bandpass filters and Power Amplifiers before the Square Law Detector and the PDA. The microcontroller logs voltage and physical temperature measurements. Figure 7 shows the block diagram of the UFLMR.
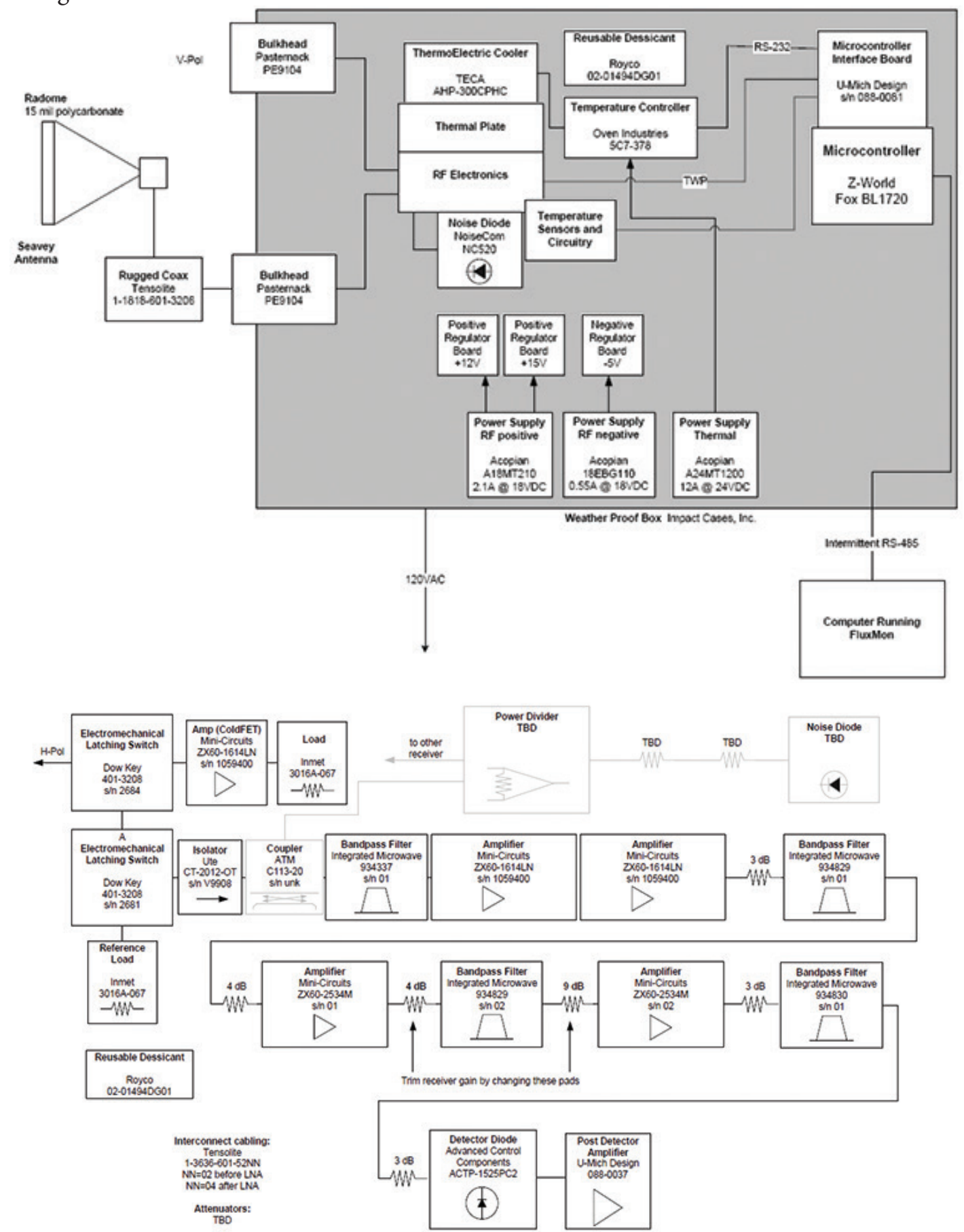

Figure 7. Block diagram of the University of Florida L-band Microwave Radiometer (De Roo 2010). 


\subsection{University of Houston LiDAR System}

\subsubsection{UNIVERSITY OF HOUSTON MOBILE TERRESTRIAL LASER SCANNING (M-TLS)}

The Mobile Terrestrial Laser Scanning system (M-TLS), also known as the terrestrial LiDAR mapping system, was integrated by the Geosensing Systems Engineering at the University of Florida. The core of the M-TLS is a commercial 2-axis ground-based laser scanner, ILRIS 3D, produced by Optech Inc. The M-TLS is enabled to acquire high-density laser clouds from terrestrial geometry and records these laser points in a XYZ coordinate system with return pulse intensity. The M-TLS operates on a mobile telescoping, rotating and tilting platform, and has up to 6 degrees of freedom, which provides for $360^{\circ}$ profile scanning. In addition, a scanner built-in 6 megapixel digital camera is capable of generating the laser intensity as well as the RGB colored textured from the targets, which enables the M-TLS 3D-colored mapping. The laser scanner in this system operates at a wavelength of $1535 \mathrm{~nm}$, with a pulse width less than 10 nanoseconds and energy of less than 10 microjoules. The sample separation can be adjusted down to $0.00115^{\circ}$, and the scanning speed is 2,000 points per second. Figure 8 shows that the M-TLS was equipped on a lift to scan the experimental field.

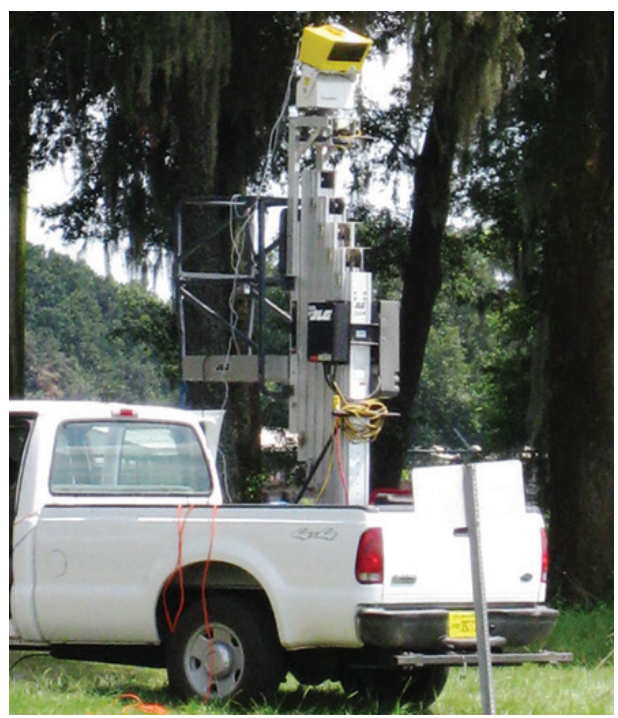

Figure 8. The M-TLS.

\subsubsection{THEORY OF OPERATION}

The ILRIS 3D laser scanner is a very precise instrument composed of two basic subsystems. The first subsystem is a laser ranging device commonly called LiDAR; the second is an optical and/or mechanical device capable of steering the laser beam in a scanning fashion over the area of interest (Fröhlich and Mettenleiter 2004). The fundamental function of LiDAR is to measure the distance between the scanner and target by laser pulse flight time. Thus, precisely determining

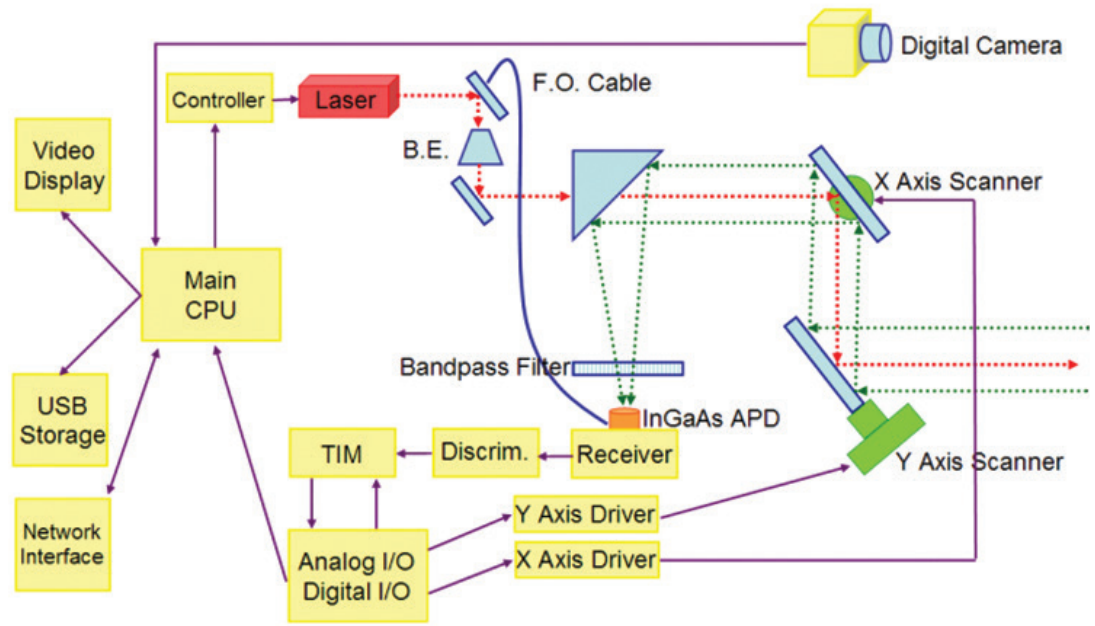

Figure 9. Optech ILRIS 3D laser scanner block diagram. 
the pulse transmitted and received time is the critical work of the system. Figure 9 shows a block diagram of the ILRIS 3D laser scanner unit.

A central microprocessor controls the subsystems, and collects, analyzes, and displays data and scanning information. The laser beam is generated by Nd YAG laser, and then a small amount of photons are diverted through the fiber optic (FO) cable to start the time-of-flight timer. After it is expanded, the laser beam passes through an optical element and then is deflected by the vertical and horizontal scanning mirror to transmit to the target.

The laser beam is reflected as a distorted waveform from the targets, so the incoming waveform needs to be tuned to focus on the detector by a fixed parabolic mirror to generate an output voltage. This voltage signal is digitized in an A/D converter and then sent to a Constant Fraction Discriminator (CFD). The CFD is a device to trigger a timing signal at a constant fraction of the input amplitude. By computing the timing interval of the outgoing and incoming pulse, the two-way time-of-flight is determined in the Time Interval Meter (TIM). Finally, the computer calculates the range to the target, records it on its internal memory, and commands the emission of a new pulse. This entire process is repeated until the end of the scan mission. Figure A-2 shows the LiDAR observations during MicroWEX-9 with airborne measurements taken on DoY 245 and ground-based measurements on DoY 246.

\subsubsection{UNIVERSITY OF HOUSTON OPTECH GEMINI AIRBORNE LIDAR TERRAIN MAPPER}

Airborne LiDAR observations were conducted on DoY 245 in 2010, using an Optech Gemini Airborne LiDAR Terrain Mapper (ALTM) equipped with a waveform digitizer, owned and operated by the National Center for Airborne Laser Mapping (NCALM), University of Houston (UH). The system is integrated with a GPS and an inertial measurement unit, and mounted on a twin-engine Cessna 337 Skymaster. The Gemini system is capable of operating laser pulse rates of up to $167 \mathrm{kHz}$, with a multiple pulse mode that is able to fire a second laser pulse while waiting for the returns of the first one, and two beam divergences of 0.25 and $0.80 \mathrm{mrad}$. Accurate geo-locations of returns from each transmitted pulse are determined by differential GPS, and the intensities of returns reflect at the near-IR wavelength of $1047 \mathrm{~nm}$. An add-on signal digitizer and computer allow for the sampling and recording of full waveform data. The ALTM detector output voltage is sampled at $1 \mathrm{GHz}$ (every 1 nanosecond) and is quantized on an 8-bit scale between 0 and 1 volts.

In the MicroWEX-9, three LiDAR datasets covering a single flight line were acquired at the averaged flying height of 600 meters above ground level, with varying scan angles and beam divergences. In order to record a complete waveform of each pulse, the pulse repetition rate of $70 \mathrm{kHz}$ was used. The first dataset was collected with a scan angle of $\pm 14^{\circ}$, a scan frequency of $60 \mathrm{~Hz}$, and using a beam divergence of $0.25 \mathrm{mrad}$. With these parameters, the swath width was $298.75 \mathrm{~m}$, with a point density of $\sim 3.6$ points $/ \mathrm{m}^{2}$ resulting in the cross-track and down-track resolutions of 0.513 and $0.542 \mathrm{~m}$, respectively. The other two datasets were collected with the same scan angle of $\pm 5^{\circ}$ and scan frequency of $65 \mathrm{~Hz}$, but different divergence of 0.25 and $0.80 \mathrm{mrad}$, respectively. Under such settings, the point density was 10.26 points $/ \mathrm{m}^{2}$ with the cross-track and down-track resolutions of 0.195 and $0.5 \mathrm{~m}$, respectively.

\subsection{Eddy Covariance System}

A Campbell Scientific eddy covariance system was located near the center of the field, as shown in Figure 3. The system included a CSAT3 anemometer and $\mathrm{KH}_{2} 0$ hygrometer as shown in Figure 10. The CSAT3 is a three-dimensional sonic anemometer, which measures wind speed and the speed of sound on three non-orthogonal axes. Orthogonal wind speed and sonic temperature are computed from these measurements. The $\mathrm{KH}_{2} 0$ measures the water vapor in the atmosphere. Its output voltage is proportional to the water vapor density flux. Latent and sensible heat fluxes were measured every 30 minutes. The height of the eddy covariance system was $1.0 \mathrm{~m}$ from the vegetation, and the orientation of the system was $220^{\circ}$ toward the southwest. On DoY 106 in 2010, the sensor was installed at a height of $1.6 \mathrm{~m}$. On DoY 124, 127, and 138 in 2010, the sensor was moved to a height of $1.88 \mathrm{~m}, 2.19 \mathrm{~m}$, and $2.58 \mathrm{~m}$, respectively. Table 3 lists the specifications of the CSAT3. Data collected by the eddy covariance system have been processed for coordinate rotation (Kaimal and Finnigan 1994; Wilczak, Oncley, and Stage 2001), WPL (Webb, Pearman, and Leuning 1980), oxygen (Van Dijk, Kohsiek, and de Bruin 2003), and sonic temperature corrections (Schotanus, Nieuwstadt, and de Bruin 2003). Figure A-3 shows the processed latent and sensible heat fluxes observed during MicroWEX-9. 


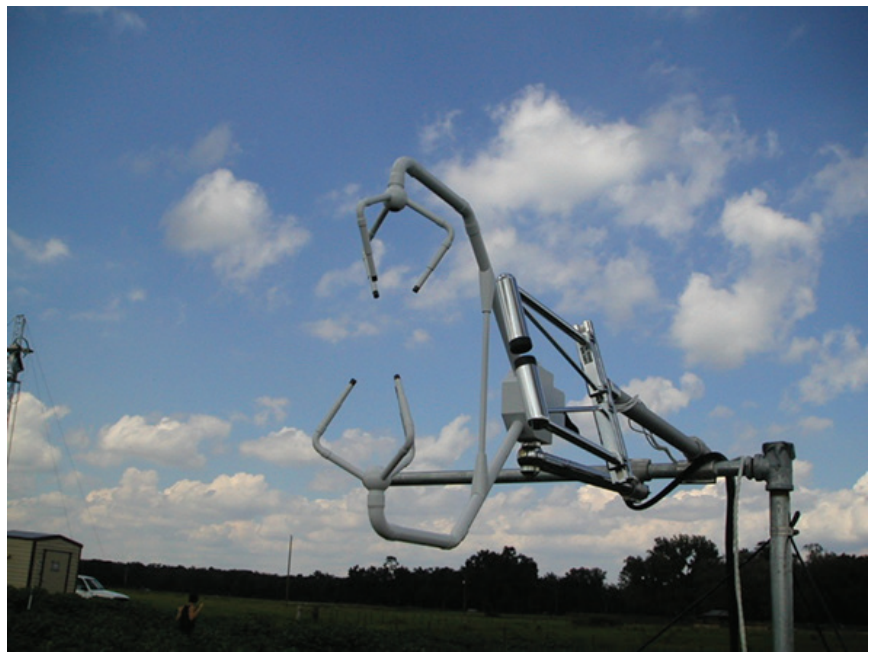

Figure 10. Eddy covariance system.

Table 3. Specifications of the CSAT3 (Campbell Scientific 1998).

\begin{tabular}{|c|c|}
\hline Description & Value \\
\hline Measurement rate & 1 to $60 \mathrm{~Hz}$ \\
\hline Noise equivalent wind & $1 \mathrm{~mm} / \mathrm{sec}$ in horizontal wind speed and $0.5 \mathrm{~mm} / \mathrm{sec}$ in vertical wind speed \\
\hline Wind measurement offset & $< \pm 4 \mathrm{~cm} / \mathrm{sec}$ over -30 to $50^{\circ} \mathrm{C}$ \\
\hline Output signals & Digital SDM or RS-232 and Analog \\
\hline Digital output signal range & $\pm 65.535 \mathrm{~m} / \mathrm{sec}$ in wind speed and $300-366 \mathrm{~m} / \mathrm{sec}$ in speed of sound \\
\hline Digital output signal resolution & $0.25-2 \mathrm{~mm} / \mathrm{sec}$ in vertical wind speed and $1 \mathrm{~mm} / \mathrm{s}$ in speed of sound \\
\hline Analog output signal range & \pm 32.768 to $\pm 65.536 \mathrm{~m} / \mathrm{sec}$ in wind speed and $300-366 \mathrm{~m} / \mathrm{sec}$ in speed of sound \\
\hline Analog output signal resolution & $\pm 8.192 \mathrm{~mm} / \mathrm{sec}$ in vertical wind speed and $16 \mathrm{~mm} / \mathrm{sec}$ in speed of sound \\
\hline Measurement path length & $10.0 \mathrm{~cm}$ vertical and $5.8 \mathrm{~cm}$ horizontal \\
\hline Transducer path angle from horizontal & 60 degrees \\
\hline Transducer & $0.64 \mathrm{~cm}$ in diameter \\
\hline Transducer mounting arms & $0.84 \mathrm{~cm}$ in diameter \\
\hline Support arms & $1.59 \mathrm{~cm}$ in diameter \\
\hline Dimensions: anemometer head & $47.3 \mathrm{~cm} \times 42.4 \mathrm{~cm}$ \\
\hline Dimensions: electronics box & $26 \mathrm{~cm} \times 16 \mathrm{~cm} \times 9 \mathrm{~cm}$ \\
\hline Dimensions: carry case & $71.1 \mathrm{~cm} \times 58.4 \mathrm{~cm} \times 33 \mathrm{~cm}$ \\
\hline Weight: anemometer head & $1.7 \mathrm{~kg}$ \\
\hline Weight: electronics box & $2.8 \mathrm{~kg}$ \\
\hline Weight: shipping & $16.8 \mathrm{~kg}$ \\
\hline Operating temperature range & $-30^{\circ} \mathrm{C}-50^{\circ} \mathrm{C}$ \\
\hline Power requirement: voltage supply & $10-16 \mathrm{VDC}$ \\
\hline Power requirement: current & $200 \mathrm{~mA}$ at $60 \mathrm{~Hz}$ measurement rate and $100 \mathrm{~mA}$ at $20 \mathrm{~Hz}$ measurement rate \\
\hline
\end{tabular}




\subsection{Net Radiometer}

A Kipp and Zonen CNR-1 four-component net radiometer (Figure 11) was located near the center of the field to measure up- and down-welling shortwave and longwave infrared radiation. The sensor consists of two pyranometers (CM-3) and two pyrgeometers (CG-3). The sensor was installed at the height of $2 \mathrm{~m}$ above ground and facing south. On DoY 126, 138, 190, and 242 in 2010, the sensor was moved to a height of $2.25 \mathrm{~m}, 2.51 \mathrm{~m}, 3.55 \mathrm{~m}$, and $5.05 \mathrm{~m}$, respectively. Table 4 shows the list of specifications of the CNR-1 net radiometer. Figure A-4 shows the down- and up-welling solar (shortwave) and far infrared (longwave) radiation observed during MicroWEX-9.

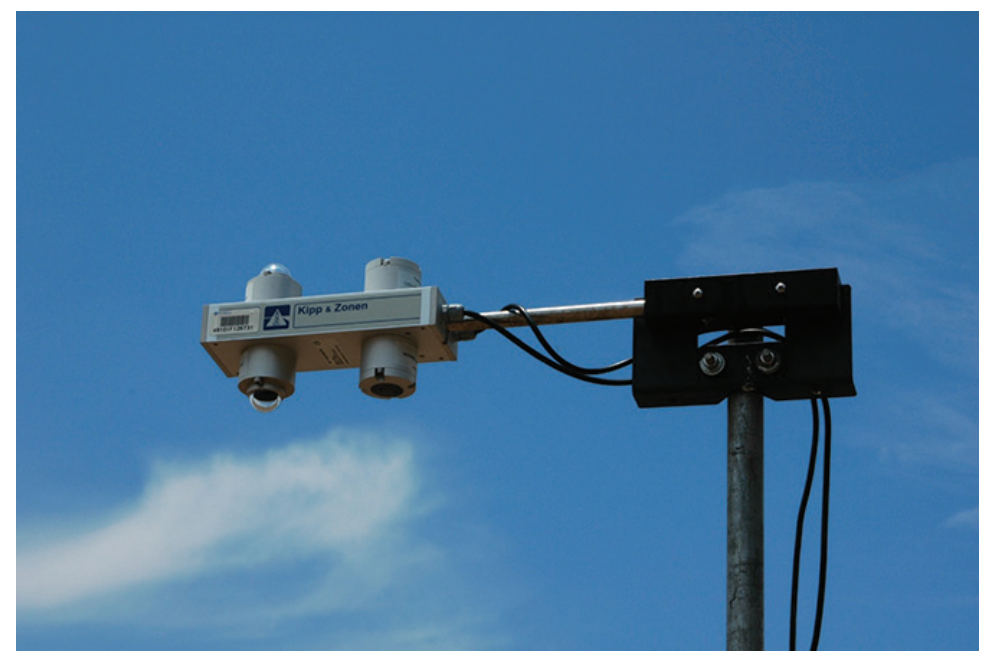

Figure 11. CNR-1 net radiometer.

Table 4. Specifications of the CNR-1 net radiometer (Campbell Scientific 2005a).

\begin{tabular}{|l|l|}
\hline \multicolumn{1}{|c|}{ Description } & \multicolumn{1}{c|}{ Value } \\
\hline Measurement spectrum: CM-3 & $305-2800 \mathrm{~nm}$ \\
\hline Measurement spectrum: CG-3 & $5000-50000 \mathrm{~nm}$ \\
\hline Response time & $18 \mathrm{sec}$ \\
\hline Sensitivity & $10-35 \mu \mathrm{V} /\left(\mathrm{W} / \mathrm{m}^{2}\right)$ \\
\hline Pt-100 sensor temperature measurement & DIN class A \\
\hline Accuracy of the Pt-100 measurement & $\pm 2 \mathrm{~K}$ \\
\hline Heating & Resistor $24 \mathrm{ohms}, 6 \mathrm{VA}$ at $12 \mathrm{volt}$ \\
\hline Maximum error due to heating: CM-3 & $10 \mathrm{~W} / \mathrm{m}^{2}$ \\
\hline Operating temperature & $-40^{\circ}-70^{\circ} \mathrm{C}$ \\
\hline Daily total radiation accuracy & $\pm 10 \%$ \\
\hline Cable length & $10 \mathrm{~m}$ \\
\hline Weight & $4 \mathrm{~kg}$ \\
\hline
\end{tabular}

\subsection{Thermal Infrared Sensor (TIR)}

An Apogee instruments IRR-PN thermal infrared sensor was installed near the East Station at $1 \mathrm{~m}$ looking at the row to observe skin temperature at nadir. On DoY 97 in 2010, another Apogee instruments IRR-PN was installed near the West Station at $1 \mathrm{~m}$ looking in between the rows. On DoY 126 in 2010, they were both raised to $2.25 \mathrm{~m}$. On DoY 160 in 2010, the east TIR sensor was installed on a pole that swings down when irrigation occurs at a height of $4 \mathrm{~m}$. During times when the irrigation system passed over the field, the pole was lowered. On DoY 284 on 2010, the east sensor was raised to a height of $5.5 \mathrm{~m}$. On DoY 354 in 2010, a similar pole for the west sensor was installed, and the sensor was mounted at a height of 
$5.5 \mathrm{~m}$. Table 5 shows the list of specifications of the thermal infrared sensor. Figure A-5 shows the surface thermal infrared temperature observed during MicroWEX-9.

Table 5. Specifications of the thermal infrared sensor (IRR-PN).

\begin{tabular}{|c|c|c|}
\hline & Description & Value \\
\hline Field of view & & $18^{\circ}$ half angle \\
\hline \multirow[t]{2}{*}{ Output } & Target temp. & $40 \mu \mathrm{V}$ per ${ }^{\circ} \mathrm{C}$ difference from sensor body \\
\hline & Sensor body temp. & $0-2500 \mathrm{mV}$ \\
\hline \multirow[t]{2}{*}{ Accuracy } & $-10-65^{\circ} \mathrm{C}$ & $\begin{array}{l} \pm 0.2^{\circ} \mathrm{C} \text { absolute accuracy } \\
\pm 0.1^{\circ} \mathrm{C} \text { uniformity } \\
\pm 0.05^{\circ} \mathrm{C} \text { repeatability }\end{array}$ \\
\hline & $-40-70^{\circ} \mathrm{C}$ & $\begin{array}{l} \pm 0.5^{\circ} \mathrm{C} \text { absolute accuracy } \\
\pm 0.3^{\circ} \mathrm{C} \text { uniformity } \\
\pm 0.1^{\circ} \mathrm{C} \text { repeatability and uniformity }\end{array}$ \\
\hline Optics & & Germanium lens \\
\hline Wavelength range & & 8-14 $\mu \mathrm{m}$ (corresponds to atmospheric window) \\
\hline Response time & & $<1$ second to changes in target temperature \\
\hline Input power & & $2.5 \mathrm{~V}$ excitation \\
\hline Operating environment & & $\begin{array}{l}-55-80^{\circ} \mathrm{C} ; 0-100 \% \mathrm{RH} \text { (non-condensing) } \\
\text { Water-resistant, designed for continuous outdoor use }\end{array}$ \\
\hline Cable & & 4.5 meters twisted, shielded 4 conductor wire with Santoprene casing \\
\hline Dimensions & & $6 \mathrm{~cm}$ long by $2.3 \mathrm{~cm}$ diameter \\
\hline Mass & & $190 \mathrm{~g}$ \\
\hline
\end{tabular}

\subsection{Air Temperature and Relative Humidity}

Air temperature and relative humidity were measured every 15 minutes at the West Station using a Campbell Scientific HMP45C Temperature and Relative Humidity Probe (Campbell Scientific 2006c). Figure A-6 shows the relative humidity and air temperature observations during MicroWEX-9.

\subsection{Soil Moisture and Temperature Probes}

Twenty-five Campbell Scientific time-domain water content reflectometers (CS616) were used to measure soil volumetric water content of 2, 4, 8, 16,32,64,120, and $170 \mathrm{~cm}$ every 15 minutes. The observations of soil moisture were duplicated at the depth of 2,4 , and $8 \mathrm{~cm}$. The calibration coefficients for the CS616 probes are listed in Table 6. Figure A-7 shows the soil temperatures observed at the depths of 2, 4, 8, 16, 32, 64, and $120 \mathrm{~cm}$ at the East Station during MicroWEX-9. Figure A-8 shows the soil temperatures observed at the same depths at the West Station. Figure A- 9 shows the volumetric soil moisture content observed at the same depths plus the deep TDRs for the East Station. Figure A-10 shows the volumetric soil moisture content observed at the same depths for the West Station.

Table 6. The calibration coefficients for the CS616
probes (Campbell Scientific 2006b).
\begin{tabular}{|l|l|}
\hline \multicolumn{1}{|c|}{ Coefficient } & \multicolumn{1}{|c|}{ Value } \\
\hline$C_{0}$ & -0.0663 \\
\hline$C_{1}$ & -0.0063 \\
\hline$C_{2}$ & 0.0007 \\
\hline
\end{tabular}




\subsection{Precipitation}

Precipitation was determined using four tipping-bucket rain gauges, two each in line with the outer edge of each radiometer footprint as shown in Figure 3. Two rain gauges were installed at a height of $130 \mathrm{~cm}$ on DoY 36 in 2010 to catch both precipitation and irrigation to determine precision. On DoY 62 in 2010, the rain gauges were uninstalled and put back in the field 26 days later in line with the outer edge of the L-band and C-band radiometer footprint. Two additional rain gauges were installed on DoY 106 in 2010 at a height to ensure only precipitation was caught. Starting on DoY 155 in 2010, the NW rain gauge was placed below the canopy. On DoY 168 in 2010, the NE and SW rain gauges were installed below the canopy. Figure A-11 shows the observed precipitation at the footprints.

\subsection{Soil Heat Flux Plates}

Three Campbell Scientific soil heat flux plates (HFT-3) were used to measure soil heat flux at two different stations. At the East Station, one was placed at $5 \mathrm{~cm}$ and one at $8 \mathrm{~cm}$. On DoY 135 in 2010, the $8 \mathrm{~cm}$ soil heat flux plate malfunctioned. At the Eddy Station, one was placed at $8 \mathrm{~cm}$. Figure A-12 shows the soil heat fluxes observed at depths of $5 \mathrm{~cm}$ and $8 \mathrm{~cm}$ at the East Station and at $8 \mathrm{~cm}$ on the Eddy during MicroWEX-9.

\section{Vegetation Sampling}

Vegetation properties in four spatially distributed sampling locations, as shown in Figure 3, were measured biweekly during the field experiment. A vegetation sampling consisted of measurements of clump height and width, as well as tiller height, width, biomass, LAI, and geometric description of the plant. Vertical distribution of moisture in the canopy was also done early in the season until the crop reached $4 \mathrm{~m}$. Two sampling locations were located where Merkron was planted in the north end of the field, while the other sampling locations included N-51 in the southwest location and N-13 in the southeast location. Each sampling included one row of elephant grass in the four sampling locations. The sampling length started between two clumps and ended at the next midpoint between clumps that was greater than or equal to $4 \mathrm{~m}$ from the starting point.

\subsection{Clump and Tiller Count}

The clumps and tillers were counted for each sampling length in each of the four sampling areas. Before DoY 231 in 2010, when the tillers were not uniform in height, three representative clumps were chosen to determine the percentages of small, medium, and large tillers in the sampling area. Figures A-13 and A-14 show the clumps and tillers per $\mathrm{m}^{2}$.

\subsection{Clump Height and Width}

Maximum clump height and width were measured by placing a tape measure at the soil surface adjacent to the stems to the maximum height of the clump. The clump width parallel to the row was measured at the base of the clump. Before DoY 298 in 2010, all clump heights and widths were measured in the sampling area described in 5.1. After DoY 298, one measurement of the maximum clump height was taken. Figures A-15 and A-16 show the average of the maximum clump heights and widths during MicroWEX-9.

\subsection{Tiller Height and Width}

One to three representative tillers were selected from the 10 sample tillers to obtain heights and widths. Tiller height and width were measured by placing a tape measure at the soil surface adjacent to the stem up to the maximum height of the crop. The maximum width of the tiller (parallel or perpendicular to the row) was also measured. Figures A-17 and A-18 show the maximum tiller height and width during MicroWEX-9.

\subsection{Wet and Dry Biomass}

Using the sampling area, 10 tillers each of representative small, medium, and large were chosen from the three clumps in section 5.1. Each tiller was cut at the base, separated into leaves and stems, and weighed immediately. The samples were dried in the oven at $50^{\circ} \mathrm{C}-60^{\circ} \mathrm{C}$ for 1 week for leaves and 2 weeks for stems. Figure A-19 shows the wet and dry biomass (in $\mathrm{kg} / \mathrm{m}^{2}$ ) observed during MicroWEX-9 for the four sampling areas. 


\subsection{LAl}

LAI was measured with destructive sampling implementing Equation 1. Using the 1-3 tillers selected in section 5.3, the leaves were separated from the stems. The length and width of the green leaves were measured. The specific leaf area (SLA) in Equation 1 was calculated, assuming a leaf as an ellipse (Boote 1994). The green leaves, senesced leaves, and the stems were then dried in an oven at $60^{\circ} \mathrm{C}$ for $48-72$ hours to measure the dry weight of the leaves and the dry biomass of the sample. The ratio of the leaf dry weight to the sample dry biomass was used to calculate the fraction of leaf $\left(\mathrm{F}_{\mathrm{LEAF}}\right)$. The total dry biomass (DM) was obtained in section 5.4.

$L A I=D M \cdot F_{\mathrm{LEAF}} \cdot S L A \quad($ Equation 1$)$

The LAI obtained is shown in Figure A-20.

\subsection{Vertical Distribution of Moisture in the Canopy}

The vertical distribution measurements were conducted on 14 days during MicroWEX-9: DoY 138, 145, 152, 159, 166, 173, 181, 187, 194, 204, 208, 215, 225, and 229 in 2010. The samplings on DoY 138 consisted of three representative tillers from the northwest area, and those on DoY 152, 166, 181, 194, 208, and 225 consisted of the one representative tiller from the area. The samplings on DoY 145 consisted of two representative tillers from the southwest area, and those on DoY 159, $173,187,204,215$, and 229 consisted of one representative tiller from that area. The tillers were cut at the base and laid out on a metal sheet with grid spacing of $2 \mathrm{~cm}$, as shown in Figure 12. The leaves were arranged to closely match their natural orientation in the field. The sample in each layer was weighed, both fresh and after drying in the oven at $60^{\circ} \mathrm{C}$ for 48 hours. Figure A-21 (a-b) shows the wet and dry weights as a function of crop height during MicroWEX-9.

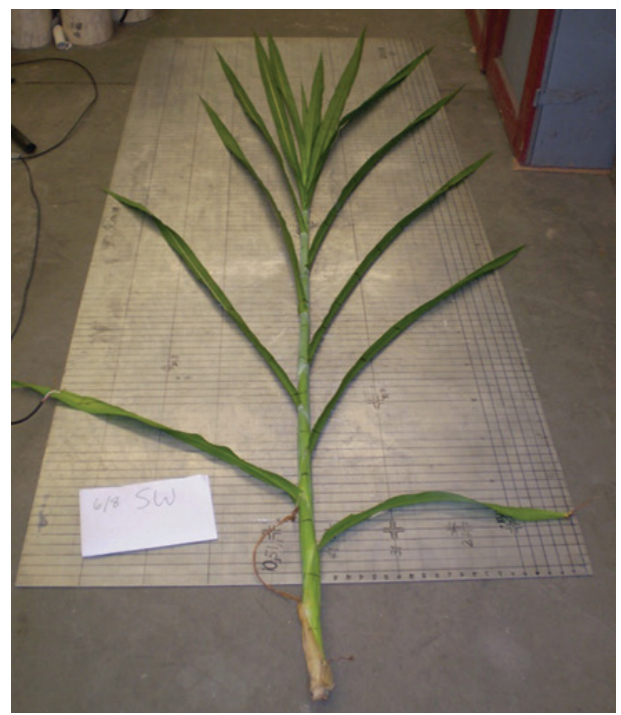

Figure 12. Tiller sample marked and ready to be subdivided into $10 \mathrm{~cm}$ layers.

\subsection{Geometric Description}

A geometric description of the tiller consisted of the leaf height from the ground, and the maximum length and width of each green leaf of the 1-3 representative tillers in section 5.3. The stem circumference was measured by using a string to wrap around the base and the tip of the plant to calculate the diameter of the stem. The stem length was measured from the base of the tiller to the base of the last leaf. Figure A-22 (a-b) shows the height of each leaf. The leaf length and width are shown in Figures A-23 (a-b) and A-24 (a-b). The stem length and diameter observed are shown in Figures A-25 and A-26. 


\section{Well Sampling}

\subsection{Water Level Measurement}

The water level measurement was processed by the Levelogger from Solinst Canada, Ltd. The Leveloggers were installed at the northern wells and set to automatically record the water level every 30 minutes. The data were downloaded onto a laptop during the well sampling. Figure A-27 shows the water table elevation and depth during MicroWEX-9.

\section{Observations}

For the microwave radiometric observations at C-band, the horizontally-polarized brightness temperatures were found to be more sensitive to soil moisture than vertically-polarized brightness temperatures during the bare soil and short vegetation cover periods (Figure A-1). As the vegetation grew, it effectively masked the contribution of microwave emission from soil, resulting in sensitivity decrease at both polarizations. Due to its higher penetration capability, the observations at lower frequencies (longer wavelengths), such as the L-band, were more sensitive to soil moisture during the growing season than at the higher frequencies of C-band. The LiDAR provided remote sensing estimates of soil roughness, row spacing, and vegetation height (Figure A-2).

The latent heat flux was higher than the sensible heat flux (Figure A-3). The average down-welling shortwave radiation was $245.39 \mathrm{~W} / \mathrm{m}^{2}$ during the growing season while the average up-welling shortwave radiation was $45.33 \mathrm{~W} / \mathrm{m}^{2}$ (Figure A-4). The average thermal infrared temperature was $297.72 \mathrm{~K}$ for the East Station and $294.83 \mathrm{~K}$ for the West Station (Figure A-5), while the average air temperature was $295.39 \mathrm{~K}$ (Figure A-6). The average relative humidity was $73.85 \%$ (Figure A-6). On DoY 148, 196, 219, and 253 the amount of precipitation in a 15-minute interval was greater than 25 mm (Figure A-11). The water table decreased after DoY 200 (Figure A-27).

During the beginning of the season, when vegetation was low, diurnal variations for soil temperature were maximum, and later in the season, the diurnal variations were minimal at the East Station (Figure A-7). Diurnal variations for soil temperatures at 64 and $120 \mathrm{~cm}$ were minimal throughout the season (Figure A-8). At the East and the West Stations, the soil was dryer closer to the plant than in the middle of the row (Figure A-9). The change in soil moisture in the deeper layers was minimal during light rains (Figure A-10). Soil heat flux measurements had large diurnal variations during the beginning of the season, with smaller variations toward the end of the season (Figure A-12).

The average clump density was $1.0 \mathrm{clump} / \mathrm{m}^{2}$ (Figure A-13) with the NW and SW vegetation sampling areas being the most uniform because of fewer gaps in those areas. The tiller density started low and reached a maximum before decreasing and reaching equilibrium (Figure A-14). The maximum height of the canopy was the highest at the NW vegetation sampling area, reaching $5.98 \mathrm{~m}$, while the NE area was the lowest, with a maximum height of $4.95 \mathrm{~m}$ (Figure A-15). The average clump width ranged from $0.14 \mathrm{~m}-0.40 \mathrm{~m}$ with an average of $0.27 \mathrm{~m}$ (Figure A-16). The maximum height of the sample tillers was the highest at the NW vegetation sampling area, reaching $5.53 \mathrm{~m}$, while the SE area was the lowest, with a maximum height of $4.60 \mathrm{~m}$ (Figure A-17). The widest maximum width of the sample tiller was an average of $1.70 \mathrm{~m}$ for the vegetation sampling areas (Figure A-18). The NE and SE areas had a lower green biomass than the other two sections (Figure A-19). The LAI increased before reaching a maximum of $8 \mathrm{~m}^{2} / \mathrm{m}^{2}$, then decreasing because of leaf senescence (Figure A-20).

After DoY 166, the moisture per $10 \mathrm{~cm}$ section in the plant remained relatively constant due to the stem, but when there was a decrease, the lowest amount of moisture was located at the top of the plant (Figure A-21). The maximum number of leaves in the NE vegetation sampling area was 36 leaves, while the SE vegetation sampling area had a maximum of 54 leaves because of the increased number of tillers (Figure A-22). The maximum leaf length was $1.4 \mathrm{~m}$ (Figure A-23), and the maximum leaf width was $0.055 \mathrm{~m}$ (Figure A-24). The length of the stem continued to increase for the NW and SW vegetation sampling areas, while the NE and SE vegetation sampling areas rapidly increased until DoY 243 (Figure A-25). The average minimum diameter was $0.015 \mathrm{~m}$, while the average maximum diameter was $0.028 \mathrm{~m}$ (Figure A-26). 


\section{Field Log}

Note: Time is in Eastern Standard Time.

December 7-10, 2009 (DoY 341-DoY 344)

08:00

Cuttings were planted

December 8, 2009 (DoY 342)

08:00

LiDAR measurements near L-band footprint

Meshboard measurements

December 9, 2009 (DoY 343)

$13: 30$

NE, NW, SW leveloggers out of the wells for repair and inventory

December 30, 2009 (DoY 364)

09:00

North - Full emergence

South - No emergence

Middle of field - Partial emergence

January 10, 2010 (DoY 10)

09:00

Plants died from freeze

January 25, 2010 (DoY 25)

09:00

North - Partial emergence

January 31, 2010 (DoY 31)

09:00

North - Full emergence

South - Partial emergence

February 5, 2010 (DoY 36)

10:30

2 Hobo rain gauges installed at a height of $1.3 \mathrm{~m}$ near the radiometer footprint in line in separate rows to determine linear move irrigation consistency over rows

February 14, 2010 (DoY 45)

\begin{tabular}{l|l} 
9:00 & Plants wilted - Frost damaged
\end{tabular}

February 16, 2010 (DoY 47)

18:00

Downloaded Hobo data

February 19, 2010 (DoY 50)

$15: 00$

Installed L-band radiometer

Downloaded Hobo data

February 23, 2010 (DoY 54)

$16: 00$

Downloaded L-band radiometer data

Installed NE and NW leveloggers

March 1, 2010 (DoY 60)

$11: 00$

Marked tractor rows 


\begin{tabular}{|c|c|}
\hline \multicolumn{2}{|c|}{ March 3, 2010 (DoY 62) } \\
\hline \multirow[t]{2}{*}{$10: 00$} & Downloaded Hobo data \\
\hline & Uninstalled Hobos in order to cultivate land \\
\hline \multirow[t]{2}{*}{$14: 45$} & Downloaded data from L-band radiometer \\
\hline & Temp probe broke for calibration \\
\hline \multicolumn{2}{|c|}{ March 4-5, 2010 (DoY 63-64) } \\
\hline $8: 00$ & Cultivate field \\
\hline \multicolumn{2}{|c|}{ March 10, 2010 (DoY 70) } \\
\hline & Downloaded data from L-band radiometer \\
\hline & L-band radiometer calibration, absorber temperature $=24.1 \sim 25.3^{\circ} \mathrm{C}$ \\
\hline & Changed desiccants in L-band radiometer \\
\hline \multicolumn{2}{|c|}{ March 15-18, 2010 (DoY 74-77) } \\
\hline $8: 00$ & Cultivate field \\
\hline \multicolumn{2}{|c|}{ March 15, 2010 (DoY 74) } \\
\hline \multirow[t]{2}{*}{$14: 15$} & Downloaded data from L-band radiometer \\
\hline & L-band radiometer calibration, absorber temperature $=24.03 \sim 24.49^{\circ} \mathrm{C}$ \\
\hline \multicolumn{2}{|c|}{ March 17, 2010 (DoY 76) } \\
\hline 13:45 & Located buried TDRs close to the NE and NW wells \\
\hline \multicolumn{2}{|c|}{ March 22, 2010 (DoY 81) } \\
\hline \multirow[t]{2}{*}{$14: 30$} & Downloaded data from L-band radiometer \\
\hline & L-band radiometer calibration, absorber temperature $=17.15 \sim 17.41^{\circ} \mathrm{C}$ \\
\hline \multicolumn{2}{|c|}{ March 23, 2010 (DoY 82) } \\
\hline \multirow[t]{2}{*}{ 9:00 } & East datalogger station installed \\
\hline & Marked L- and C-band radiometer footprints \\
\hline \multicolumn{2}{|c|}{ March 24, 2010 (DoY 83) } \\
\hline \multirow[t]{2}{*}{$13: 30$} & $\begin{array}{l}\text { Installed TDRs, thermistors, soil heat flux plate, and Apogee east TIR (1 m looking at row) at the East } \\
\text { datalogger stations }\end{array}$ \\
\hline & Launched program \\
\hline \multicolumn{2}{|c|}{ March 25, 2010 (DoY 84) } \\
\hline & Herbicide application of Butyrac 1.75, 1 qt per acre for wild mustard \\
\hline \multicolumn{2}{|c|}{ March 26, 2010 (DoY 85) } \\
\hline \multirow[t]{3}{*}{$14: 30$} & Downloaded data from L-band radiometer \\
\hline & L-band radiometer calibration, sky temperature $=25.35 \sim 25.68^{\circ} \mathrm{C}$ \\
\hline & Adjusted offset for L-band radiometer \\
\hline
\end{tabular}


March 29, 2010 (DoY 88)

\begin{tabular}{|l|l|}
\hline $14: 30$ & $\begin{array}{l}\text { Downloaded data from L-band radiometer } \\
\text { L-band radiometer calibration, sky temperature }=21.41 \sim 22.39^{\circ} \mathrm{C} \\
\text { Adjusted offset for L-band radiometer } \\
\text { Installed } 2 \text { Hobos in line with the edge of the radiometer foot prints } \\
\text { Downloaded data from East Station } \\
\text { Soil thermistor at } 4 \mathrm{~cm} \text {, low malfunctioned }\end{array}$ \\
\hline March 30, 2010 (DoY 89) & $\begin{array}{l}\text { Downloaded data from L-band radiometer } \\
\text { L-band radiometer calibration, sky temperature }=23.54 \sim 24.90^{\circ} \mathrm{C} \\
\text { Adjusted offset for L-band radiometer } \\
\text { Took out and reburied soil heat flux plate at } 8 \mathrm{~cm} \\
\text { Took out soil thermistor at } 4 \mathrm{~cm}\end{array}$ \\
\hline
\end{tabular}

March 31, 2010 (DoY 90)

$14: 00$

Downloaded data from L-band radiometer

L-band radiometer calibration, sky temperature $=25.31 \sim 26.73^{\circ} \mathrm{C}$

April 3, 2010 (DoY 93)

\begin{tabular}{l|l}
$9: 30$ & Vegetation sampling NW
\end{tabular}

April 5, 2010 (DoY 95)

$15: 20$

Downloaded data from L-band radiometer

L-band radiometer calibration, sky temperature $=29.76 \sim 30.20^{\circ} \mathrm{C}$

Downloaded data from East Station and Hobo

April 6-7, 2010 (DoY 96-97)

$15: 20$

Installed CNR

Installed west TIR (1 m)

Installed poles for Eddy Covariance Station

Connected power to West Station

April 11, 2010 (DoY 101)

$8: 30$

CNR hit by linear move irrigation system and fell down; no visible damage

9:30

Vegetation sampling NE

Moved TDRs and Thermistors J005-J008 $(2 \mathrm{~cm}$ and $4 \mathrm{~cm})$ closer to J001-J004 $(2 \mathrm{~cm}$ and $4 \mathrm{~cm})$

Buried the soil heat flux probe at the East datalogger station at $5 \mathrm{~cm}$ and $8 \mathrm{~cm}$

Downloaded data from East Station

Downloaded data from Hobo

April 12, 2010 (DoY 102)

15:00

Downloaded data from L-band radiometer

L-band radiometer calibration, sky temperature $=25.81 \sim 26.74^{\circ} \mathrm{C}$

$15: 20$

Shut down L-band radiometer

April 13, 2010 (DoY 103)

$13: 00$

Moved C-band trailer

Re-installed CNR pole 


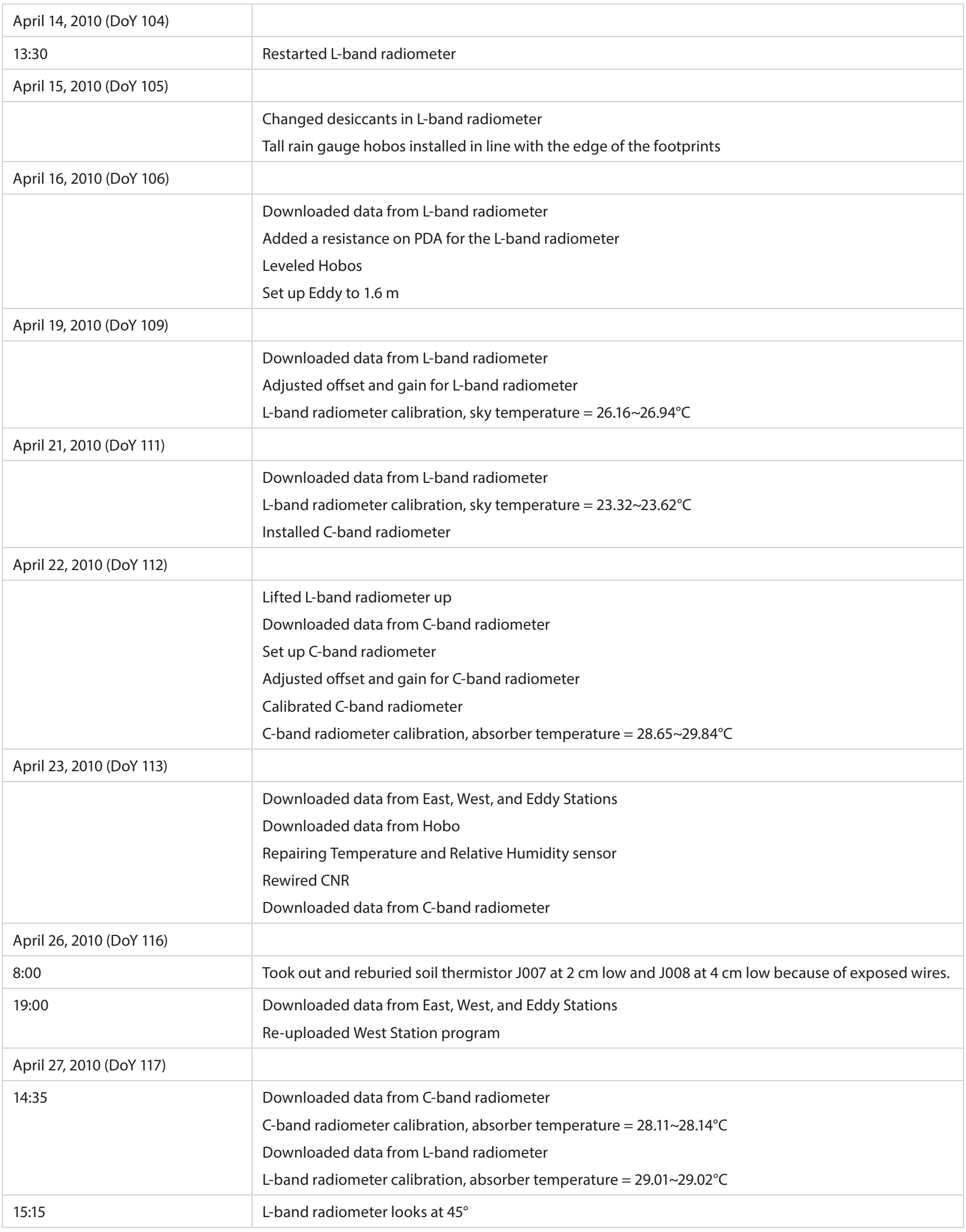




\begin{tabular}{|c|c|}
\hline \multicolumn{2}{|l|}{ April 30, 2010 (DoY 120) } \\
\hline $8: 30$ & $\begin{array}{l}\text { Downloaded data from C-band radiometer } \\
\text { C-band radiometer calibration, absorber temperature }=25.87 \sim 26.17^{\circ} \mathrm{C} \\
\text { Downloaded data from L-band radiometer } \\
\text { L-band radiometer calibration, sky temperature }=25.06 \sim 25.29^{\circ} \mathrm{C} \\
\text { Vegetation sampling in NW } \\
\text { Downloaded data from East, West, and Eddy Stations } \\
\text { Re-uploaded Eddy program } \\
\text { Cleaned } \mathrm{KH}_{2} \mathrm{O}\end{array}$ \\
\hline \multicolumn{2}{|l|}{ May 4, 2010 (DoY 124) } \\
\hline $9: 20$ & $\begin{array}{l}\text { Marked NW and NE vegetation area at } 60 \mathrm{ft} \text { x } 60 \mathrm{ft} \text { (10 rows) } \\
\text { Downloaded data from East, West, and Eddy Stations } \\
\text { Downloaded data from C-band and L-band radiometers } \\
\text { Flipped Hygrometer so larger source tube is on top, due to manual instructions } \\
\text { Raised Eddy to } 1.88 \mathrm{~m}\end{array}$ \\
\hline \multicolumn{2}{|l|}{ May 6, 2010 (DoY 126) } \\
\hline $9: 40$ & $\begin{array}{l}\text { Raised east and west TIR to } 2.25 \mathrm{~m} \\
\text { Raised CNR to } 2.25 \mathrm{~m}\end{array}$ \\
\hline \multicolumn{2}{|l|}{ May 7, 2010 (DoY 127) } \\
\hline $9: 20$ & $\begin{array}{l}\text { Downloaded data from East, West, and Eddy Stations } \\
\text { Downloaded data from C-band and L-band radiometers } \\
\text { Moved NE, NW and SW rain gauge Hobos } \\
\text { Raised Eddy to } 2.19 \mathrm{~m} \\
\text { Buried } 8 \mathrm{~cm} \text { Eddy SHF } \\
\text { Buried } 64 \text { and } 120 \mathrm{~cm} \text { TDR and thermistor on West Station }\end{array}$ \\
\hline \multicolumn{2}{|l|}{ May 9, 2010 (DoY 129) } \\
\hline $9: 30$ & Marked SE and SW vegetation sampling area $60 \mathrm{ft} \times 60 \mathrm{ft}$ \\
\hline \multicolumn{2}{|l|}{ May 11, 2010 (DoY 131) } \\
\hline $8: 30$ & $\begin{array}{l}\text { Downloaded data from C-band radiometer } \\
\text { Vegetation sampling in } \mathrm{NE}\end{array}$ \\
\hline \multicolumn{2}{|l|}{ May 12, 2010 (DoY 132) } \\
\hline $8: 30$ & $\begin{array}{l}\text { Downloaded data from C-band radiometer } \\
\text { C-band radiometer calibration, absorber temperature }=27.29 \sim 27.64^{\circ} \mathrm{C} \\
\text { Downloaded data from L-band radiometer } \\
\text { L-band radiometer calibration, sky temperature }=28.43 \sim 29.16^{\circ} \mathrm{C} \\
\text { Downloaded data from East, West, and Eddy Stations } \\
\text { Leveled the Hobos } \\
\text { Changed desiccants for L-band and C-band radiometers }\end{array}$ \\
\hline
\end{tabular}




\begin{tabular}{|c|c|}
\hline \multicolumn{2}{|l|}{ May 13, 2010 (DoY 133) } \\
\hline $8: 30$ & $\begin{array}{l}\text { Downloaded data from C-band radiometer } \\
\text { C-band radiometer calibration, absorber temperature }=36.30 \sim 36.52^{\circ} \mathrm{C} \\
\text { Downloaded data from L-band radiometer } \\
\text { L-band radiometer calibration, absorber temperature }=37.05 \sim 38.22^{\circ} \mathrm{C} \\
\text { Vegetation sampling in SE and SW }\end{array}$ \\
\hline \multicolumn{2}{|l|}{ May 15, 2010 (DoY 135) } \\
\hline $8: 30$ & $8 \mathrm{~cm}$ east SHF malfunctioned \\
\hline \multicolumn{2}{|l|}{ May 18, 2010 (DoY 138) } \\
\hline $8: 40$ & $\begin{array}{l}\text { Downloaded data from East, West, and Eddy Stations } \\
\text { Downloaded data from Hobos } \\
\text { Downloaded data from C-band and L-band radiometers } \\
\text { Raised Eddy to } 2.58 \mathrm{~m} \\
\text { Raised CNR to } 2.51 \mathrm{~m} \\
\text { Raised temperature and Relative Humidity to } 2 \mathrm{~m} \\
\text { Vertical distribution in NE } \\
\text { Increased sampling area to } 60 \mathrm{ft} \times 75 \mathrm{ft}\end{array}$ \\
\hline \multicolumn{2}{|l|}{ May 20, 2010 (DoY 140) } \\
\hline $8: 30$ & $\begin{array}{l}\text { Downloaded data from L-band radiometer } \\
\text { L-band radiometer calibration, sky temperature }=26.85 \sim 27.47^{\circ} \mathrm{C} \\
\text { Downloaded data from C-band radiometer } \\
\text { C-band radiometer calibration, absorber temperature }=30.93 \sim 31.04^{\circ} \mathrm{C} \\
\text { Vegetation sampling in NE and NW }\end{array}$ \\
\hline \multicolumn{2}{|l|}{ May 21, 2010 (DoY 141) } \\
\hline $8: 30$ & Downloaded data from L-band radiometer \\
\hline \multicolumn{2}{|l|}{ May 25, 2010 (DoY 145) } \\
\hline $8: 40$ & $\begin{array}{l}\text { Downloaded data from East and Eddy Stations } \\
\text { West Station battery low } \\
\text { Downloaded data from Hobos } \\
\text { Downloaded data from C-band and L-band radiometers } \\
\text { Buried } 2 \text { L and } 4 \text { L thermistor and TDR } \\
\text { Downloaded NW and NE levelogger } \\
\text { Vertical distribution in SW }\end{array}$ \\
\hline \multicolumn{2}{|l|}{ May 27, 2010 (DoY 147) } \\
\hline $8: 30$ & Vegetation sampling in SE and SW \\
\hline \multicolumn{2}{|l|}{ May 28, 2010 (DoY 148) } \\
\hline $2: 30$ & $\begin{array}{l}\text { Downloaded data from L-band radiometer } \\
\text { L-band radiometer calibration, absorber temperature }=34.20 \sim 34.30^{\circ} \mathrm{C} \\
\text { Downloaded data from C-band radiometer } \\
\text { C-band radiometer calibration, absorber temperature }=33.13 \sim 33.40^{\circ} \mathrm{C} \\
\text { Installed new battery for West datalogger station and fixed solar panel }\end{array}$ \\
\hline
\end{tabular}


June 1, 2010 (DoY 152)

\begin{tabular}{l|l}
$8: 15$ & Downloaded data from C-band radiometer \\
C-band radiometer calibration, absorber temperature $=26.49 \sim 26.81^{\circ} \mathrm{C}$ \\
Downloaded data from L-band radiometer \\
L-band radiometer calibration, sky temperature $=30.35 \sim 31.22^{\circ} \mathrm{C}$ \\
Downloaded data from East, West, and Eddy Stations \\
Downloaded data from Hobos \\
Vertical distribution in NE
\end{tabular}

June 3, 2010 (DoY 154)

\begin{tabular}{l|l} 
8:30 & Vegetation sampling in NE and NW
\end{tabular}

June 4, 2010 (DoY 155)

Downloaded data from C-band and L-band radiometers

Buried in TDRS and thermistors in west

Buried SHF

Lowered NW rain gauge Hobo below canopy

June 8, 2010 (DoY 159)

$8: 15$

Downloaded data from C-band radiometer

C-band radiometer calibration, absorber temperature $=27.52 \sim 27.75^{\circ} \mathrm{C}$

Downloaded data from L-band radiometer

L-band radiometer calibration, sky temperature $=27.70 \sim 29.05^{\circ} \mathrm{C}$

Downloaded data from East, West, and Eddy Stations

Downloaded data from Hobos SE not working

Vertical distribution in SW

June 9, 2010 (DoY 160)

$8: 45$

Installed new pole for east TIR (4 m)

Raised Relative Humidity and temperature probe

June 10, 2010 (DoY 161)

$8: 15$

East TIR pole snapped at base

Moved TIR to East Station pole

Replaced SE Hobo battery, still not working

Vegetation sampling in SE and SW

June 11, 2010 (DoY 162)

$8: 00$

Downloaded data from C-band radiometer

C-band radiometer calibration, absorber temperature $=28.90 \sim 29.58^{\circ} \mathrm{C}$

Downloaded data from L-band radiometer

L-band radiometer calibration, sky temperature $=29.20 \sim 29.49^{\circ} \mathrm{C}$

Changed desiccants for L-band and C-band radiometers 


\begin{tabular}{|c|c|}
\hline \multicolumn{2}{|l|}{ June 15, 2010 (DoY 166) } \\
\hline $8: 15$ & $\begin{array}{l}\text { Downloaded data from C-band radiometer } \\
\text { C-band radiometer calibration, absorber temperature }=31.46 \sim 31.89^{\circ} \mathrm{C} \\
\text { Downloaded data from L-band radiometer } \\
\text { L-band radiometer calibration, sky temperature }=34.32 \sim 33.78^{\circ} \mathrm{C} \\
\text { Downloaded data from East, West, and Eddy Stations } \\
\text { Downloaded data from Hobos } \\
\text { Vertical distribution in NW }\end{array}$ \\
\hline \multicolumn{2}{|l|}{ June 16, 2010 (DoY 167) } \\
\hline $8: 45$ & $\begin{array}{l}\text { TDRs on West Station blown fuse } \\
\text { Installed east TIR ( } 4 \mathrm{~m})\end{array}$ \\
\hline \multicolumn{2}{|l|}{ June 17, 2010 (DoY 168) } \\
\hline $8: 45$ & $\begin{array}{l}\text { Vegetation sampling in NE and SW } \\
\text { Downloaded data from C-band and L-band radiometer }\end{array}$ \\
\hline \multicolumn{2}{|l|}{ June 18, 2010 (DoY 169) } \\
\hline $8: 45$ & $\begin{array}{l}\text { Lowered NE and SW rain gauges Hobos } \\
\text { Downloaded data from Hobos }\end{array}$ \\
\hline \multicolumn{2}{|l|}{ June 22, 2010 (DoY 173) } \\
\hline $8: 45$ & $\begin{array}{l}\text { Vertical distribution in SW } \\
\text { Installed reflectors for L-band footprint } \\
\text { TIR pole knocked down } \\
\text { Took out SE rain gauge Hobo } \\
\text { Downloaded data from L-band radiometer } \\
\text { L-band radiometer calibration, absorber temperature }=30.60 \sim 30.63^{\circ} \mathrm{C} \\
\text { Downloaded data from C-band radiometer } \\
\text { C-band radiometer calibration, absorber temperature }=38.14 \sim 38.46^{\circ} \mathrm{C}\end{array}$ \\
\hline \multicolumn{2}{|l|}{ June 23, 2010 (DoY 174) } \\
\hline $8: 15$ & $\begin{array}{l}\text { Downloaded data from L-band radiometer } \\
\text { Downloaded data from East, West, and Eddy Stations }\end{array}$ \\
\hline \multicolumn{2}{|l|}{ June 24, 2010 (DoY 175) } \\
\hline $8: 45$ & $\begin{array}{l}\text { Downloaded data from L-band radiometer } \\
\text { L-band radiometer calibration, sky temperature }=28.90 \sim 30.89^{\circ} \mathrm{C} \\
\text { Downloaded data from C-band radiometer } \\
\text { Vegetation sampling in SE and SW } \\
\text { Re-installed TIR pole }\end{array}$ \\
\hline
\end{tabular}




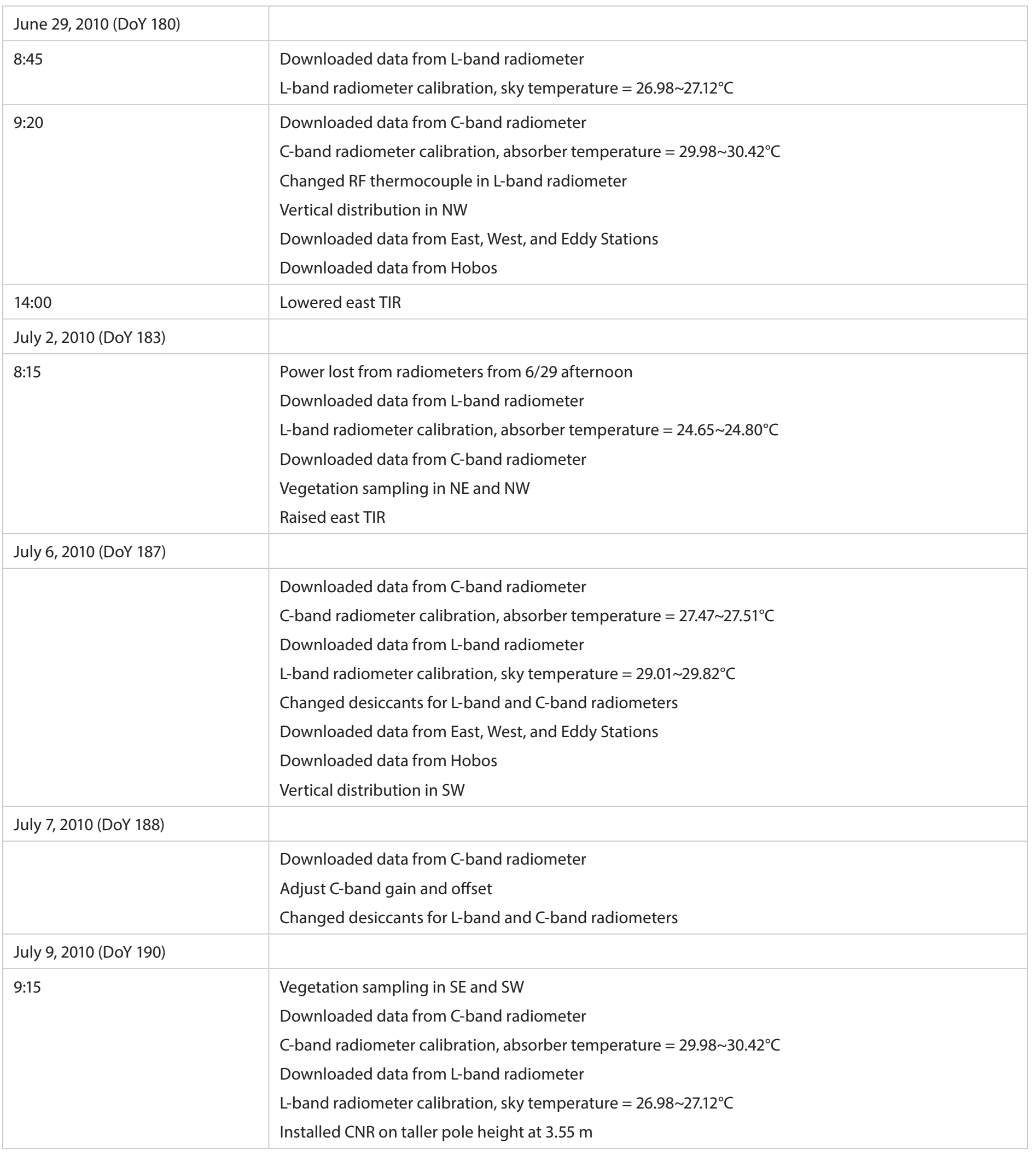




\begin{tabular}{|c|c|}
\hline \multicolumn{2}{|c|}{ July 13, 2010 (DoY 194) } \\
\hline & $\begin{array}{l}\text { Downloaded data from L-band radiometer } \\
\text { L-band radiometer calibration, sky temperature }\left(40^{\circ} \text { elevation }\right)=29.80 \sim 30.65^{\circ} \mathrm{C} \\
\text { L-band radiometer calibration, sky temperature }\left(30^{\circ} \text { elevation }\right)=29.94 \sim 30.53^{\circ} \mathrm{C} \\
\text { L-band radiometer calibration, absorber temperature }=29.81 \sim 29.96^{\circ} \mathrm{C} \\
\text { L-band radiometer calibration, absorber temperature }\left(21.5^{\circ} \text { elevation }\right)=30.50 \sim 31.01^{\circ} \mathrm{C} \\
\text { Downloaded data from C-band radiometer }\end{array}$ \\
\hline $9: 20$ & $\begin{array}{l}\text { Vertical distribution in NW } \\
\text { Downloaded data from East, West, and Eddy Stations }\end{array}$ \\
\hline $10: 15$ & $\begin{array}{l}\text { Downloaded data from Hobos } \\
\text { Cleared some plants around Eddy solar panel } \\
\text { Solo cup off east TIR }\end{array}$ \\
\hline \multicolumn{2}{|c|}{ July 14, 2010 (DoY 195) } \\
\hline $14: 30$ & Lowered east TIR and CNR \\
\hline \multicolumn{2}{|c|}{ July 15, 2010 (DoY 196) } \\
\hline 9:00 & $\begin{array}{l}\text { Vegetation sampling in NE and NW } \\
\text { Downloaded data from C-band radiometer } \\
\text { C-band radiometer calibration, absorber temperature }=28.33 \sim 28.93^{\circ} \mathrm{C} \\
\text { C-band radiometer calibration, sky temperature }\left(40^{\circ} \text { elevation }\right)=28.08 \sim 28.88^{\circ} \mathrm{C} \\
\text { C-band radiometer calibration, absorber temperature }\left(60^{\circ} \text { elevation }\right)=28.20 \sim 28.49^{\circ} \mathrm{C} \\
\text { Downloaded data from L-band radiometer } \\
\text { Installed Solo cup on east TIR }\end{array}$ \\
\hline $18: 45$ & $\begin{array}{l}\text { Raised east TIR and CNR } \\
\text { Power out for field }\end{array}$ \\
\hline \multicolumn{2}{|c|}{ July 16, 2010 (DoY 197) } \\
\hline & $\begin{array}{l}\text { Power back at the field } \\
\text { Downloaded data from C-band and L-band radiometers } \\
\text { Restarted radiometers }\end{array}$ \\
\hline \multicolumn{2}{|c|}{ July 22, 2010 (DoY 203) } \\
\hline $9: 00$ & $\begin{array}{l}\text { Vegetation sampling in SE and SW } \\
\text { Downloaded data from L-band radiometer } \\
\text { L-band radiometer calibration, sky temperature }=27.84 \sim 28.79^{\circ} \mathrm{C} \\
\text { Downloaded data from C-band radiometer } \\
\text { C-band radiometer calibration, absorber temperature }=32.96 \sim 33.49^{\circ} \mathrm{C}\end{array}$ \\
\hline \multicolumn{2}{|c|}{ July 23, 2010 (DoY 204) } \\
\hline $9: 00$ & $\begin{array}{l}\text { Vertical distribution in SW } \\
\text { Downloaded data from East, West, and Eddy Stations } \\
\text { Downloaded data from Hobos }\end{array}$ \\
\hline
\end{tabular}




\begin{tabular}{|c|c|}
\hline & $\begin{array}{l}\text { Downloaded data from C-band radiometer } \\
\text { C-band radiometer calibration, absorber temperature }=30.57 \sim 30.95^{\circ} \mathrm{C} \\
\text { Adjust gain and offset for C-band radiometer } \\
\text { Downloaded data from L-band radiometer } \\
\text { L-band radiometer calibration, absorber temperature }=38.16 \sim 39.03^{\circ} \mathrm{C} \\
\text { Changed desiccants for L-band and C-band radiometers } \\
\text { Vertical distribution in NW }\end{array}$ \\
\hline 10:00 & Downloaded data from East, West, and Eddy Stations \\
\hline $10: 30$ & $\begin{array}{l}\text { Downloaded data from Hobos } \\
\text { GPS points around field } \\
\text { GPS points of stations and rain gauges } \\
\text { Rewired TDRs on West (well TDR malfunction) }\end{array}$ \\
\hline \multicolumn{2}{|c|}{ July 29, 2010 (DoY 210) } \\
\hline $8: 45$ & $\begin{array}{l}\text { Vegetation sampling in NE and NW } \\
\text { Downloaded data from C-band radiometer } \\
\text { C-band radiometer calibration, absorber temperature }=29.30 \sim 29.57^{\circ} \mathrm{C}\end{array}$ \\
\hline $9: 30$ & $\begin{array}{l}\text { Restarted C-band radiometer } \\
\text { Downloaded data from L-band radiometer } \\
\text { L-band radiometer calibration, absorber temperature }=38.16 \sim 39.03^{\circ} \mathrm{C}\end{array}$ \\
\hline $10: 00$ & Restarted L-band radiometer \\
\hline \multicolumn{2}{|c|}{ August 3, 2010 (DoY 215) } \\
\hline & $\begin{array}{l}\text { Downloaded data from L-band radiometer } \\
\text { L-band radiometer calibration, sky temperature }=26.94 \sim 27.08^{\circ} \mathrm{C} \\
\text { Adjusted gain for L-band radiometer } \\
\text { Changed desiccants for L-band radiometer } \\
\text { L-band radiometer calibration, sky temperature }=28.45 \sim 28.93^{\circ} \mathrm{C}\end{array}$ \\
\hline 10:00 & $\begin{array}{l}\text { Restarted L-band radiometer } \\
\text { Downloaded data from C-band radiometer }\end{array}$ \\
\hline 10:15 & $\begin{array}{l}\text { Restarted C-band radiometer } \\
\text { Vertical distribution in SW } \\
\text { Downloaded data from East, West, and Eddy Stations } \\
\text { Downloaded data from Hobos }\end{array}$ \\
\hline \multicolumn{2}{|c|}{ August 4, 2010 (DoY 216) } \\
\hline $14: 00$ & Lowered east TIR and CNR \\
\hline
\end{tabular}




\begin{tabular}{|c|c|}
\hline \multicolumn{2}{|c|}{ August 5, 2010 (DoY 217) } \\
\hline & $\begin{array}{l}\text { Downloaded data from C-band radiometer } \\
\text { C-band radiometer calibration, absorber temperature }=33.12 \sim 33.29^{\circ} \mathrm{C}\end{array}$ \\
\hline $9: 30$ & $\begin{array}{l}\text { Restarted C-band radiometer } \\
\text { Downloaded data from L-band radiometer } \\
\text { L-band radiometer calibration, sky temperature }=27.78 \sim 29.44^{\circ} \mathrm{C}\end{array}$ \\
\hline $10: 00$ & $\begin{array}{l}\text { Restarted L-band radiometer } \\
\text { Vegetation sampling in SE and SW }\end{array}$ \\
\hline \multicolumn{2}{|c|}{ August 6, 2010 (DoY 218) } \\
\hline $8: 50$ & Raised east TIR and CNR \\
\hline \multicolumn{2}{|c|}{ August 10, 2010 (DoY 222) } \\
\hline $8: 50$ & $\begin{array}{l}\text { Downloaded data from C-band radiometer } \\
\text { C-band radiometer calibration, absorber temperature }=29.16 \sim 29.17^{\circ} \mathrm{C} \\
\text { Changed desiccants for C-band radiometer }\end{array}$ \\
\hline $9: 45$ & $\begin{array}{l}\text { Restarted C-band radiometer } \\
\text { Downloaded data from L-band radiometer }\end{array}$ \\
\hline $10: 00$ & $\begin{array}{l}\text { Restarted L-band radiometer } \\
\text { Downloaded data from East, West, and Eddy Stations } \\
\text { Downloaded data from Hobos NE malfunctioned }\end{array}$ \\
\hline \multicolumn{2}{|c|}{ August 12, 2010 (DoY 224) } \\
\hline $8: 30$ & Vegetation sampling in NE and NW \\
\hline \multicolumn{2}{|c|}{ August 13, 2010 (DoY 225) } \\
\hline $9: 45$ & $\begin{array}{l}\text { Downloaded data from C-band radiometer } \\
\text { C-band radiometer calibration, absorber temperature }=30.26 \sim 30.31^{\circ} \mathrm{C}\end{array}$ \\
\hline $10: 15$ & Restarted C-band radiometer \\
\hline 10:16 & $\begin{array}{l}\text { Downloaded data from L-band radiometer } \\
\text { L-band radiometer calibration, sky temperature }=31.46 \sim 33.17^{\circ} \mathrm{C}\end{array}$ \\
\hline $10: 45$ & $\begin{array}{l}\text { Restarted L-band radiometer } \\
\text { Vertical distribution in NW }\end{array}$ \\
\hline \multicolumn{2}{|c|}{ August 17, 2010 (DoY 229) } \\
\hline 9:00 & $\begin{array}{l}\text { Downloaded data from L-band radiometer } \\
\text { L-band radiometer calibration, sky temperature }=31.88 \sim 32.21^{\circ} \mathrm{C} \\
\text { Changed desiccants for L-band radiometer }\end{array}$ \\
\hline $9: 30$ & Restarted L-band radiometer \\
\hline $9: 31$ & Downloaded data from C-band radiometer \\
\hline $9: 45$ & $\begin{array}{l}\text { Restarted C-band radiometer } \\
\text { Vertical distribution in SW } \\
\text { Downloaded data from East and West Stations } \\
\text { Downloaded data from Hobo South filled with water }\end{array}$ \\
\hline
\end{tabular}




\begin{tabular}{|c|c|}
\hline \multicolumn{2}{|c|}{ August 18, 2010 (DoY 230) } \\
\hline $7: 15$ & Downloaded data from East Station \\
\hline \multicolumn{2}{|c|}{ August 19, 2010 (DoY 231) } \\
\hline & $\begin{array}{l}\text { Downloaded data from L-band radiometer } \\
\text { L-band radiometer calibration, absorber temperature }=31.30 \sim 31.46^{\circ} \mathrm{C}\end{array}$ \\
\hline $9: 30$ & $\begin{array}{l}\text { Restarted L-band radiometer } \\
\text { Downloaded data from C-band radiometer } \\
\text { C-band radiometer calibration, absorber temperature }=35.92 \sim 35.99^{\circ} \mathrm{C}\end{array}$ \\
\hline 10:15 & $\begin{array}{l}\text { Restarted C-band radiometer } \\
\text { Vegetation sampling in SE and SW }\end{array}$ \\
\hline \multicolumn{2}{|c|}{ August 24, 2010 (DoY 236) } \\
\hline $9: 12$ & $\begin{array}{l}\text { Downloaded data from C-band radiometer } \\
\text { C-band radiometer calibration, absorber temperature }=34.88 \sim 35.95^{\circ} \mathrm{C} \\
\text { Changed desiccants for C-band radiometer }\end{array}$ \\
\hline 10:02 & Downloaded data from L-band radiometer \\
\hline 10:15 & Restarted L-band radiometer \\
\hline $10: 30$ & Restarted C-band radiometer \\
\hline \multicolumn{2}{|c|}{ August 25, 2010 (DoY 237) } \\
\hline $7: 15$ & Installed Eddy pole \\
\hline \multicolumn{2}{|c|}{ August 26, 2010 (DoY 238) } \\
\hline 9:01 & $\begin{array}{l}\text { Downloaded data from C-band radiometer } \\
\text { C-band radiometer calibration, absorber temperature }=29.89 \sim 29.95^{\circ} \mathrm{C}\end{array}$ \\
\hline $9: 30$ & Restarted C-band radiometer \\
\hline $9: 28$ & $\begin{array}{l}\text { Downloaded data from L-band radiometer } \\
\text { L-band radiometer calibration, sky temperature }=27.50 \sim 28.60^{\circ} \mathrm{C}\end{array}$ \\
\hline $9: 45$ & $\begin{array}{l}\text { Restarted L-band radiometer } \\
\text { Downloaded data from East and West Stations } \\
\text { Downloaded data from Hobo NW filled with water } \\
\text { Cut around East and West Station solar panels }\end{array}$ \\
\hline \multicolumn{2}{|c|}{ August 30, 2010 (DoY 242) } \\
\hline $8: 00$ & $\begin{array}{l}\text { Vegetation sampling in NE and NW } \\
\text { Raised CNR } 5.05 \mathrm{~m}\end{array}$ \\
\hline \multicolumn{2}{|c|}{ August 31, 2010 (DoY 243) } \\
\hline $8: 55$ & $\begin{array}{l}\text { Downloaded data from C-band radiometer } \\
\text { C-band radiometer calibration, absorber temperature }=29.58 \sim 29.85^{\circ} \mathrm{C}\end{array}$ \\
\hline $9: 20$ & $\begin{array}{l}\text { Downloaded data from L-band radiometer } \\
\text { L-band radiometer calibration, absorber temperature }=29.46 \sim 29.68^{\circ} \mathrm{C}\end{array}$ \\
\hline $9: 30$ & Restarted C-band radiometer \\
\hline $10: 00$ & $\begin{array}{l}\text { Restarted L-band radiometer } \\
\text { Downloaded data from East and West Stations }\end{array}$ \\
\hline
\end{tabular}




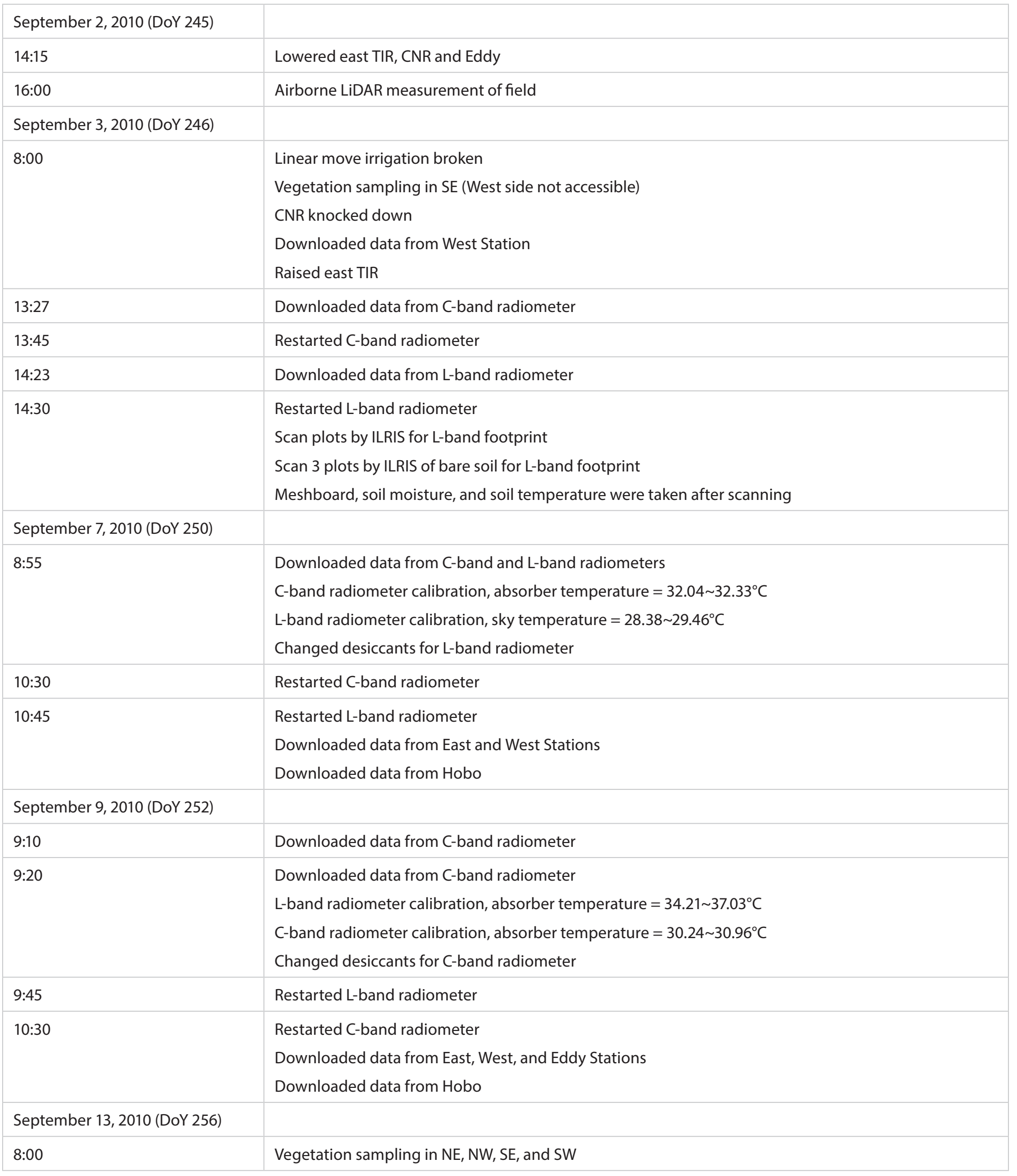




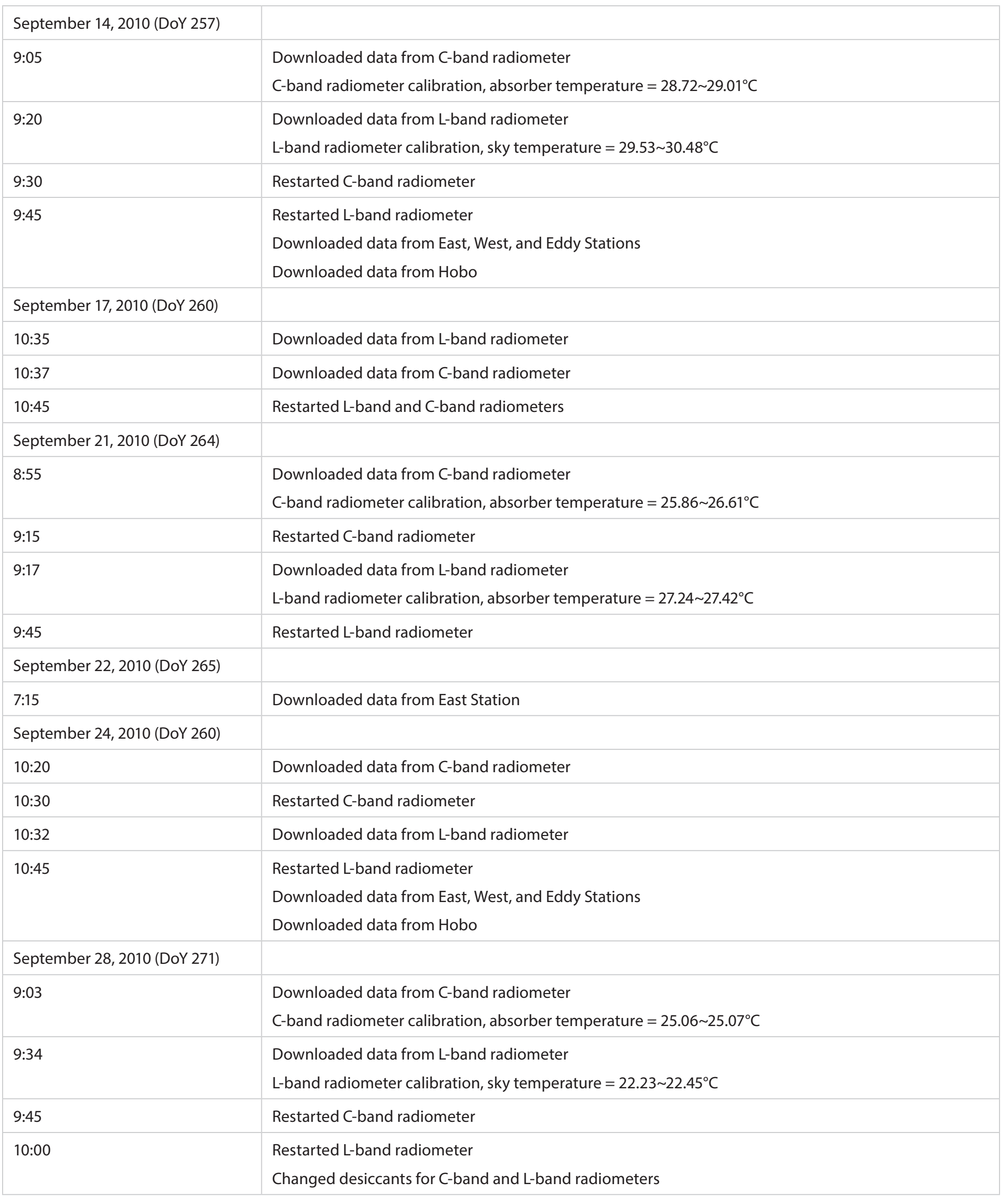




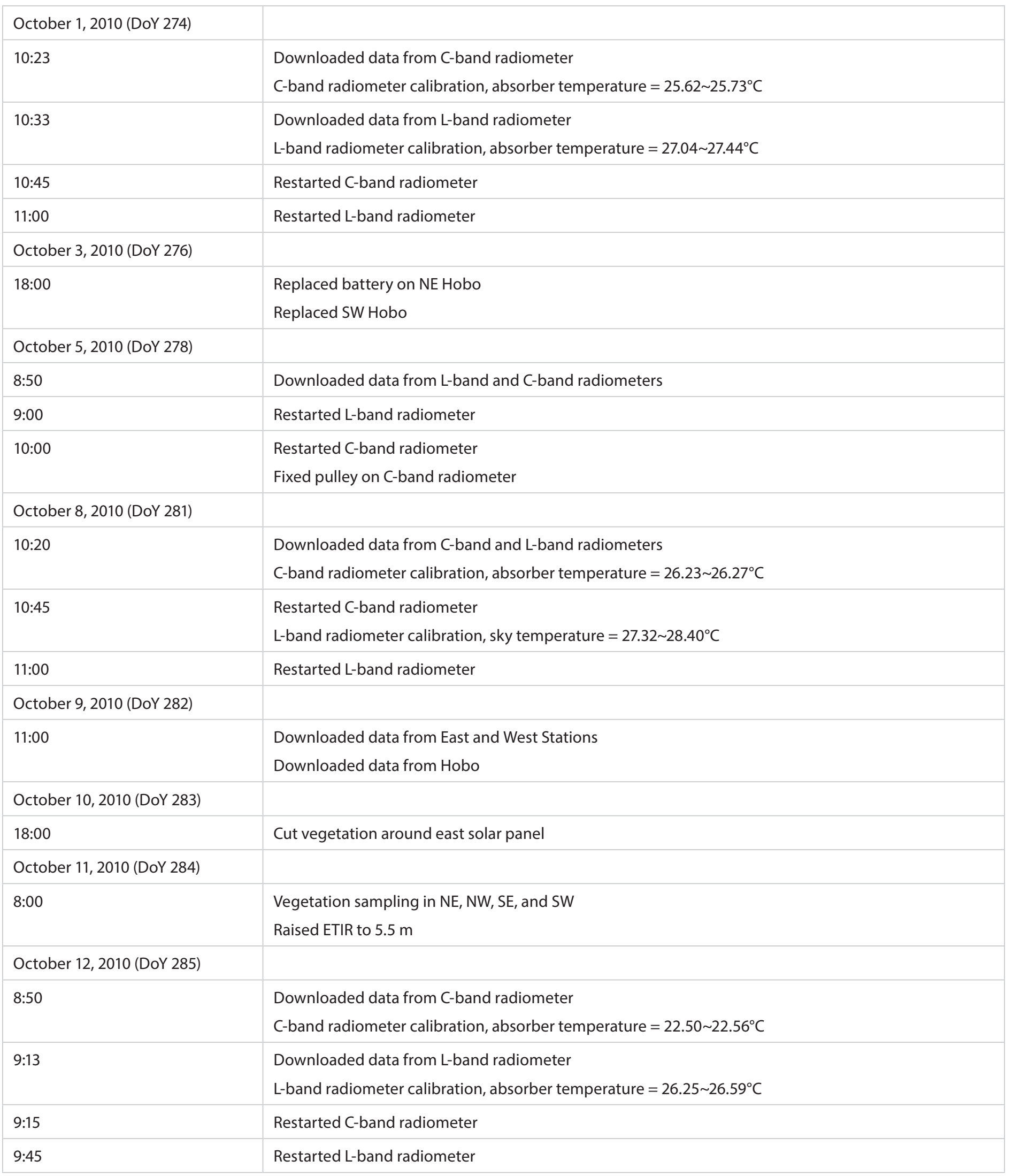




\begin{tabular}{|c|c|}
\hline \multicolumn{2}{|c|}{ October 14, 2010 (DoY 287) } \\
\hline 7:15 & Lowered East TIR pole \\
\hline $15: 32$ & Downloaded data from C-band radiometer \\
\hline $15: 45$ & Restarted C-band radiometer \\
\hline $15: 47$ & Downloaded data from L-band radiometer \\
\hline $16: 00$ & $\begin{array}{l}\text { Restarted L-band radiometer } \\
\text { Downloaded data from East and West Stations } \\
\text { Downloaded data from Hobo }\end{array}$ \\
\hline \multicolumn{2}{|c|}{ October 19, 2010 (DoY 292) } \\
\hline 9:14 & $\begin{array}{l}\text { Downloaded data from C-band radiometer } \\
\text { C-band radiometer calibration, absorber temperature }=26.79 \sim 27.54^{\circ} \mathrm{C}\end{array}$ \\
\hline 9:36 & $\begin{array}{l}\text { Downloaded data from L-band radiometer } \\
\text { L-band radiometer calibration, sky temperature }=23.48 \sim 24.53^{\circ} \mathrm{C} \\
\text { Changed desiccants for C-band and L-band radiometers }\end{array}$ \\
\hline 10:00 & Restarted C-band radiometer \\
\hline 10:30 & Restarted L-band radiometer \\
\hline \multicolumn{2}{|c|}{ October 20, 2010 (DoY 293) } \\
\hline $18: 15$ & Raised East TIR pole \\
\hline \multicolumn{2}{|c|}{ October 21, 2010 (DoY 294) } \\
\hline $9: 40$ & $\begin{array}{l}\text { Downloaded data from L-band radiometer } \\
\text { L-band radiometer calibration, absorber temperature }=24.29 \sim 25.07^{\circ} \mathrm{C}\end{array}$ \\
\hline 10:15 & $\begin{array}{l}\text { Restarted L-band radiometer } \\
\text { Downloaded data from C-band radiometer } \\
\text { C-band radiometer calibration, absorber temperature }=25.86 \sim 25.94^{\circ} \mathrm{C}\end{array}$ \\
\hline $10: 45$ & $\begin{array}{l}\text { Restarted C-band radiometer } \\
\text { Downloaded data from East and West Stations } \\
\text { Downloaded data from Hobo }\end{array}$ \\
\hline \multicolumn{2}{|c|}{ October 26, 2010 (DoY 294) } \\
\hline $8: 50$ & $\begin{array}{l}\text { Downloaded data from C-band and L-band radiometers } \\
\text { C-band radiometer calibration, absorber temperature }=28.66 \sim 29.13^{\circ} \mathrm{C} \\
\text { L-band radiometer calibration, sky temperature }=26.05 \sim 27.59^{\circ} \mathrm{C}\end{array}$ \\
\hline $9: 30$ & Restarted C-band radiometer \\
\hline $9: 45$ & Restarted L-band radiometer \\
\hline \multicolumn{2}{|c|}{ October 29, 2010 (DoY 302) } \\
\hline $14: 35$ & Downloaded data from C-band and L-band radiometers \\
\hline $14: 45$ & $\begin{array}{l}\text { Restarted C-band and L-band radiometers } \\
\text { Downloaded data from West Station }\end{array}$ \\
\hline
\end{tabular}




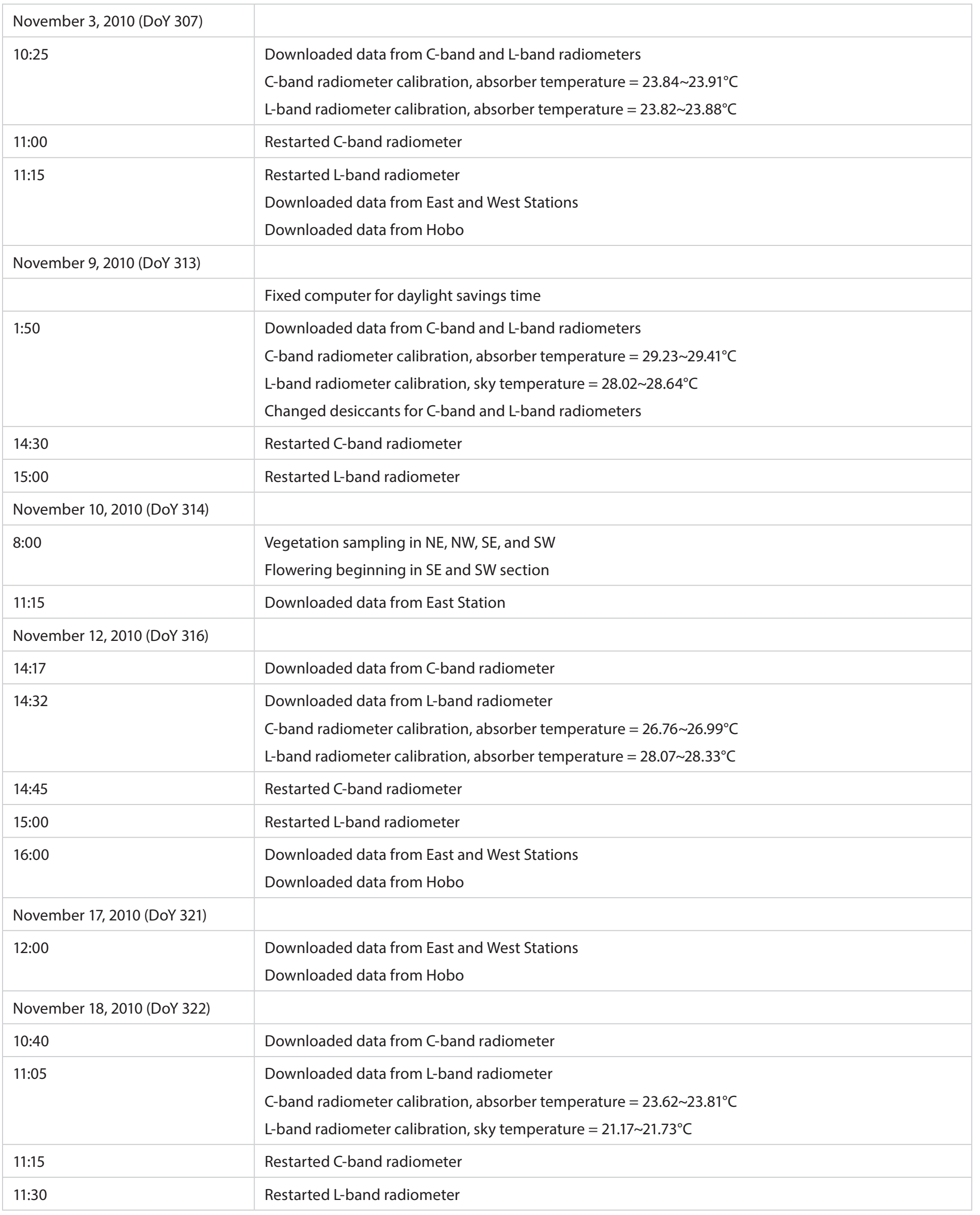




\begin{tabular}{|c|c|}
\hline \multicolumn{2}{|l|}{ November 22, 2010 (DoY 322) } \\
\hline $8: 00$ & $\begin{array}{l}\text { Vegetation sampling in NE, NW, SE, and SW } \\
\text { Flowering in all sections } \\
\text { North tree line started to be cut down this week }\end{array}$ \\
\hline \multicolumn{2}{|l|}{ November 23, 2010 (DoY 327) } \\
\hline 9:20 & Downloaded data from L-band radiometer \\
\hline 9:50 & $\begin{array}{l}\text { Downloaded data from C-band radiometer } \\
\text { L-band radiometer calibration, absorber temperature }=24.14 \sim 25.26^{\circ} \mathrm{C} \\
\text { C-band radiometer calibration, absorber temperature }=27.83 \sim 28.08^{\circ} \mathrm{C} \\
\text { Removed L-band radiometer } \\
\text { Removed C-band radiometer }\end{array}$ \\
\hline \multicolumn{2}{|l|}{ November 24, 2010 (DoY 328) } \\
\hline & $\begin{array}{l}\text { Downloaded data from West Station } \\
\text { Downloaded data from Hobo }\end{array}$ \\
\hline \multicolumn{2}{|l|}{ December 1, 2010 (DoY 335) } \\
\hline 18:00 & $\begin{array}{l}\text { Downloaded data from East and West Stations } \\
\text { Downloaded data from Hobo }\end{array}$ \\
\hline \multicolumn{2}{|l|}{ December 6, 2010 (DoY 340) } \\
\hline $8: 45$ & $\begin{array}{l}\text { Vegetation sampling in NE, NW, SE, and SW } \\
\text { Freeze damage present }\end{array}$ \\
\hline \multicolumn{2}{|l|}{ December 17, 2010 (DoY 351) } \\
\hline & $\begin{array}{l}\text { L-band back } \\
\text { Changed desiccants for L-band radiometer }\end{array}$ \\
\hline \multicolumn{2}{|l|}{ December 20, 2010 (DoY 354) } \\
\hline & $\begin{array}{l}\text { L-band reinstalled } \\
\text { L-band radiometer calibration, absorber temperature }=7.38 \sim 8.15^{\circ} \mathrm{C}\end{array}$ \\
\hline 10:00 & $\begin{array}{l}\text { Restarted L-band radiometer } \\
\text { West TIR pole installed } \\
\text { Eddy installed }\end{array}$ \\
\hline \multicolumn{2}{|l|}{ December 23, 2010 (DoY 357) } \\
\hline 9:00 & $\begin{array}{l}\text { Removed West sensors from ground } \\
\text { Downloaded data from East, West, and Eddy Stations }\end{array}$ \\
\hline \multicolumn{2}{|l|}{ December 29, 2010 (DoY 363) } \\
\hline $12: 30$ & Downloaded data from East, West, and Eddy Stations \\
\hline $3: 20$ & $\begin{array}{l}\text { Downloaded data from L-band radiometer } \\
\text { L-band radiometer calibration, sky temperature }=16.20 \sim 16.61^{\circ} \mathrm{C}\end{array}$ \\
\hline 4:45 & $\begin{array}{l}\text { Restarted L-band radiometer } \\
\text { Wrapped West Station wires }\end{array}$ \\
\hline \multirow[t]{2}{*}{ December 30, 2010 (DoY 364) } & \\
\hline & Downloaded data from East Station \\
\hline
\end{tabular}




\begin{tabular}{|l|l|}
\hline January 2, 2011 (DoY 2) & $\begin{array}{l}\text { Downloaded data from East, West, and Eddy Stations } \\
\text { Downloaded data from Hobo }\end{array}$ \\
\hline January 4, 2011 (DoY 4) & $\begin{array}{l}\text { Removed East sensors from ground } \\
\text { Downloaded data from Hobo } \\
\text { Removed Hobos from field }\end{array}$ \\
\hline Moved East TIR to West TIR pole \\
\hline January 6, 2011 (DoY 6) & $\begin{array}{l}\text { Harvest began on south side of field } \\
\text { Cleaned Eddy }\end{array}$ \\
\hline $10: 05$ & $\begin{array}{l}\text { Downloaded data from L-band radiometer } \\
\text { L-band radiometer calibration, sky temperature }=13.71 ~ 14.34^{\circ} \mathrm{C}\end{array}$ \\
\hline $10: 45$ & \begin{tabular}{l} 
Restarted L-band radiometer \\
\hline
\end{tabular} \\
\hline
\end{tabular}




\section{References}

Apogee Instruments, Inc. Infrared Radiometer Owner's Manual, Model: IRR-PN. Logan, UT: Apogee Instruments Inc., 2007.

Boote, K.J. “Data Requirements for Model Evaluation and Techniques for Sampling Crop Growth and Development." In: DSSAT version 3.5, Volume 4, ed. Gerrit Hoogenboom, Paul W. Wilken, and Gordon Y. Tsuji. (Honolulu, HI: University of Hawaii, 1994):215-229.

Campbell Scientific. CSAT3 Three Dimensional Sonic Anemometer Instruction Manual. Logan, UT: Campbell Scientific Inc., 1998.

Campbell Scientific. HFT3 Soil Heat Flux Plate Instruction Manual. Logan, UT: Campbell Scientific Inc., 2003.

Campbell Scientific. CNR1 Net Radiometer Instruction Manual. Logan, UT: Campbell Scientific Inc., $2006 a$.

Campbell Scientific. CS616 and CS625 Water Content Reflectometers Instruction Manual. Logan, UT: Campbell Scientific Inc., 2006b.

Campbell Scientific. Campbell Scientific Model HMP45C Temperature and Relative Humidity Probe Instruction Manual. Logan, UT: Campbell Scientific Inc., 2006c.

De Roo, R.D. University of Florida C-band Radiometer Summary. Space Physics Research Laboratory, University of Michigan, Ann Arbor, Michigan, March 2002.

De Roo, R.D. TMRS-3 Radiometer Tuning Procedures. Space Physics Research Laboratory, University of Michigan, Ann Arbor, Michigan, March 2003.

De Roo, R.D. Personal communication, 2010.

Fernandez-Diaz, J.C. "Scientific Applications of the Mobile Terrestrial Laser Scanner (M-TLS) System.” Master's Thesis, University of Florida, Gainesville, FL. Available at: http://purl.fcla.edu/fcla/etd/UFE0021101, 2007.

Fröhlich, C., and M. Mettenleiter. "Terrestrial Laser Scanning - New Perspectives in 3d Surveying." International Society for Photogrammetry and Remote Sensing Working Group VIII/2 'Laser-Scanners for Forest and Landscape Assessment,' Freiburg, Germany (2004):7-13.

Kaimal, J.C., and J.J. Finnigan. Atmospheric Boundary Layer Flows: Their Structure and Measurement. New York: Oxford University Press, 2004.

Schotanus, P., F.T.M. Nieuwstadt, and H.A.R. de Bruin. “Temperature Measurement with a Sonic Anemometer and Its Application to Heat and Moisture Fluxes.” Boundary-Layer Meteorology 26 (2003):81-93.

University of Edinburgh. EdiRe data software. Available at: http://www.geos.ed.ac.uk/abs/research/micromet/EdiRe/.

Van Dijk, A., W. Kohsiek, and H.A.R. de Bruin. "Oxygen Sensitivity of Krypton and Lyman-alpha Hygrometer." Journal of Atmospheric and Ocean Technology 20 (2003):143-151.

Webb, E.K., G.I. Pearman, and R. Leuning. "Correction of Flux Measurements for Density Effects Due to Heat and Water Vapor Transfer.” Quarterly Journal of the Royal Meteorological Society 106 (1980):85-100.

Wilczak, J.M., S.P. Oncley, and S.A. Stage. "Sonic Anemometer Tilt Correction Algorithms." Boundary-Layer Meteorology 99 (2001):127-150. 


\section{Acknowledgements}

The authors would like to acknowledge Mr. James Boyer and his team at the PSREU in Citra, Florida, for excellent field management. MicroWEX-9 was supported by a grant from NASA-NIP (Grant number: 0005065) and the Earth Science Directorate, National Science Foundation (Grant number: EAR-0337277).

\section{A. Field Observations}

\section{Figure Captions}

Figure A-1. Microwave brightness at C-band at Vertical and Horizontal polarization and L-band at

Horizontal polarization. ................................................................................................................................... 41

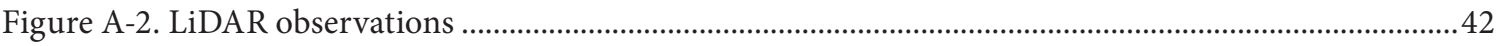

Figure A-3. Latent (LE) and sensible (H) heat fluxes at Eddy Covariance Station. ..........................................4

Figure A-4. Down- and up-welling shortwave and longwave radiation.............................................................4

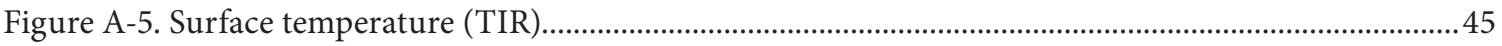

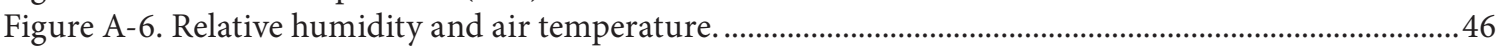

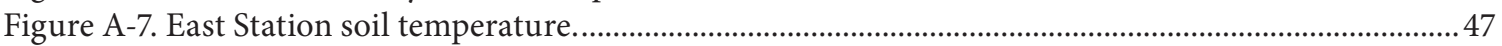

Figure A-8. West Station soil temperature.................................................................................................. 48

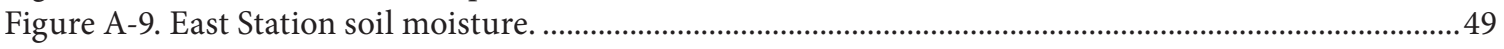

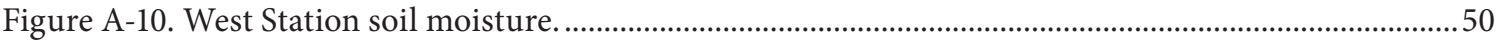

Figure A-11. Rainfall from the rain gauge at the east and west edge of footprint. ...........................................51

Figure A-12. Eddy Station and East Station soil heat fluxes..........................................................................52

Figure A-13. Clumps in one square meter................................................................................................... 53

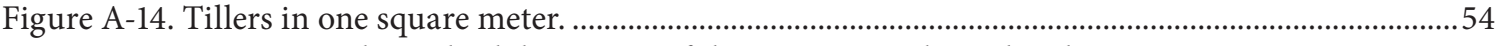

Figure A-15. Averages and standard deviations of the maximum clump height.............................................55

Figure A-16. Averages and standard deviations of the base width......................................................................56

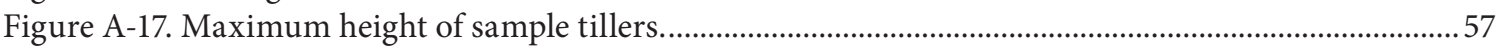

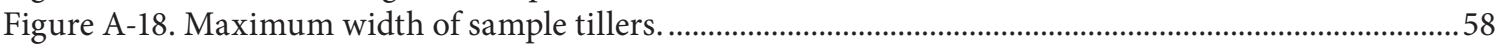

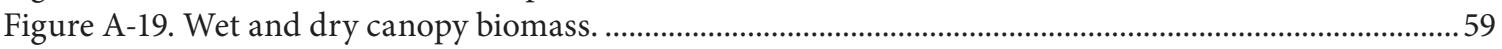

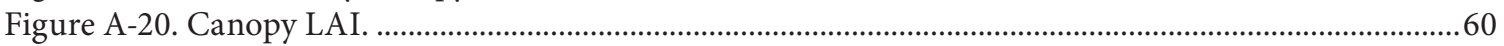

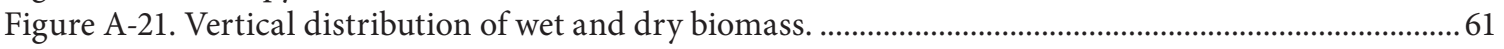

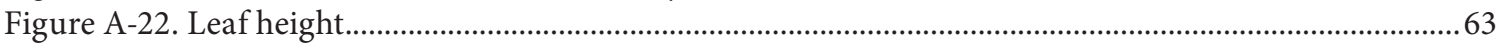

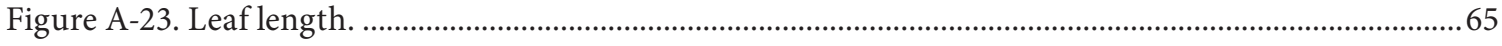

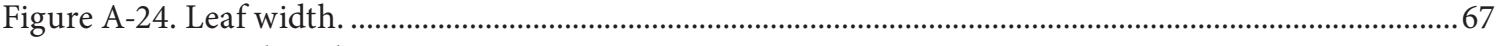

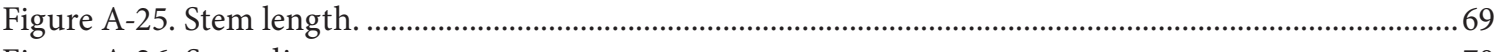

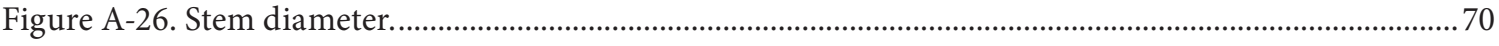

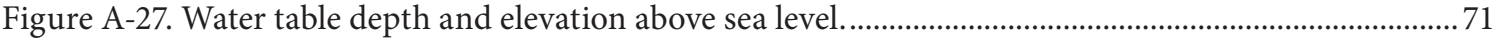



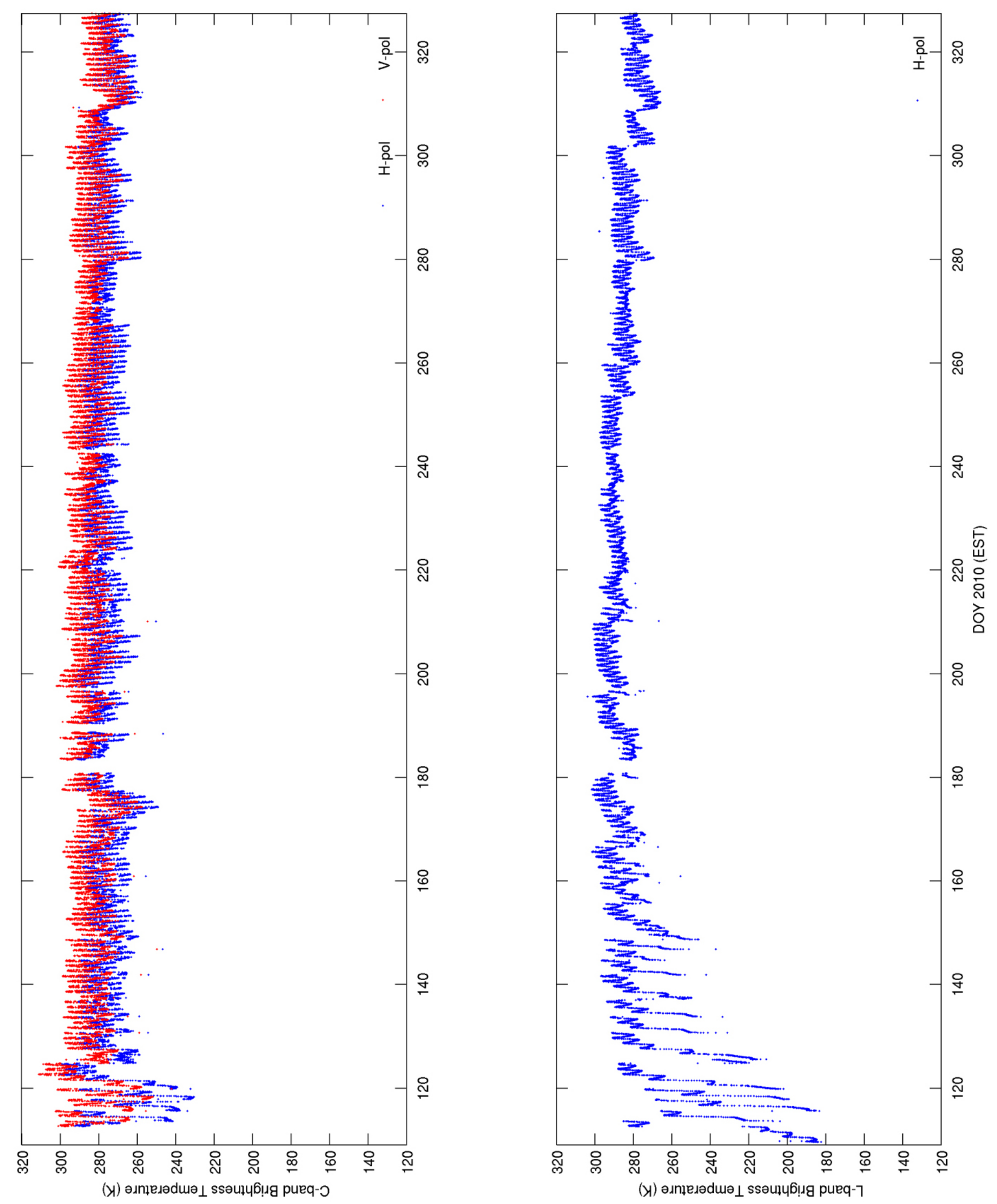

Figure A-1. Microwave brightness at C-band at Vertical and Horizontal polarization and L-band at Horizontal polarization. 


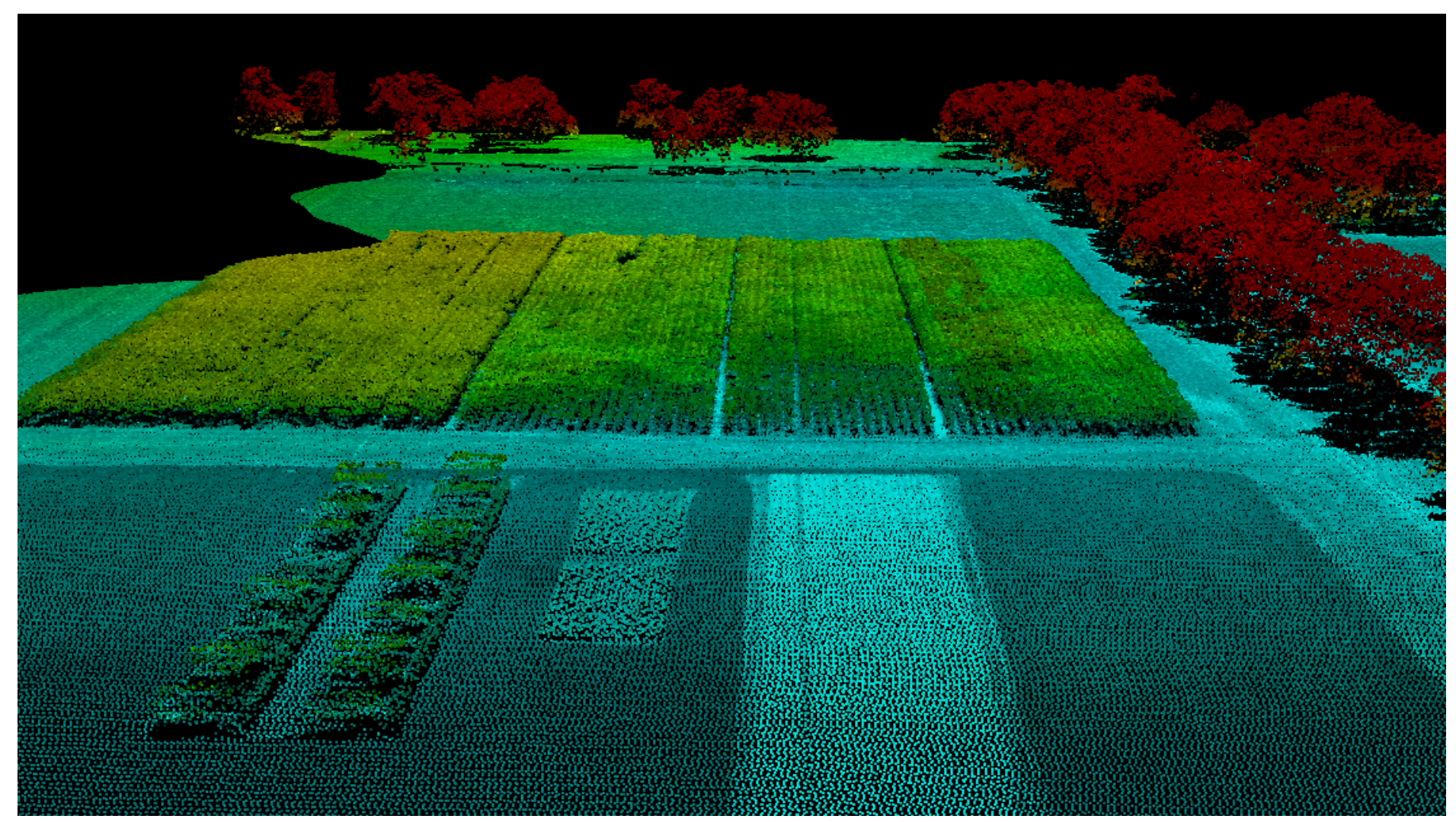

Measurement on DoY 245

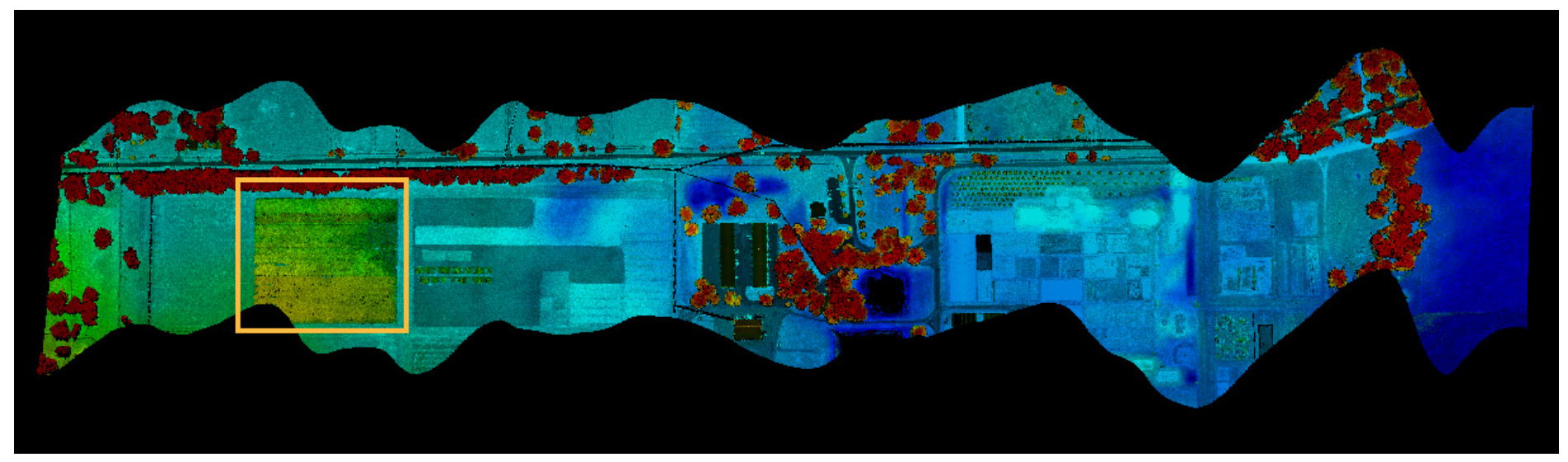

Measurement on DoY 245

Figure A-2. LiDAR observations 


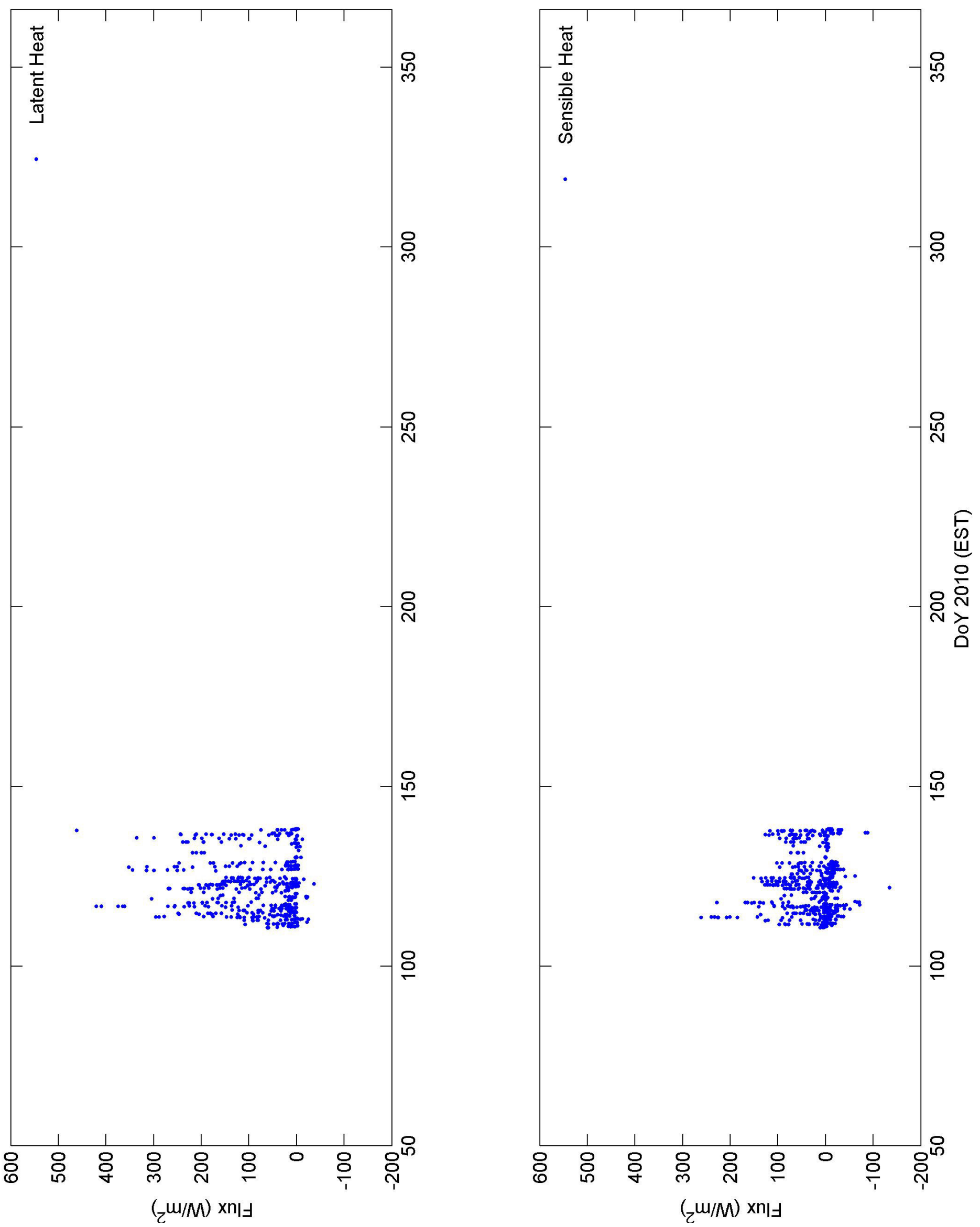

Figure A-3. Latent (LE) and sensible (H) heat fluxes at Eddy Covariance Station. 

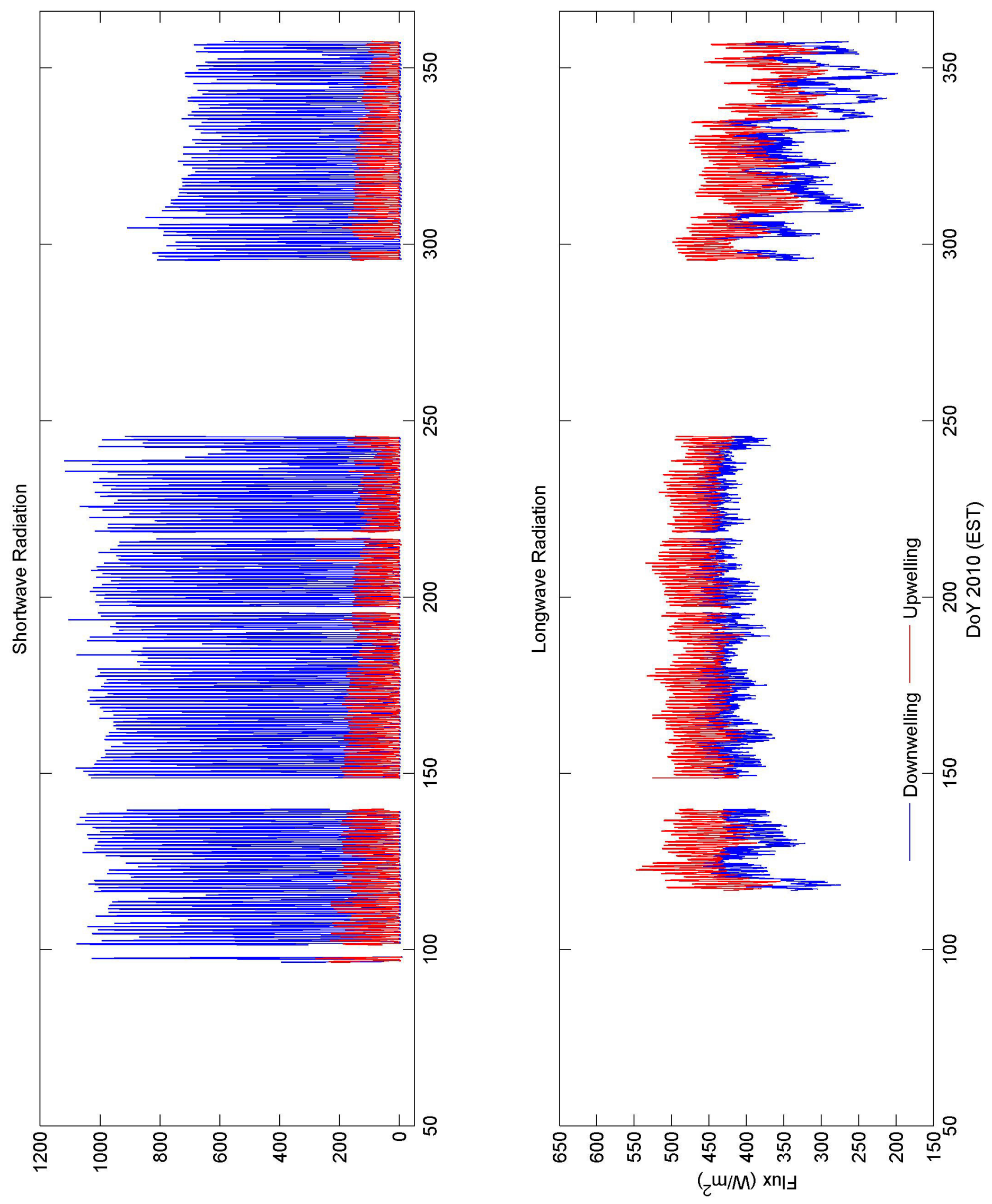

Figure A-4. Down- and up-welling shortwave and longwave radiation. 

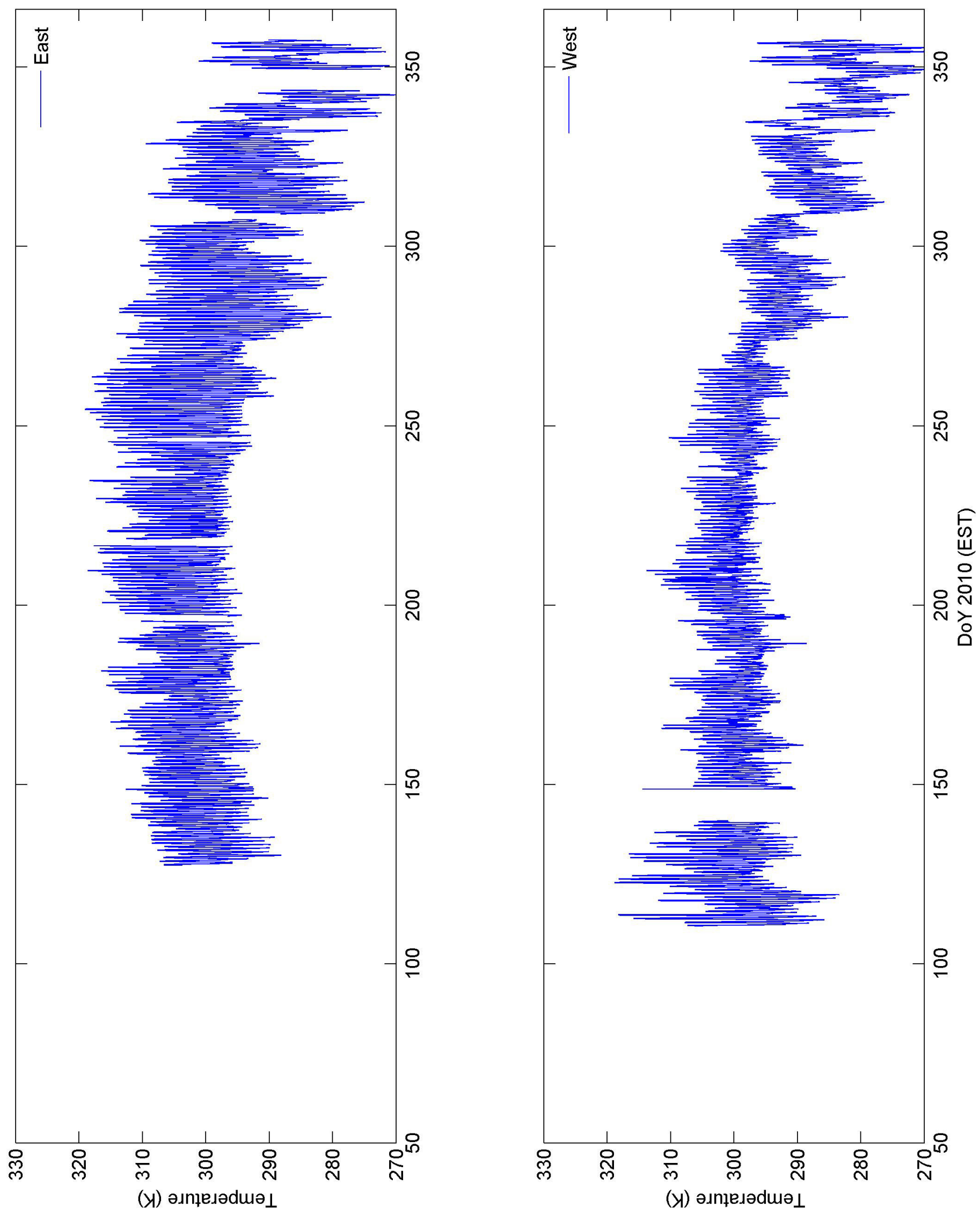

Figure A-5. Surface temperature (TIR). 

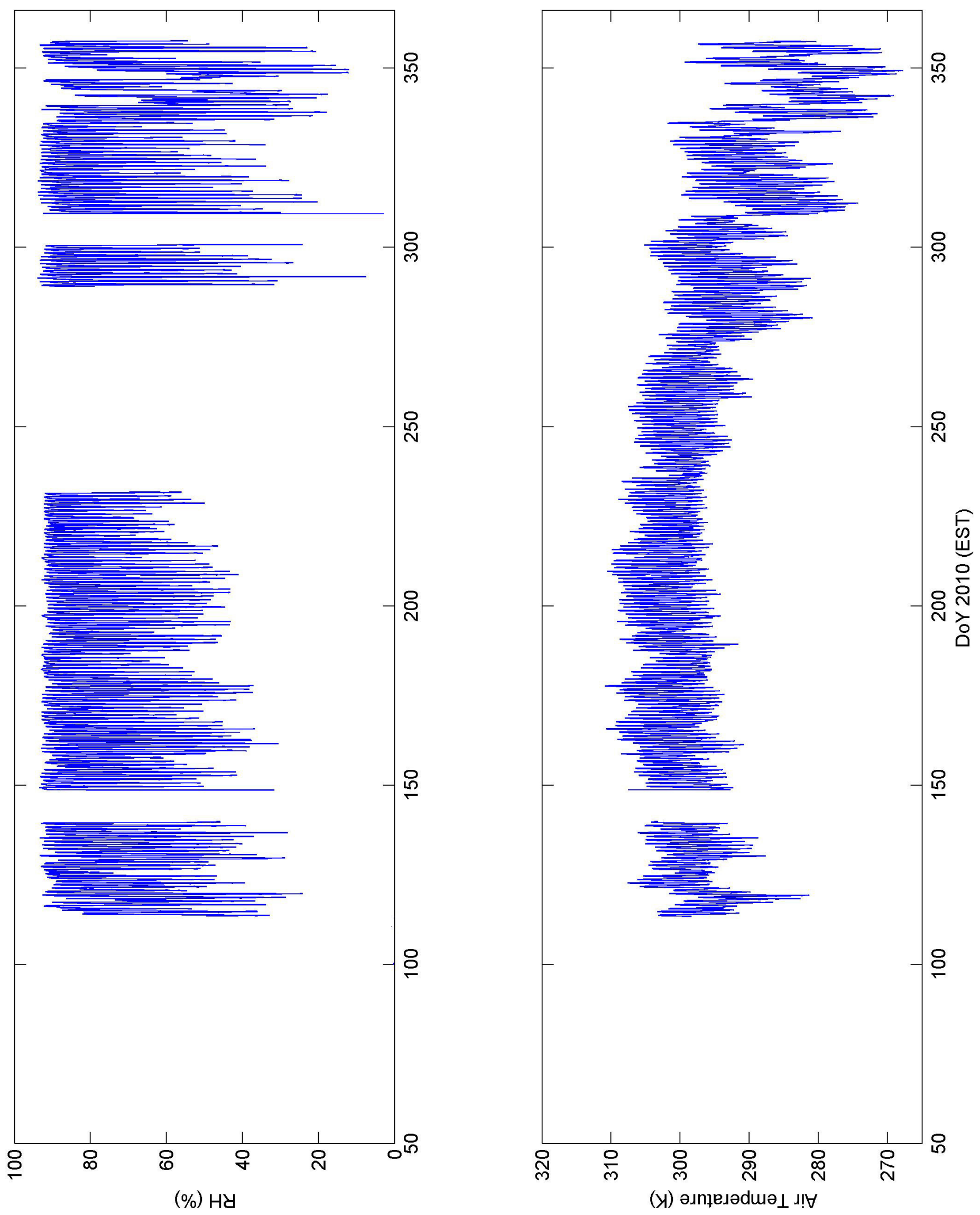

Figure A-6. Relative humidity and air temperature. 


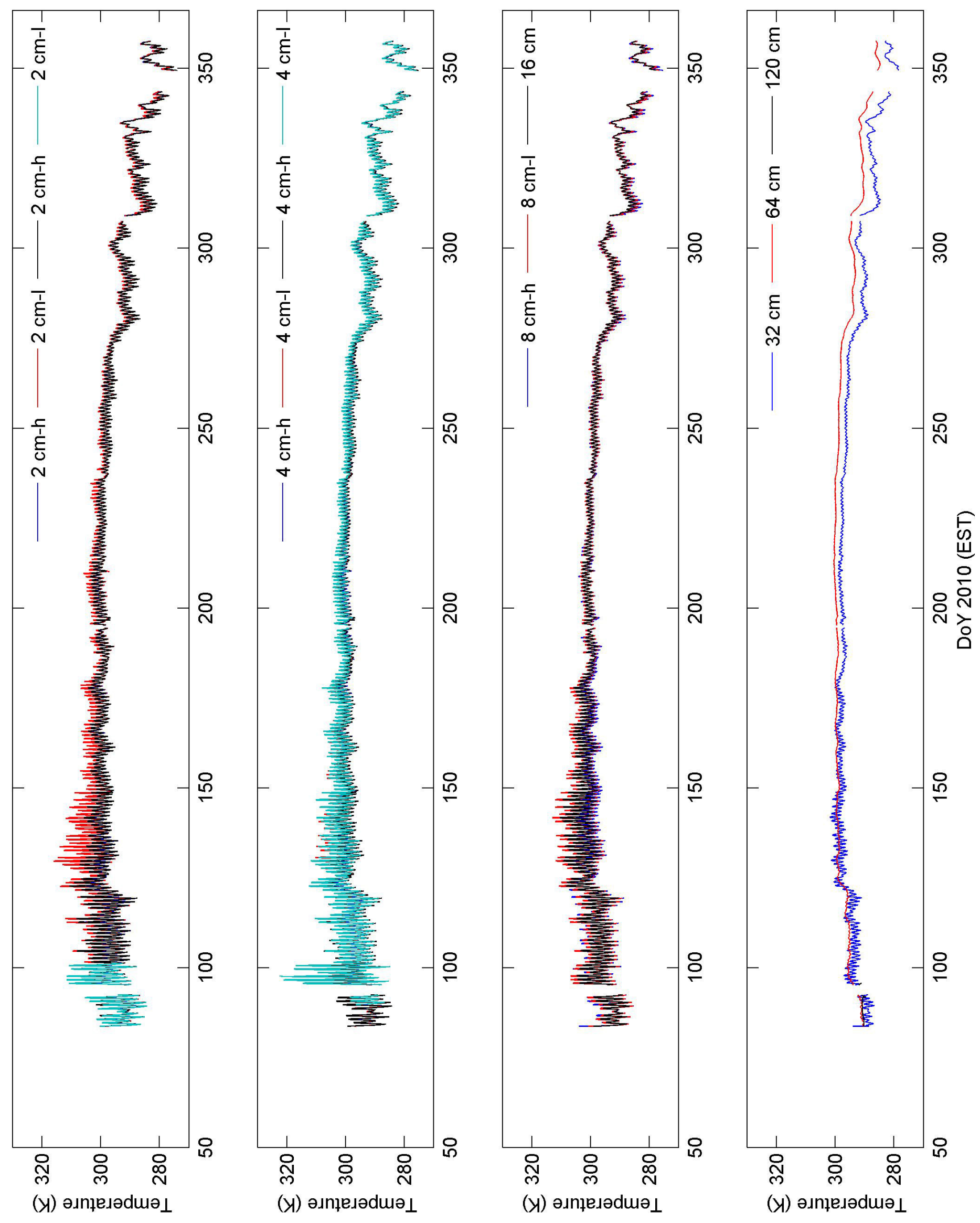

Figure A-7. East Station soil temperature. 


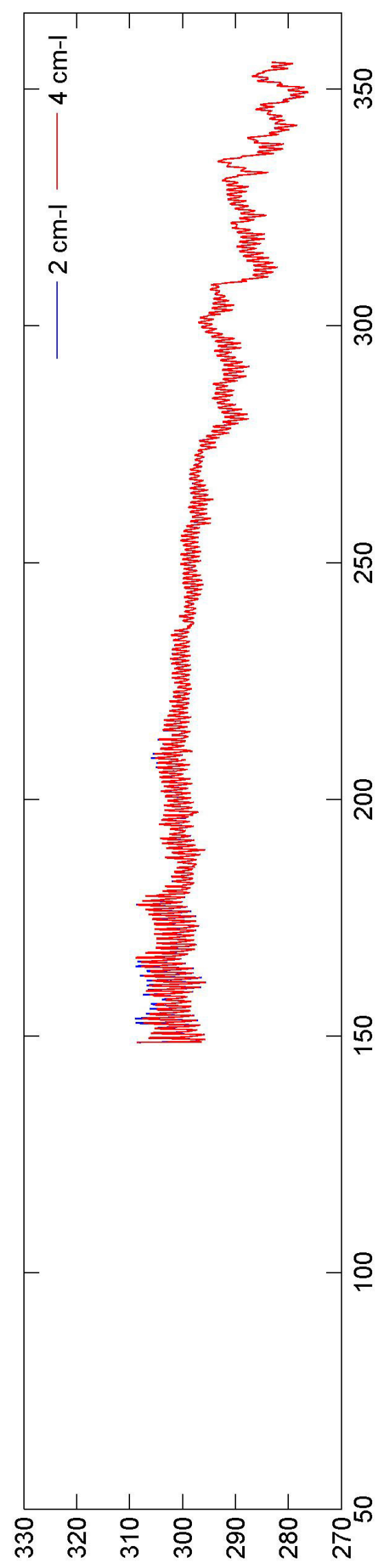

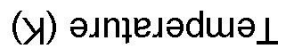

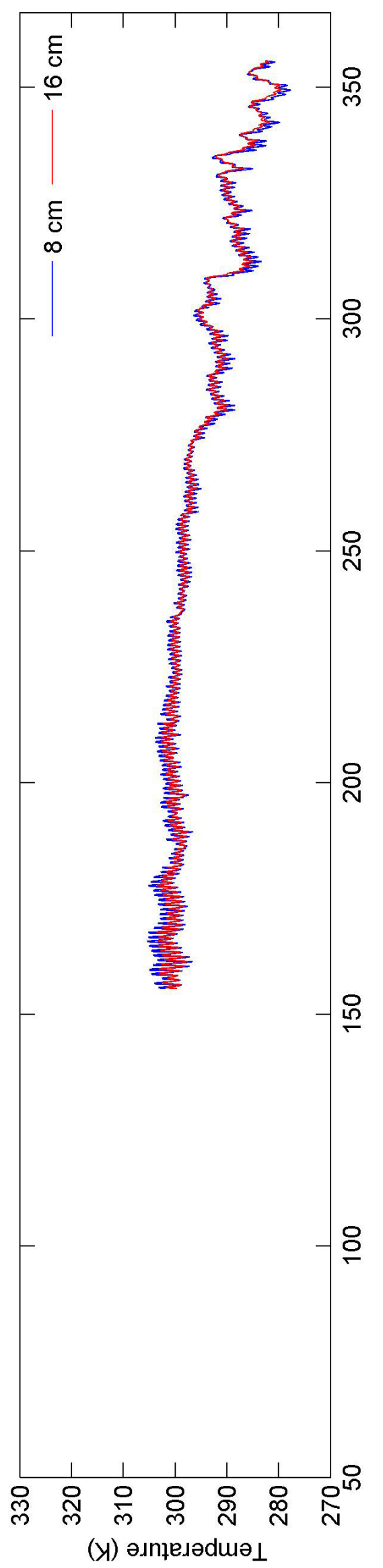

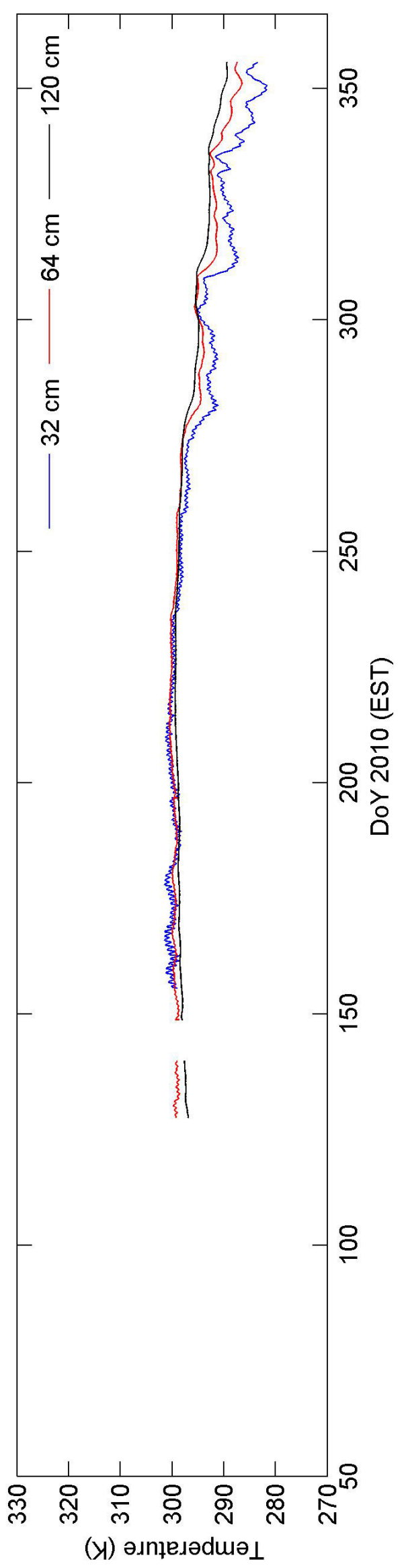

Figure A-8. West Station soil temperature. 


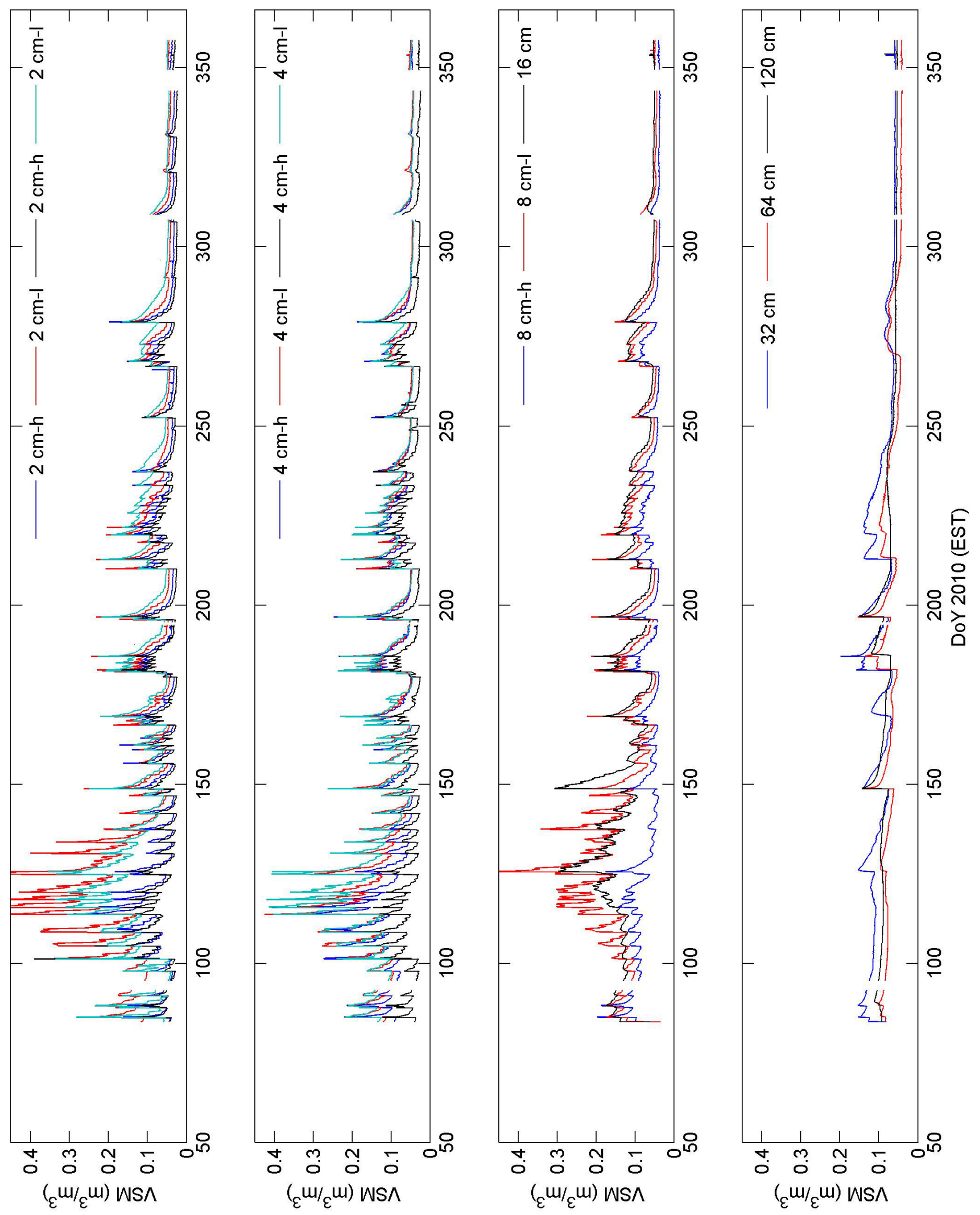

Figure A-9. East Station soil moisture. 


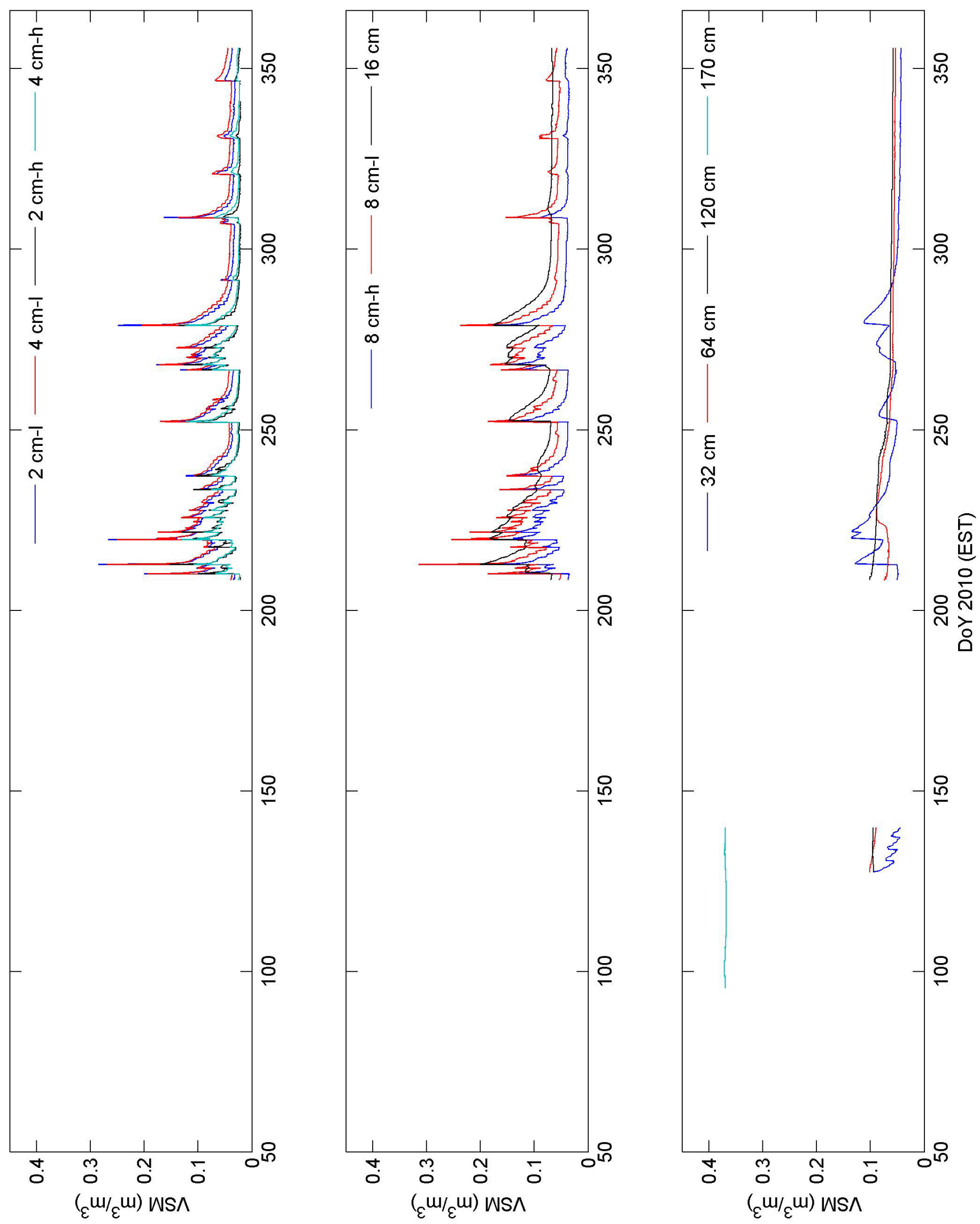

Figure A-10. West Station soil moisture. 


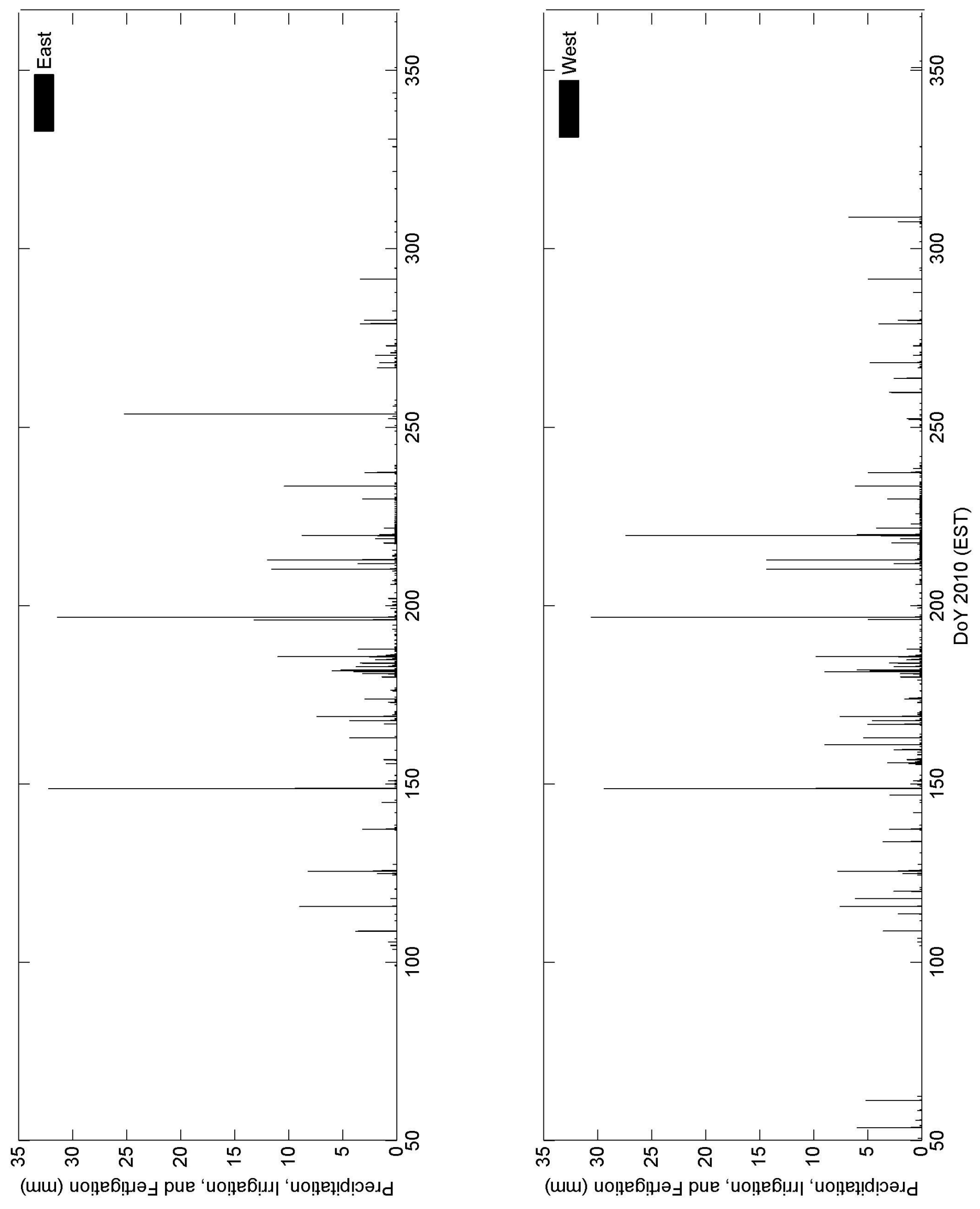

Figure A-11. Rainfall from the rain gauge at the east and west edge of footprint. 


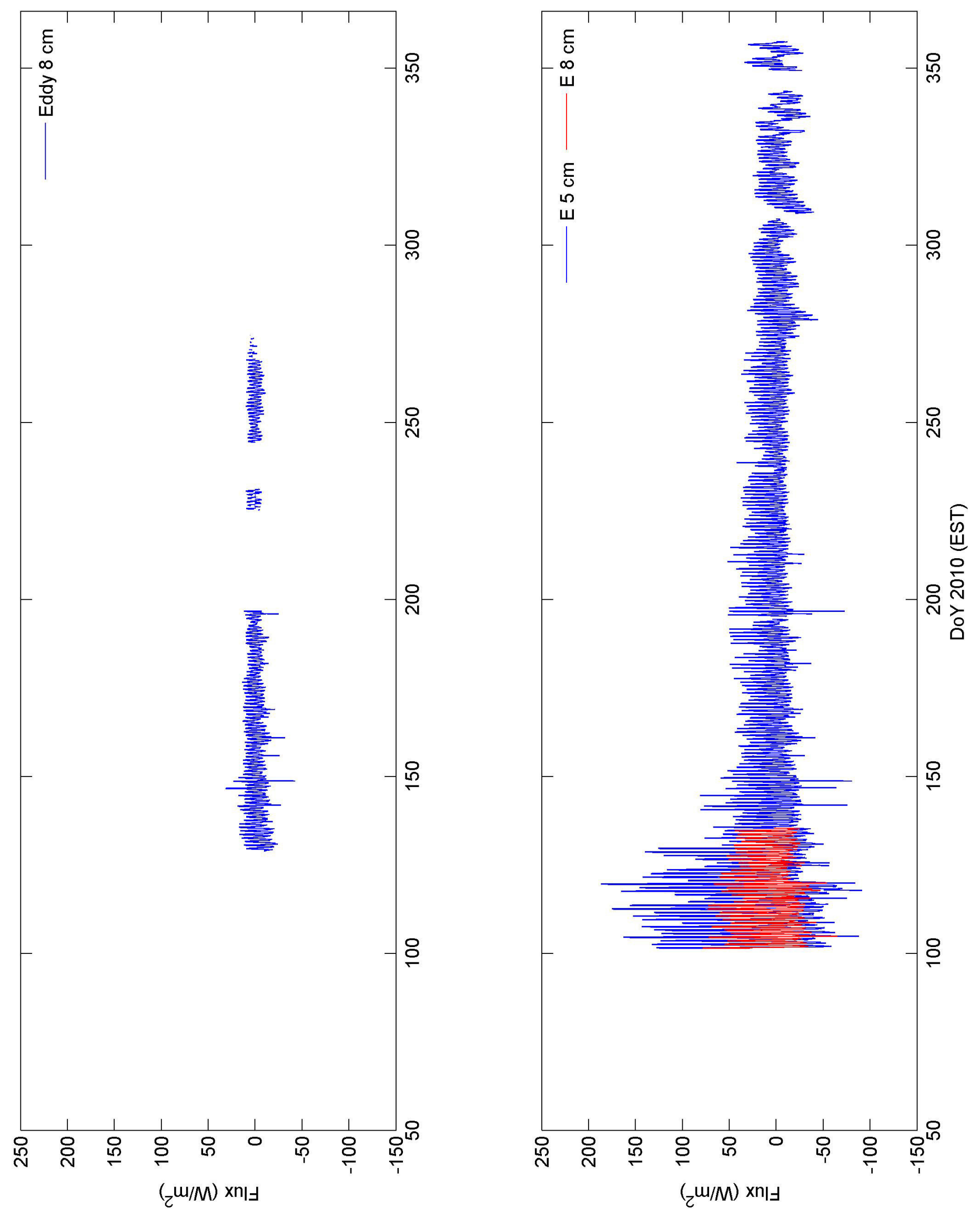

Figure A-12. Eddy Station and East Station soil heat fluxes. 

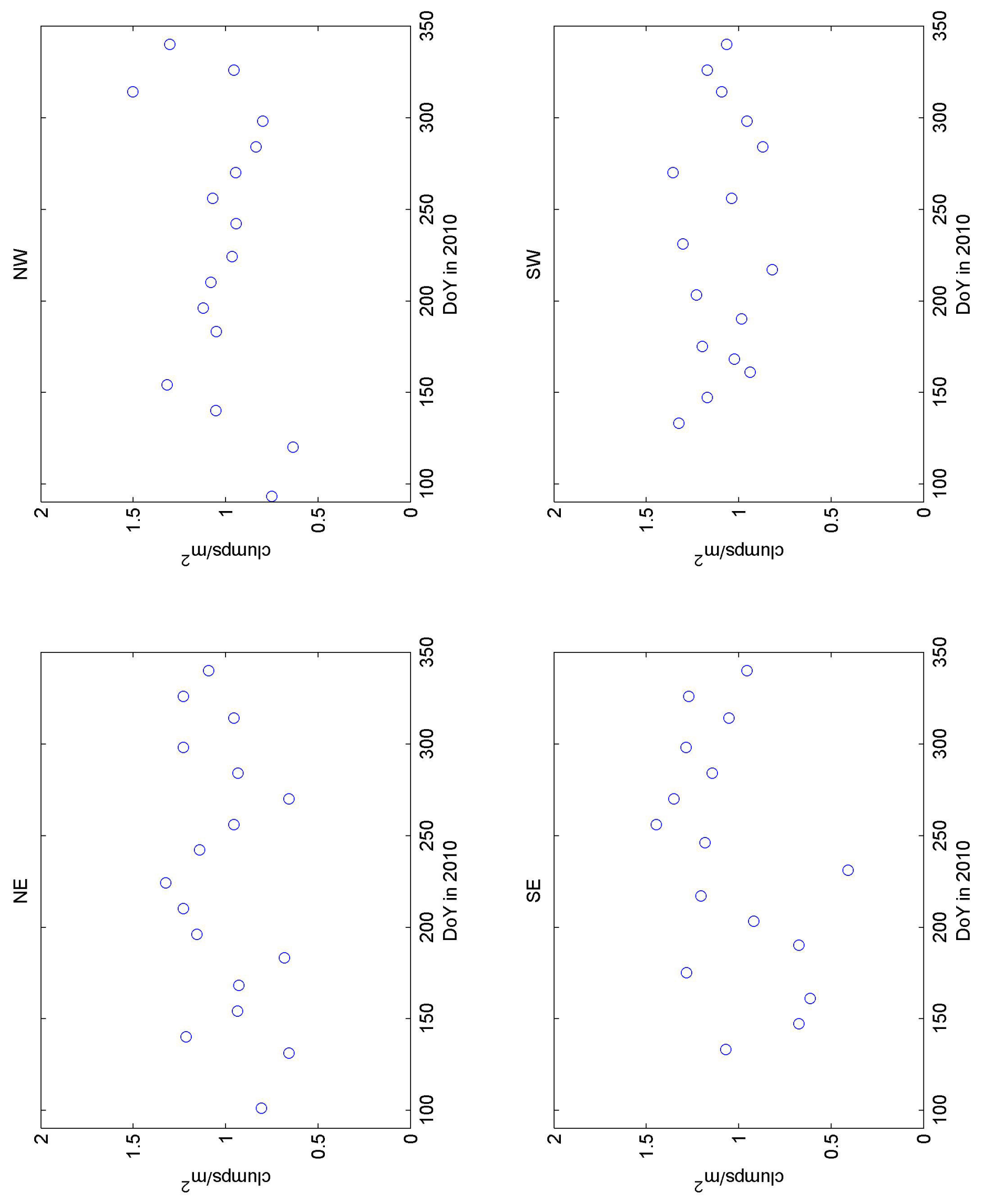

Figure A-13. Clumps in one square meter. 

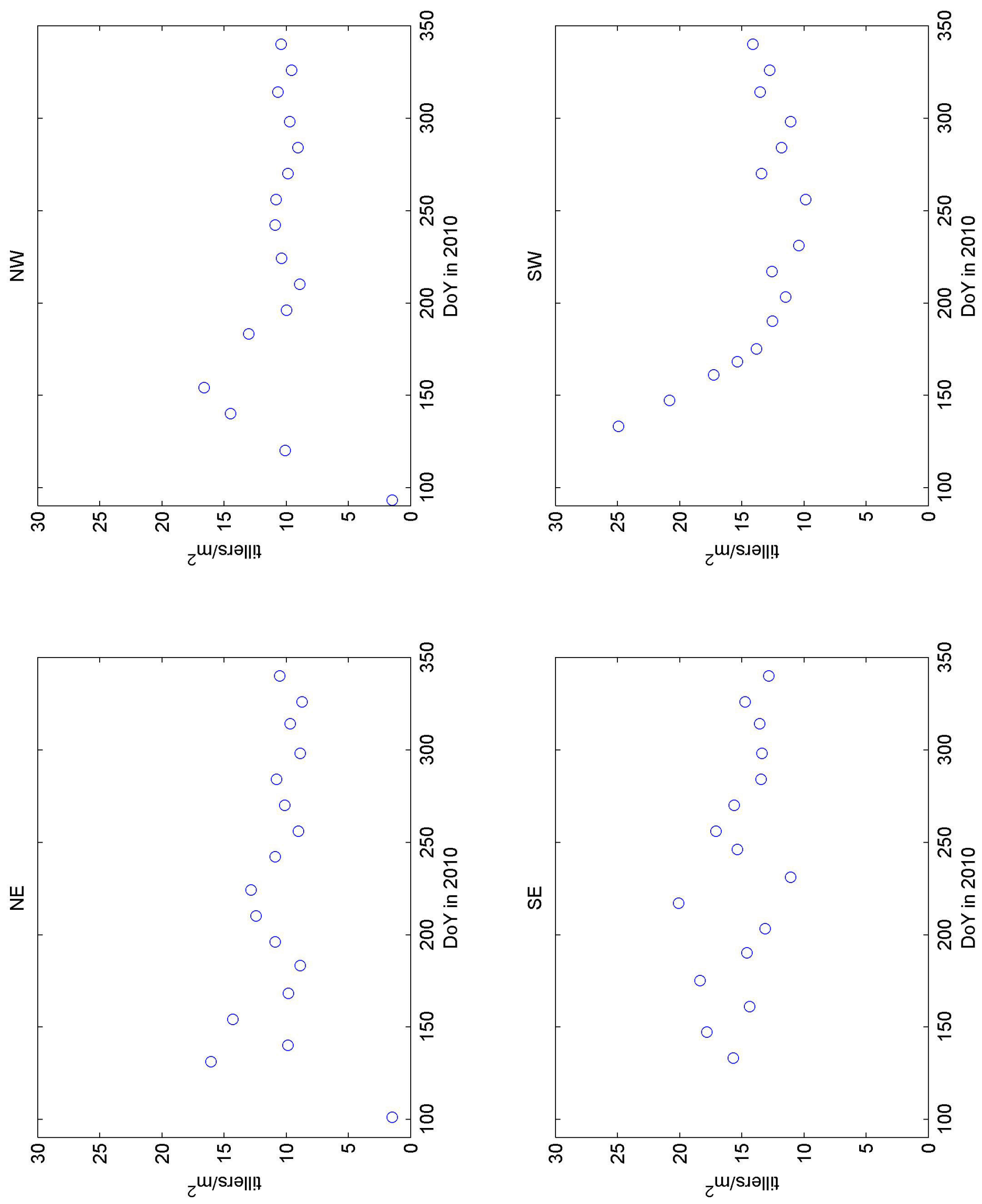

Figure A-14. Tillers in one square meter. 


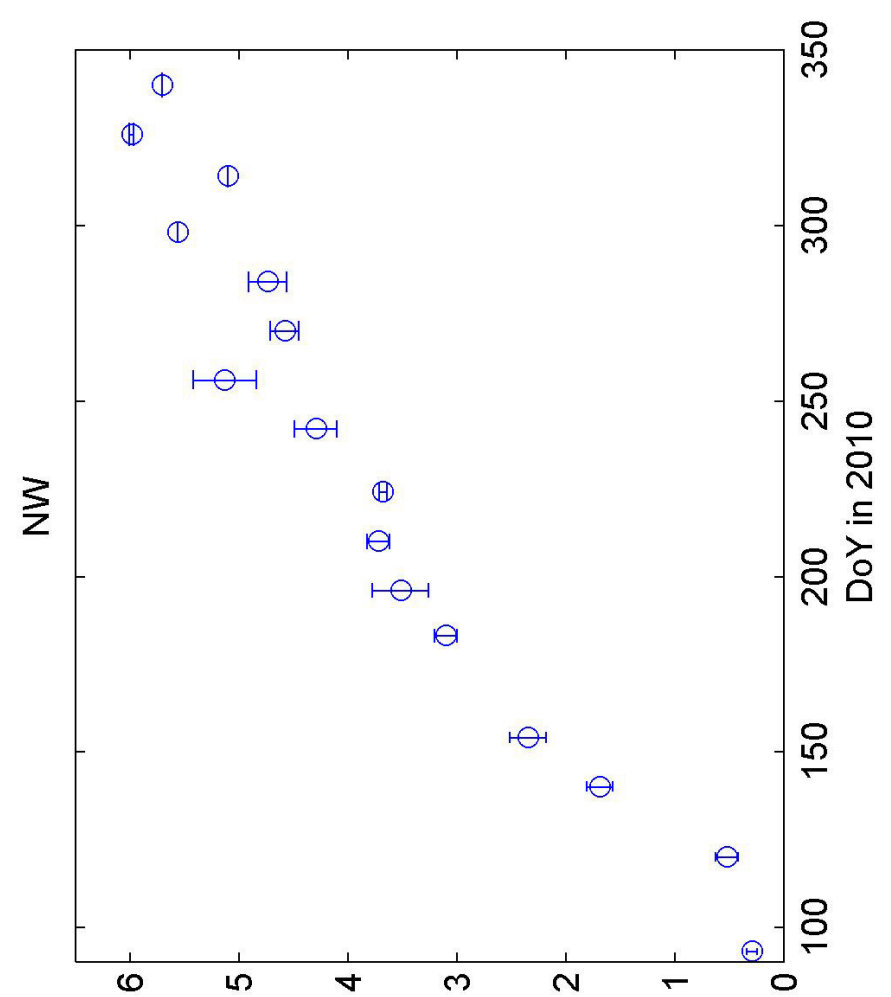

(w) 146 !əㅂ

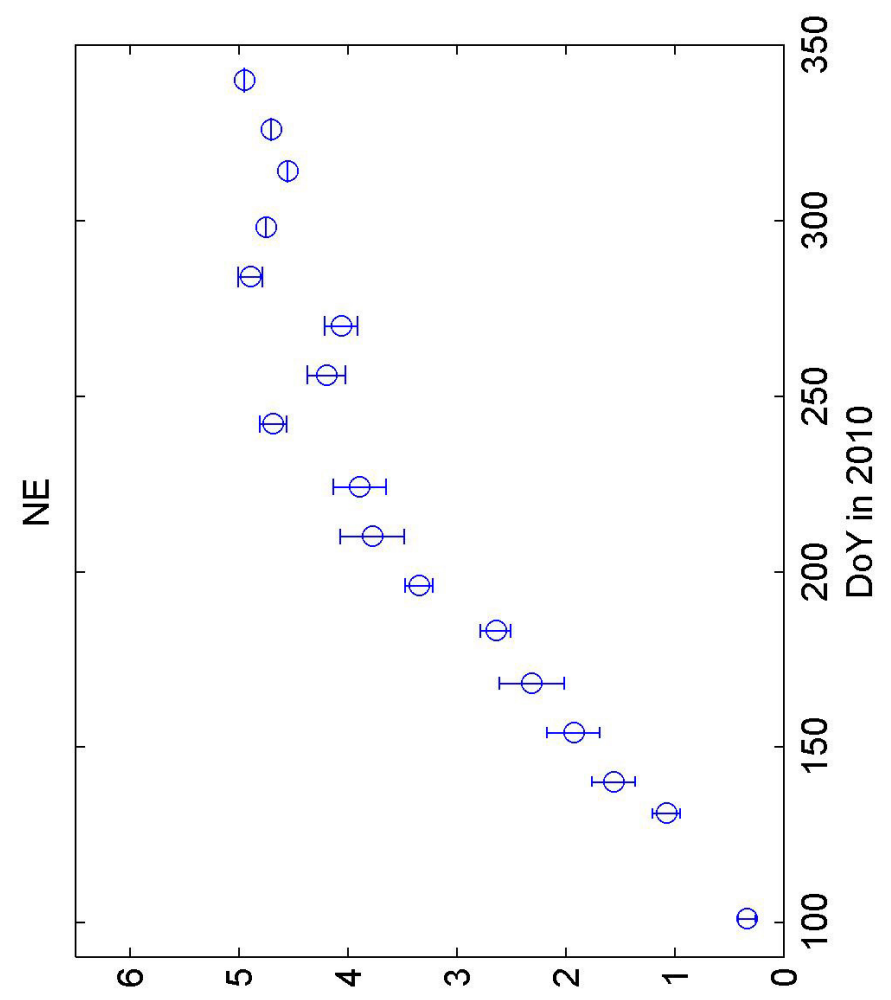

(ui) +46 !े

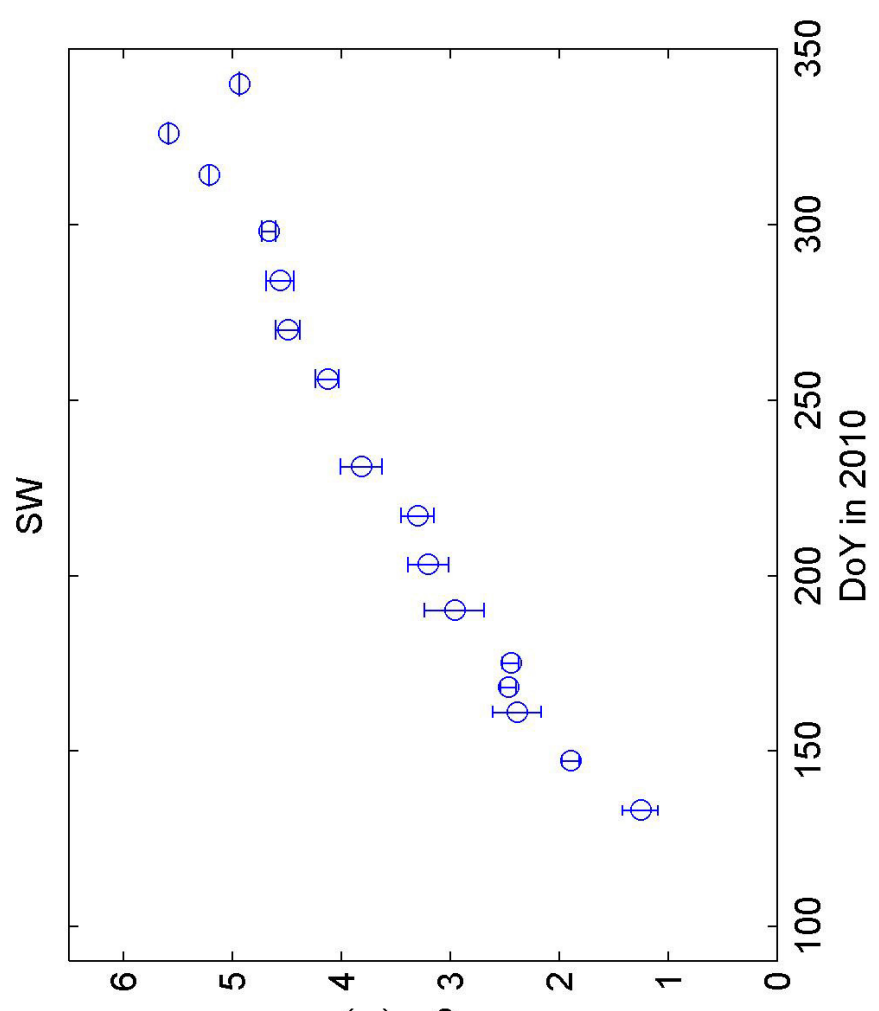

(w) 1460 !ә

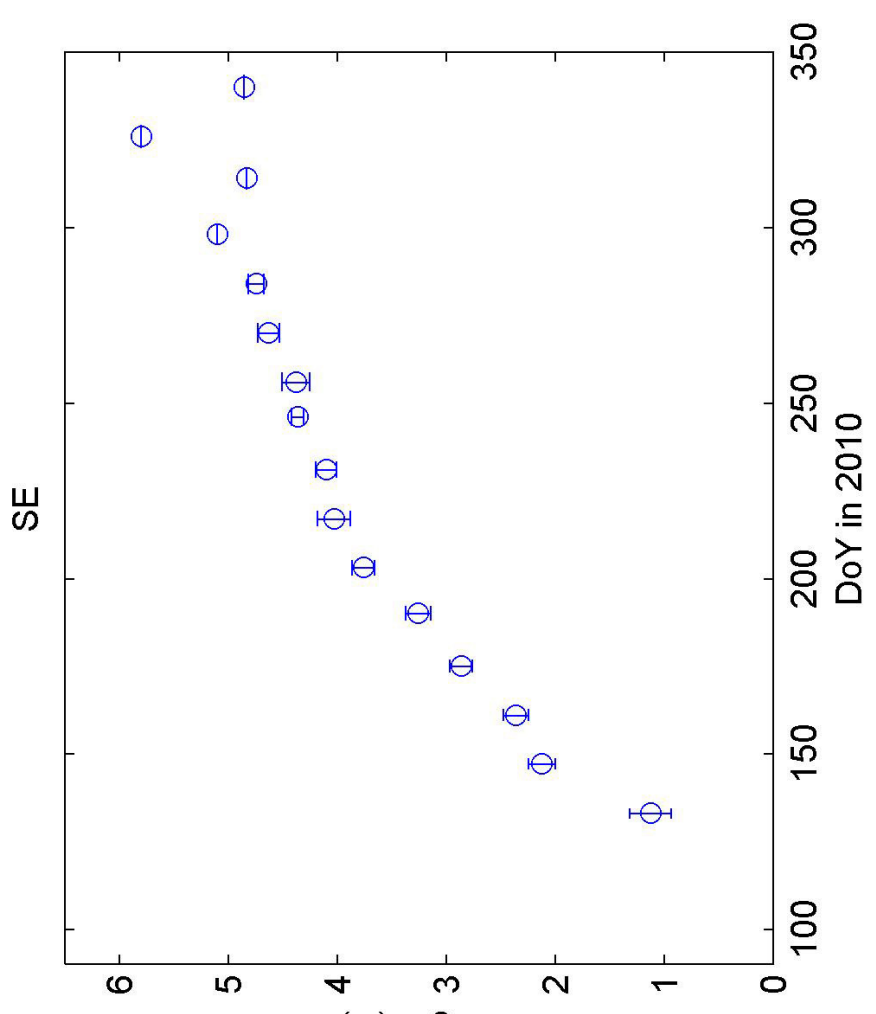

(ui) 146 !े॰

Figure A-15. Averages and standard deviations of the maximum clump height. 


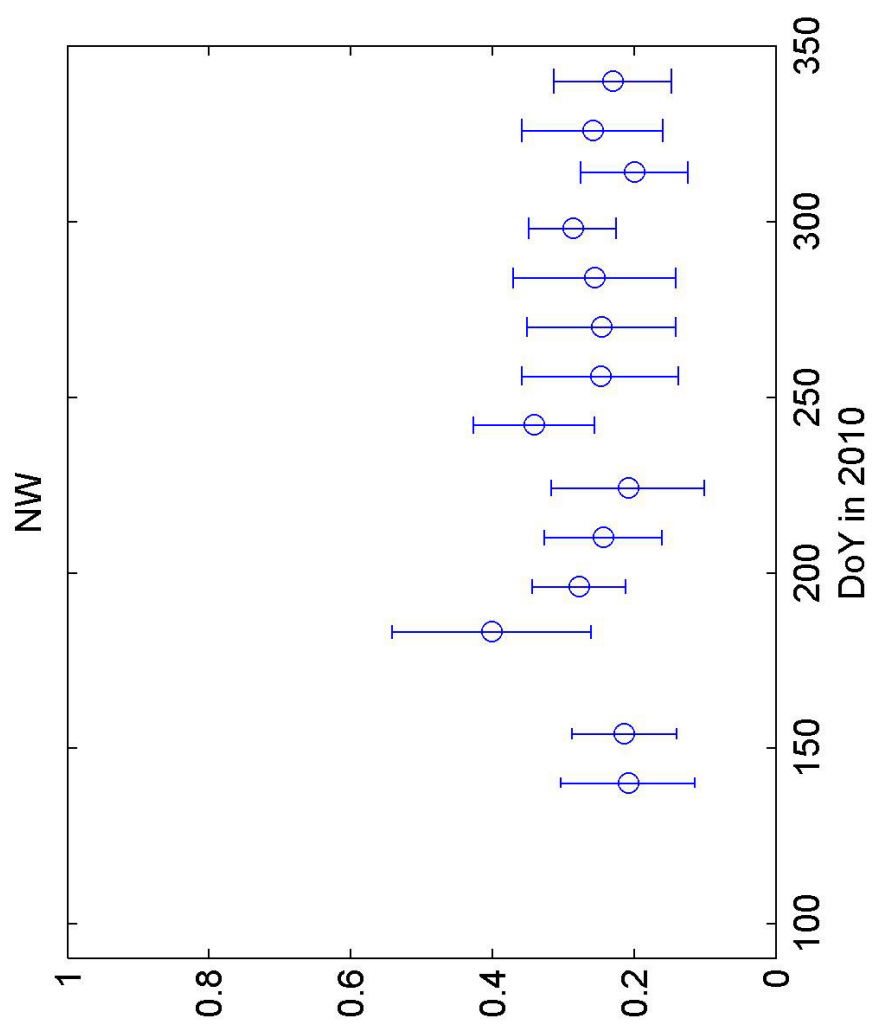

(u) ч1р!M

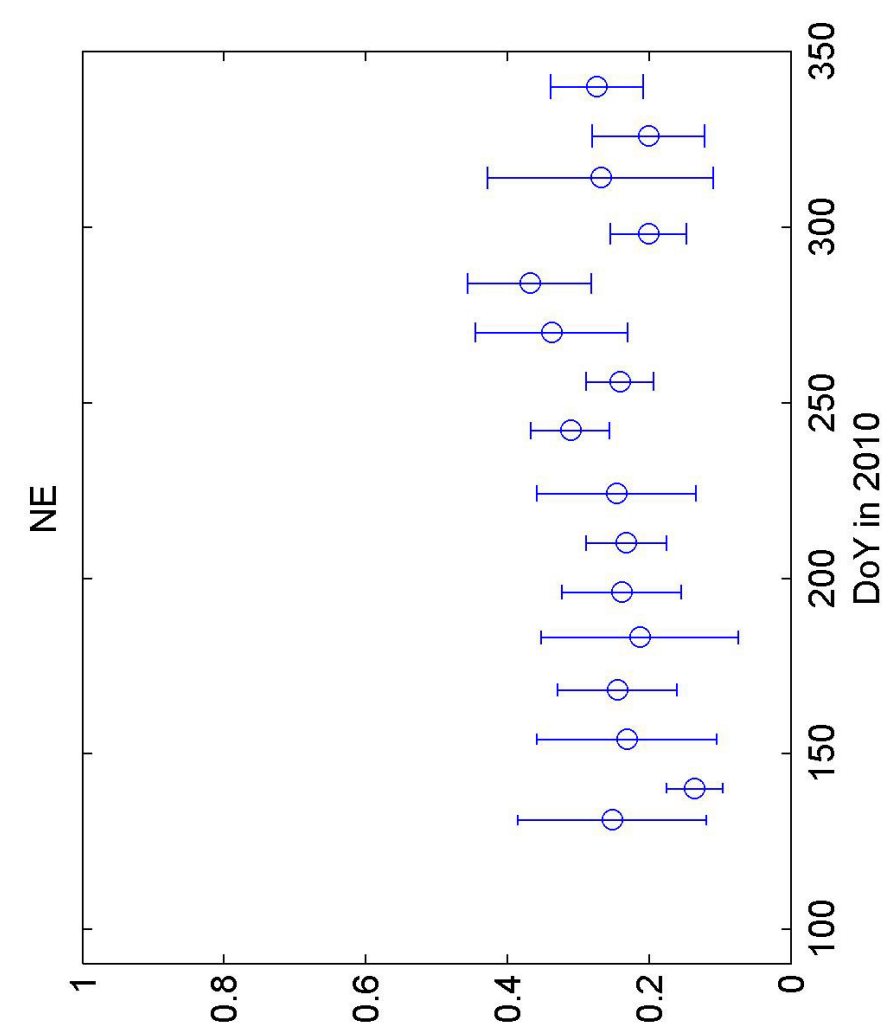

(u) чІр!M

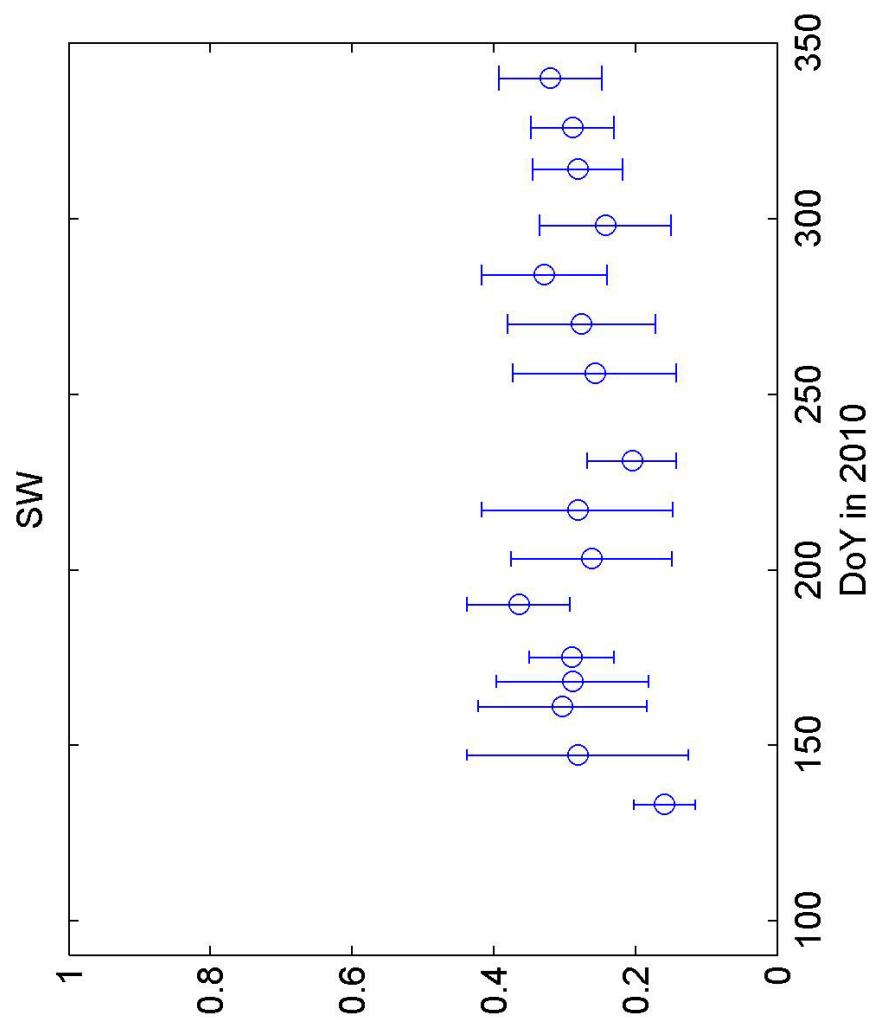

(w) чІрІМ

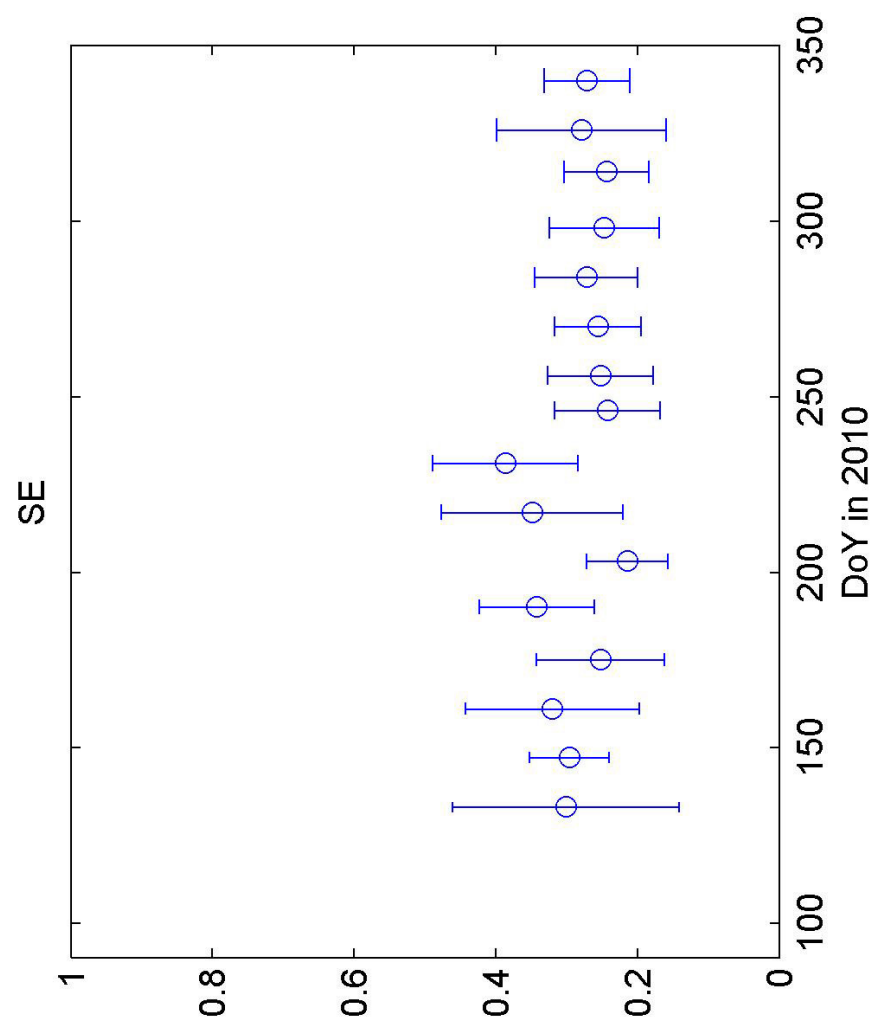

(w) чІрIM

Figure A-16. Averages and standard deviations of the base width. 

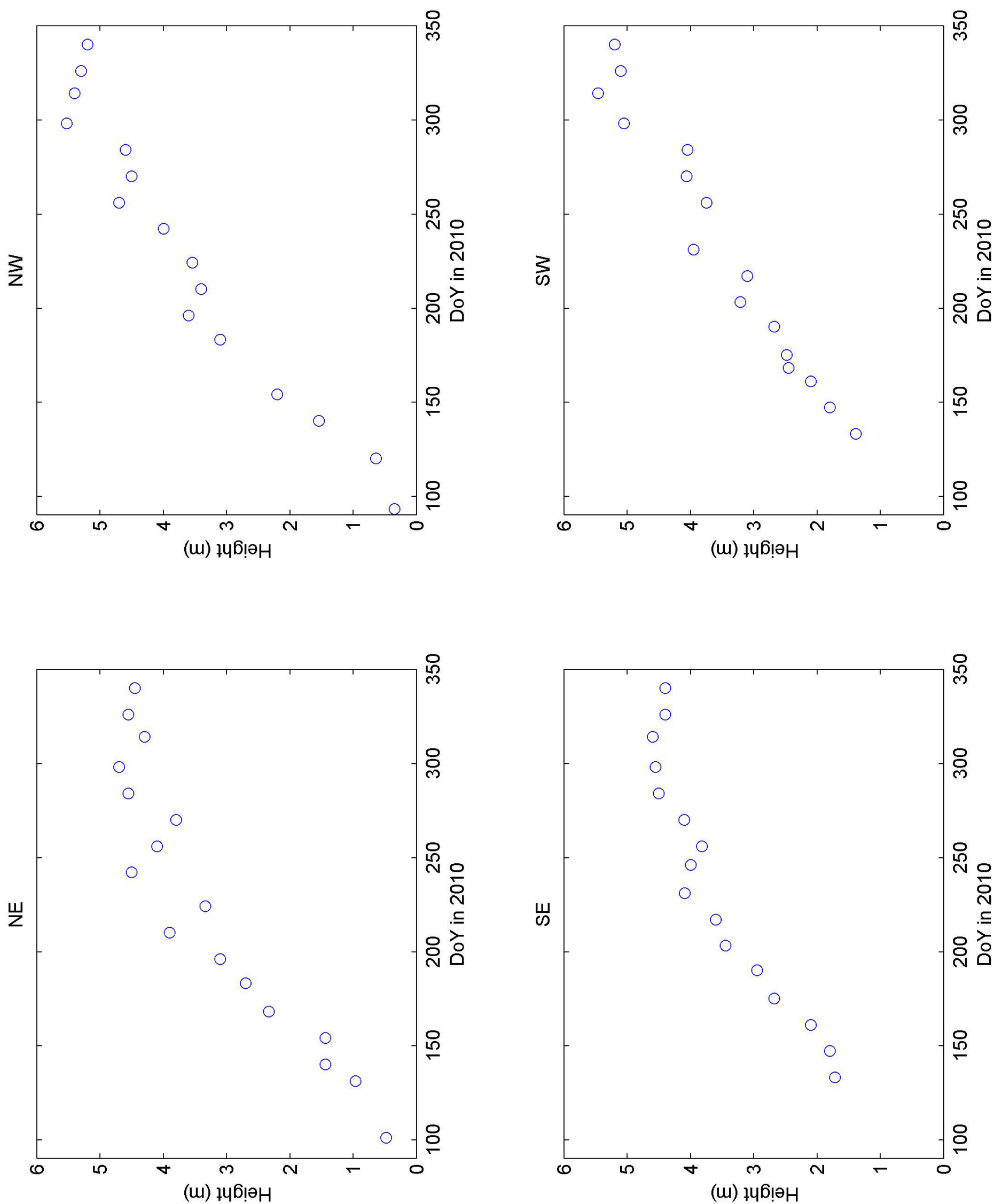

Figure A-17. Maximum height of sample tillers. 


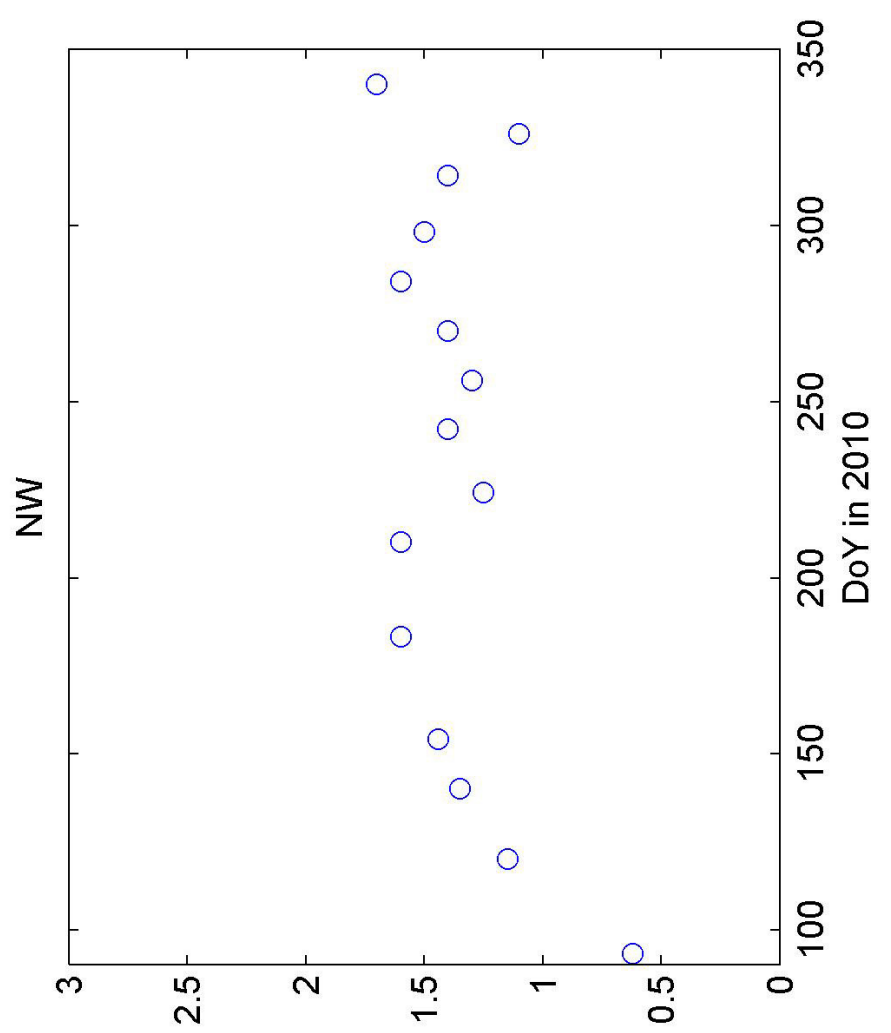

(w) पIP!M

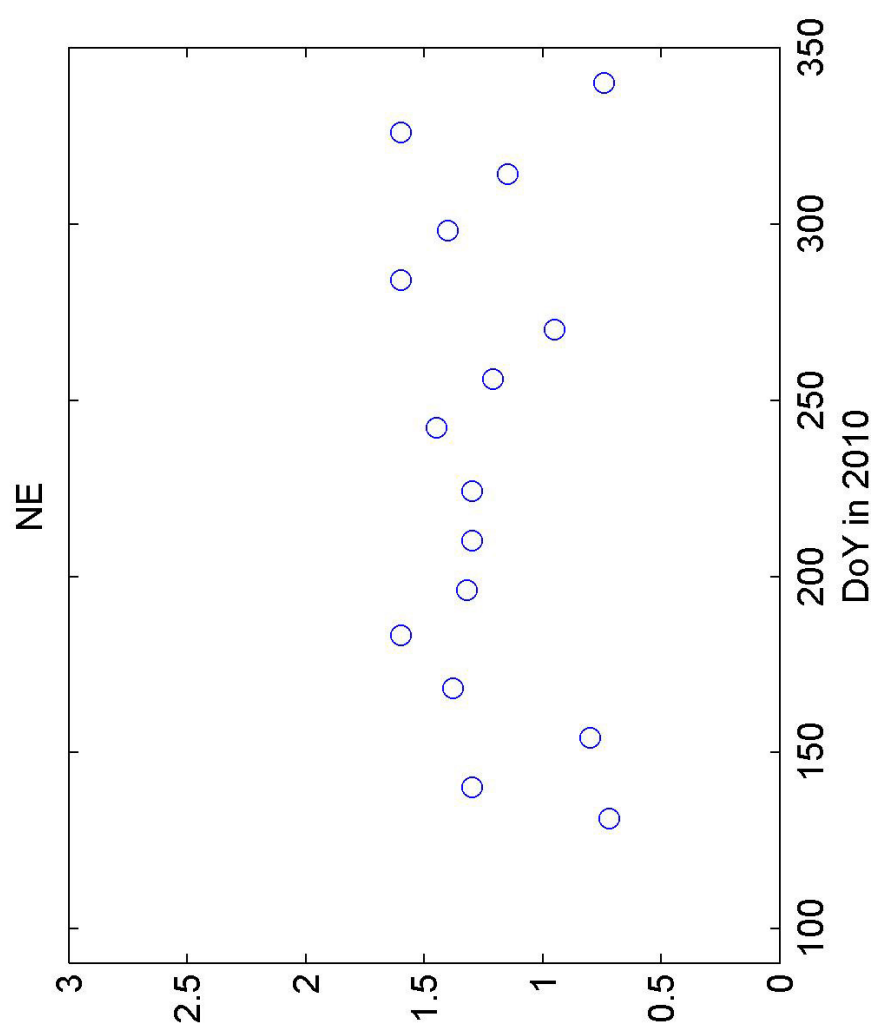

(w) ЧтP!M

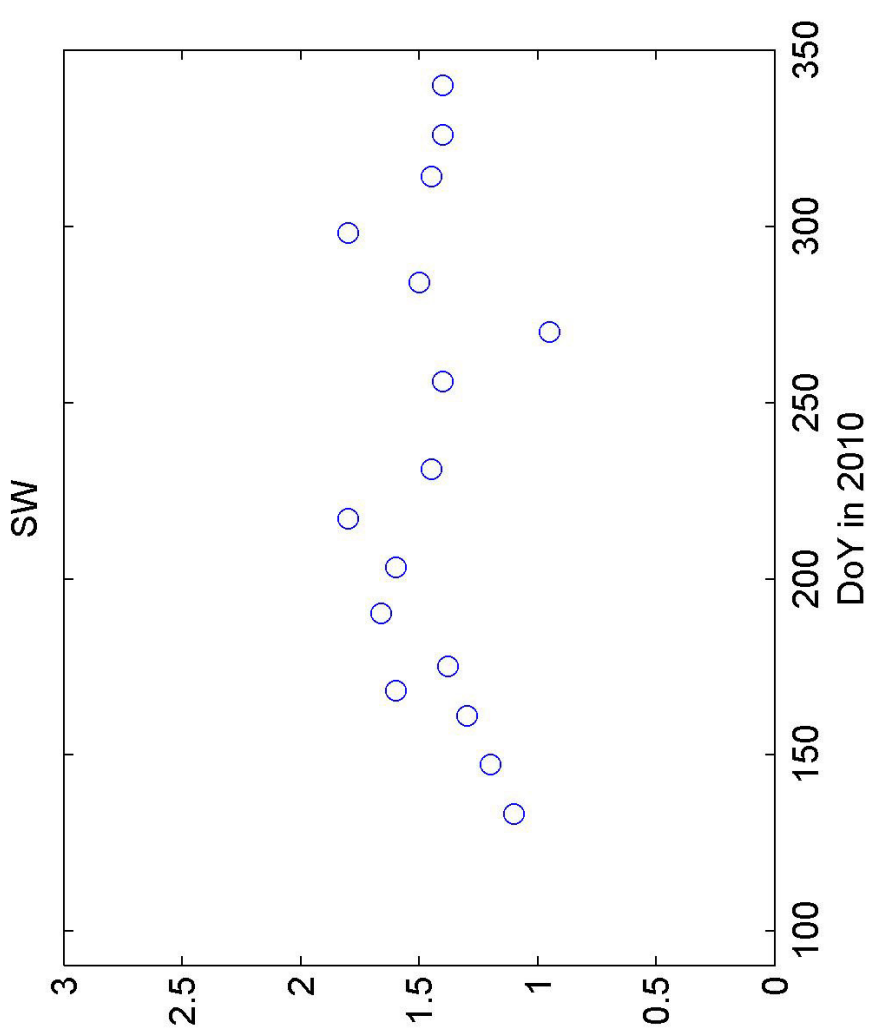

(w) पIP!M

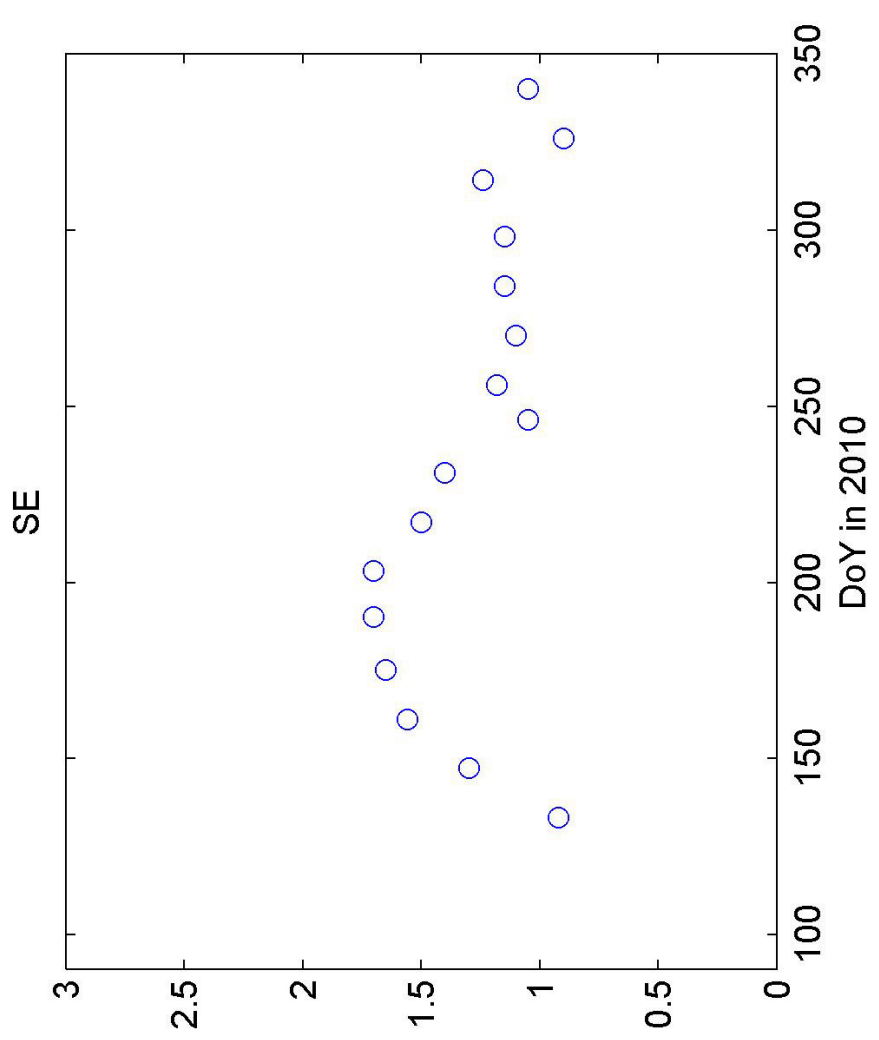

(w) чIP!M

Figure A-18. Maximum width of sample tillers. 

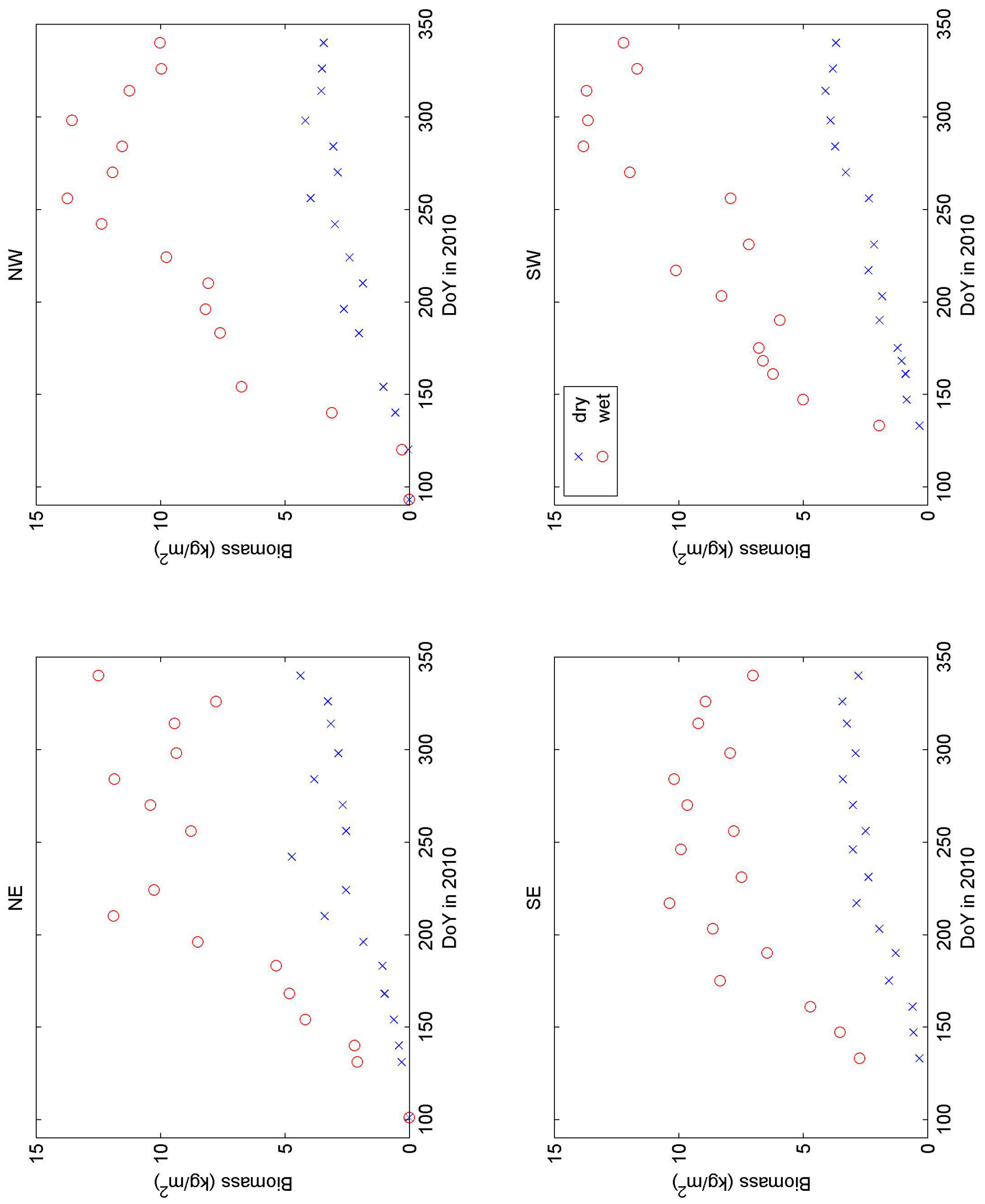

Figure A-19. Wet and dry canopy biomass. 
Archival copy: for current recommendations see http://edis.ifas.ufl.edu or your local extension office.
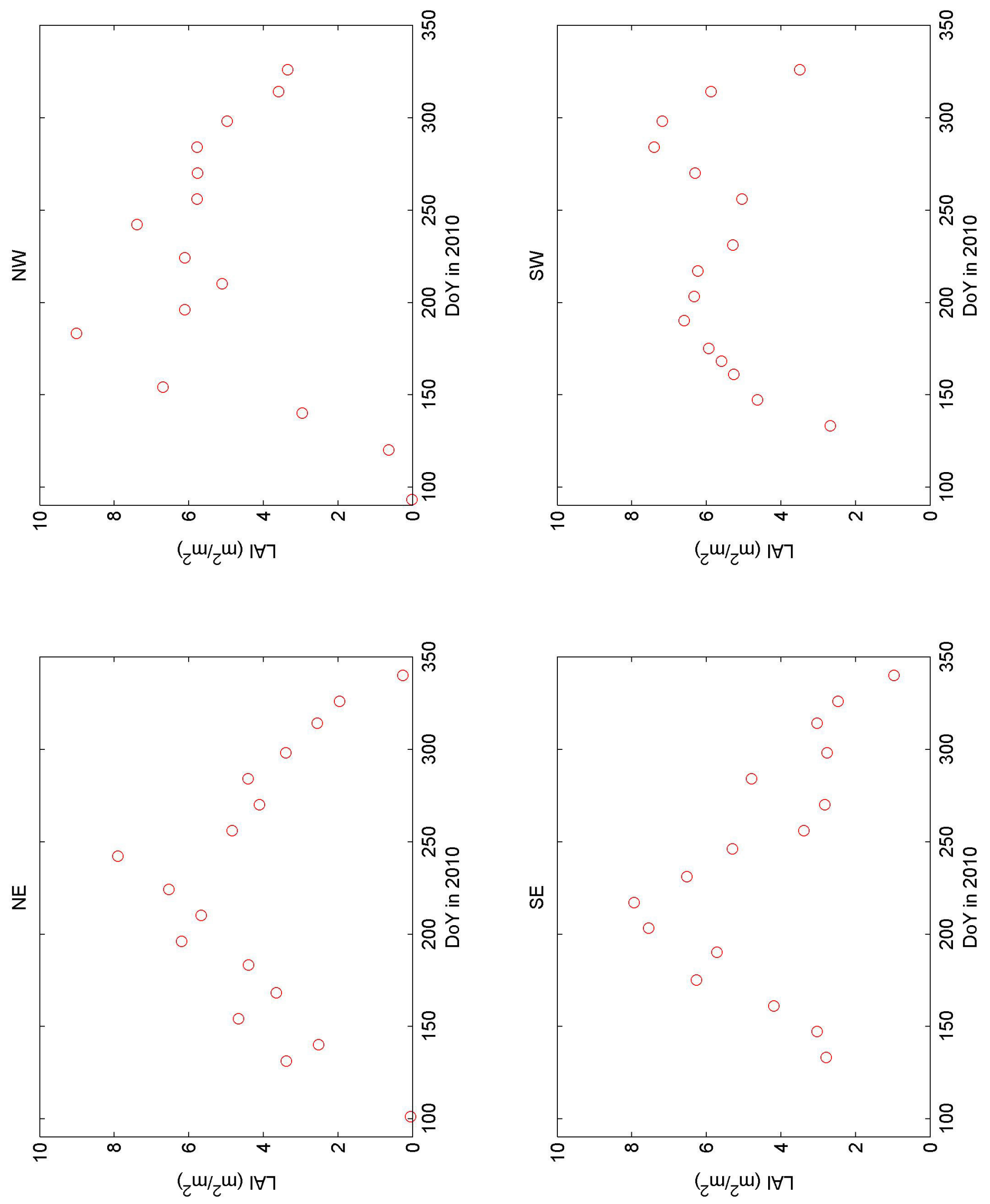

Figure A-20. Canopy LAI. 


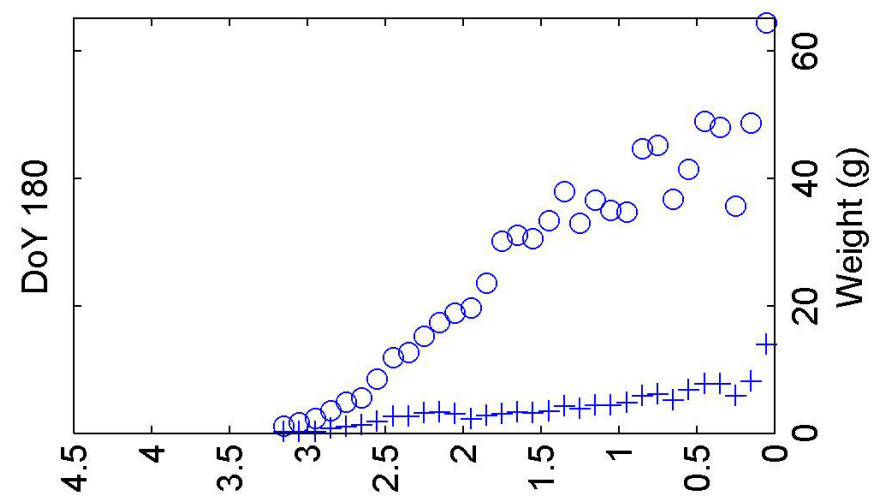

(u) $¥ 46 !$
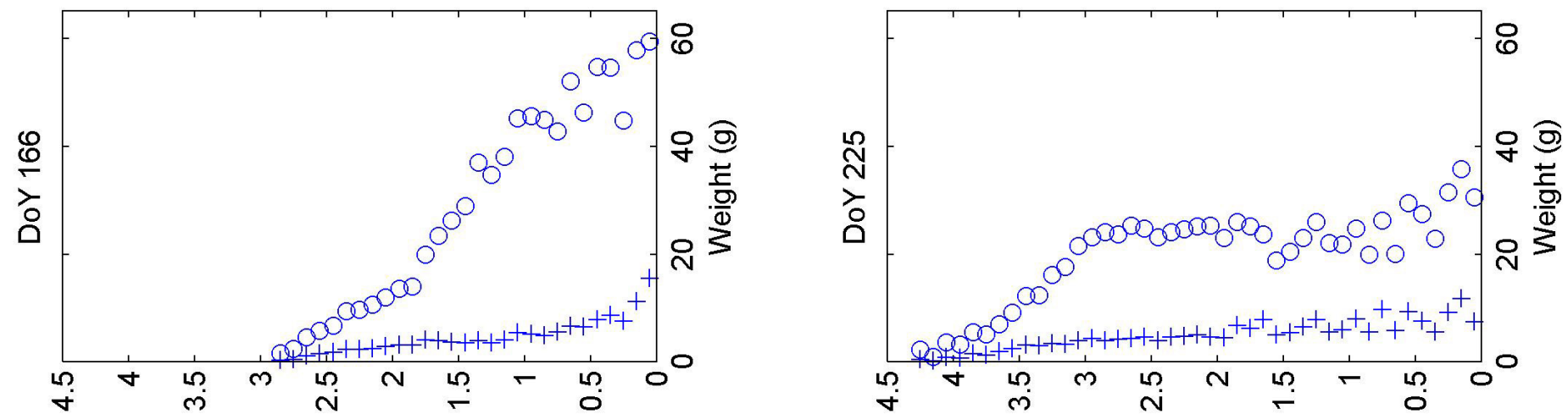

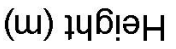

(u) $746 !$ əे
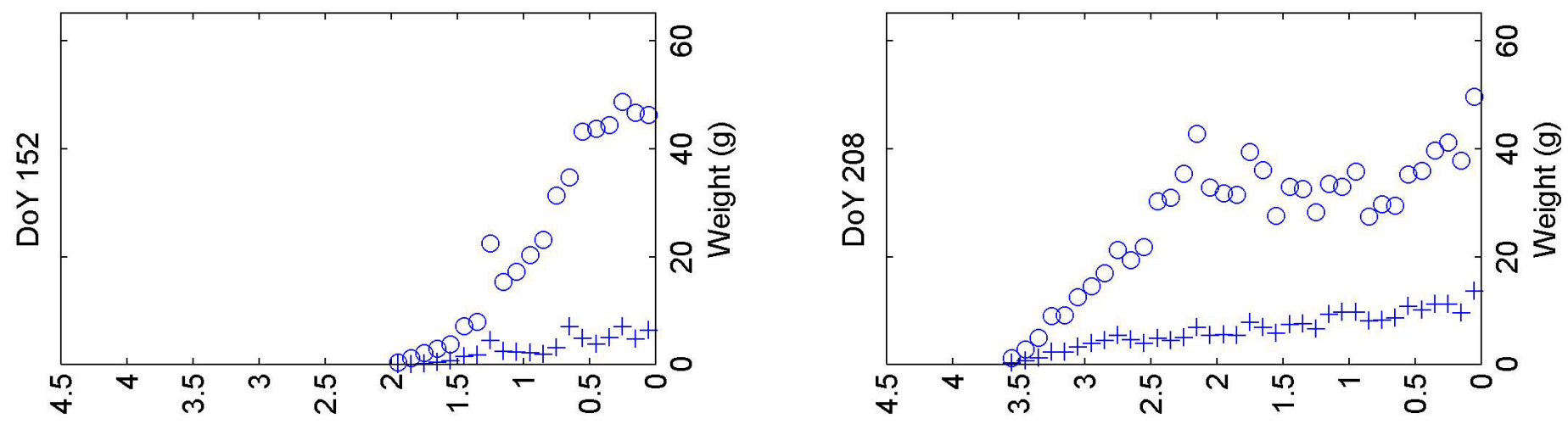

(w) +461 әे

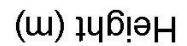

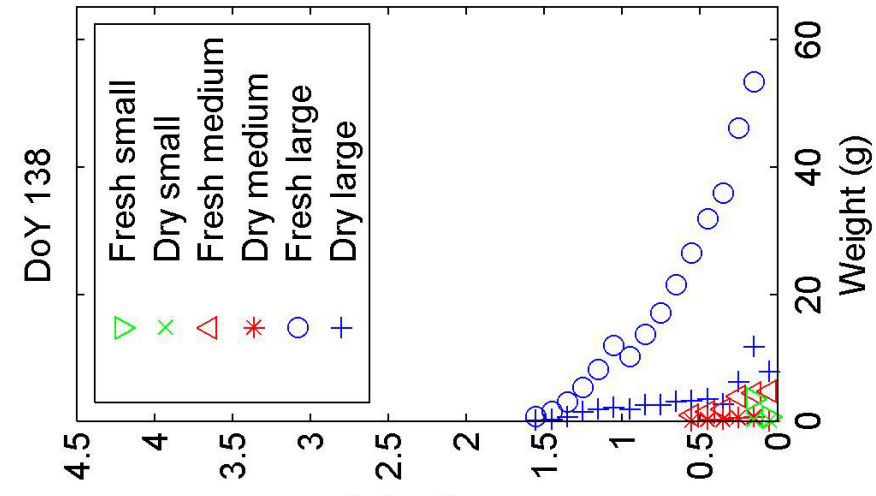

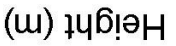

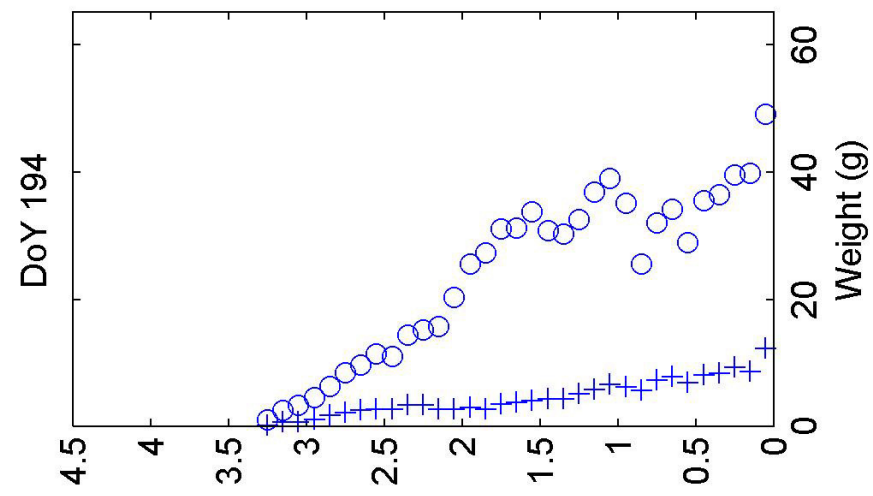

(u) $+46 !$

Figure A-21.(a) Vertical distribution of wet and dry biomass. 


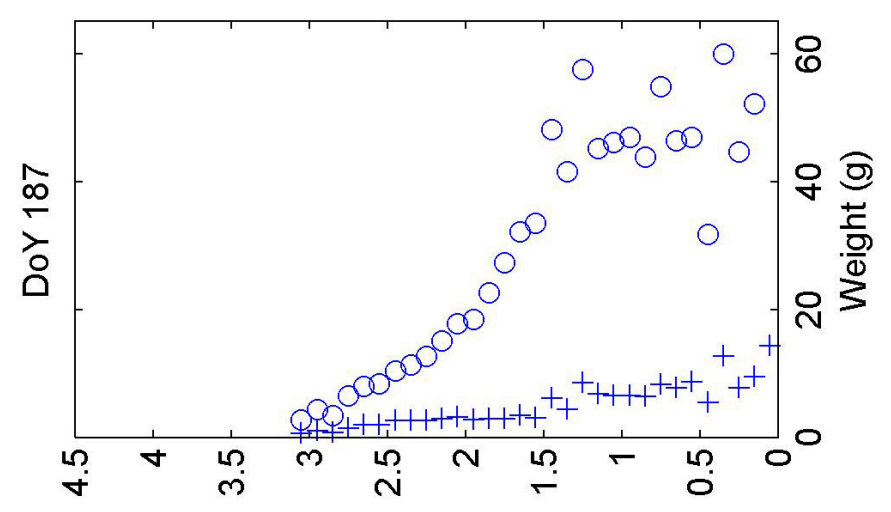

(ii) $+46 !$
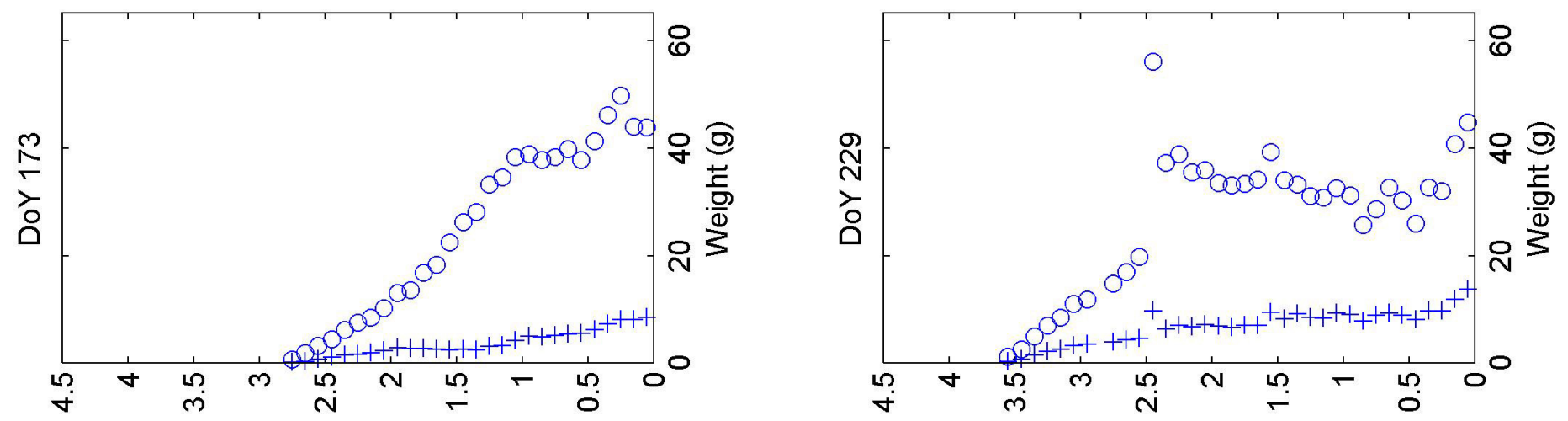

(iv) $+46 !$

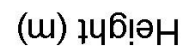

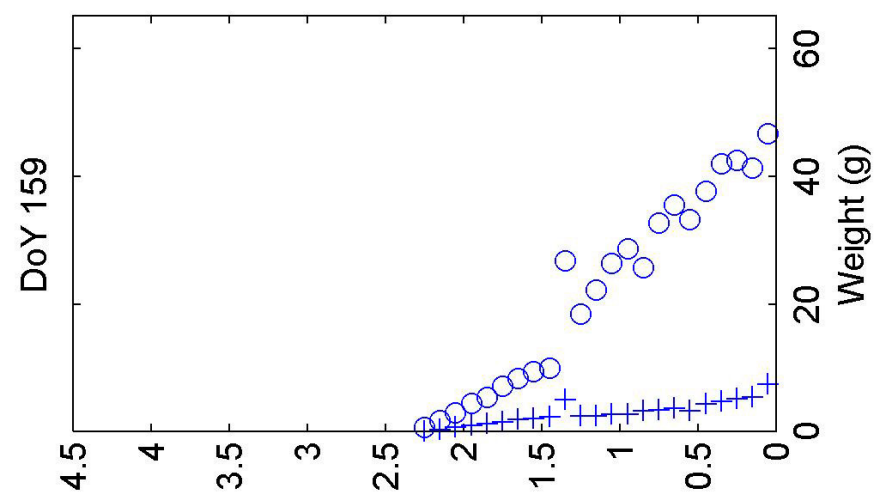

(w) $+46 !$

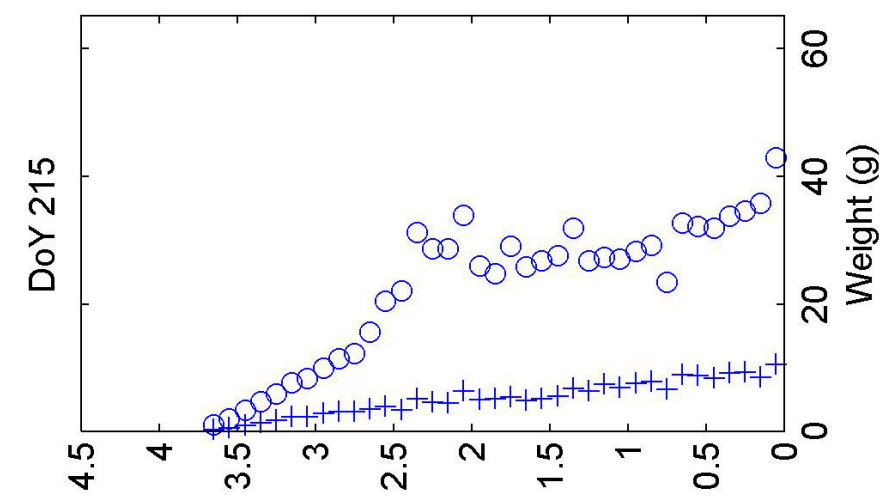

(w) $+46 !$

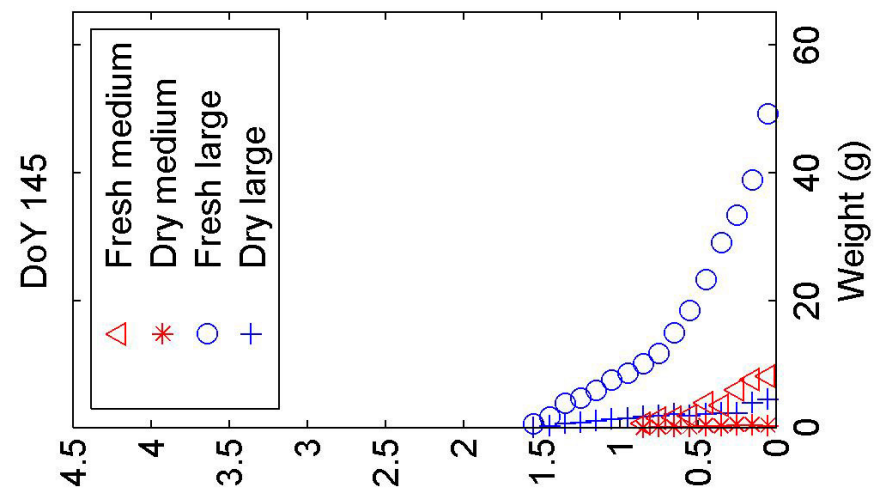

(w) $+46 !$

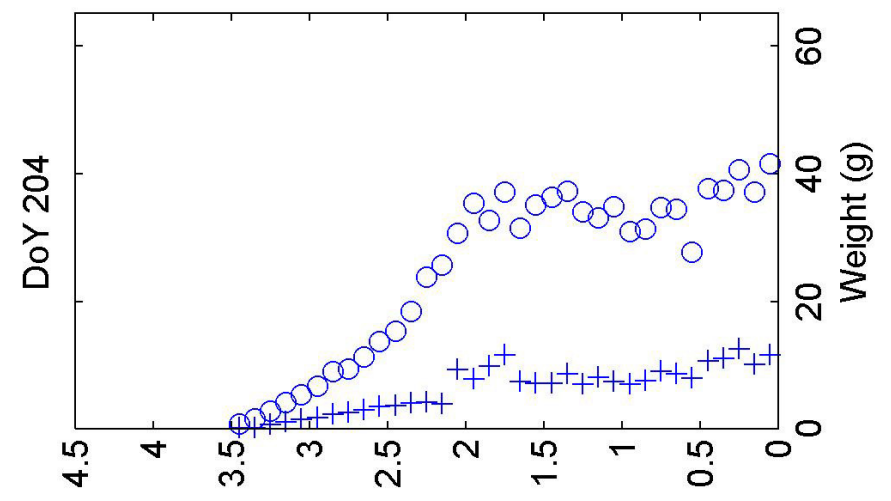

(w)

Figure A-21. (b) Vertical distribution of wet and dry biomass. 

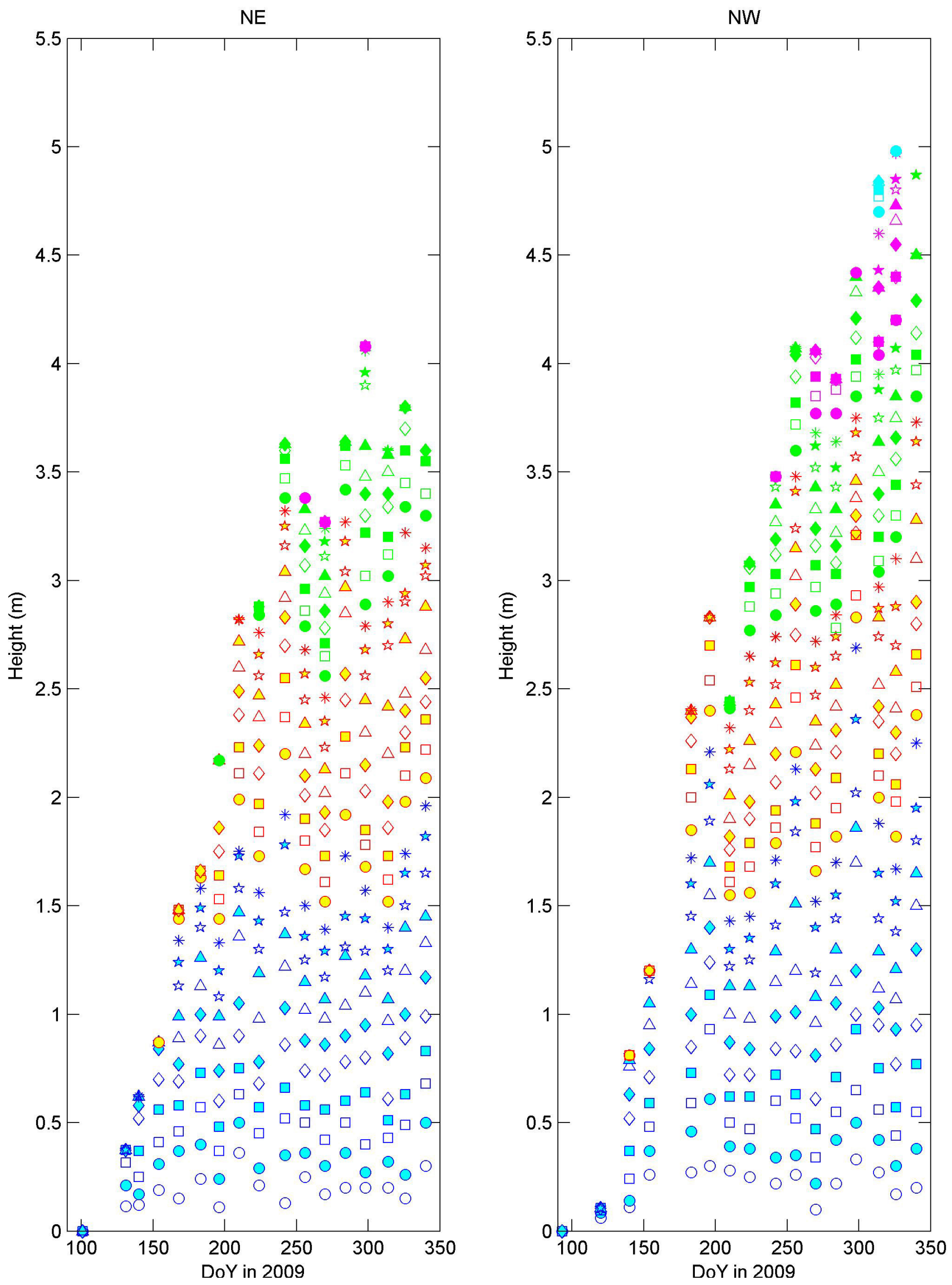

Figure A-22. (a) Leaf height. 

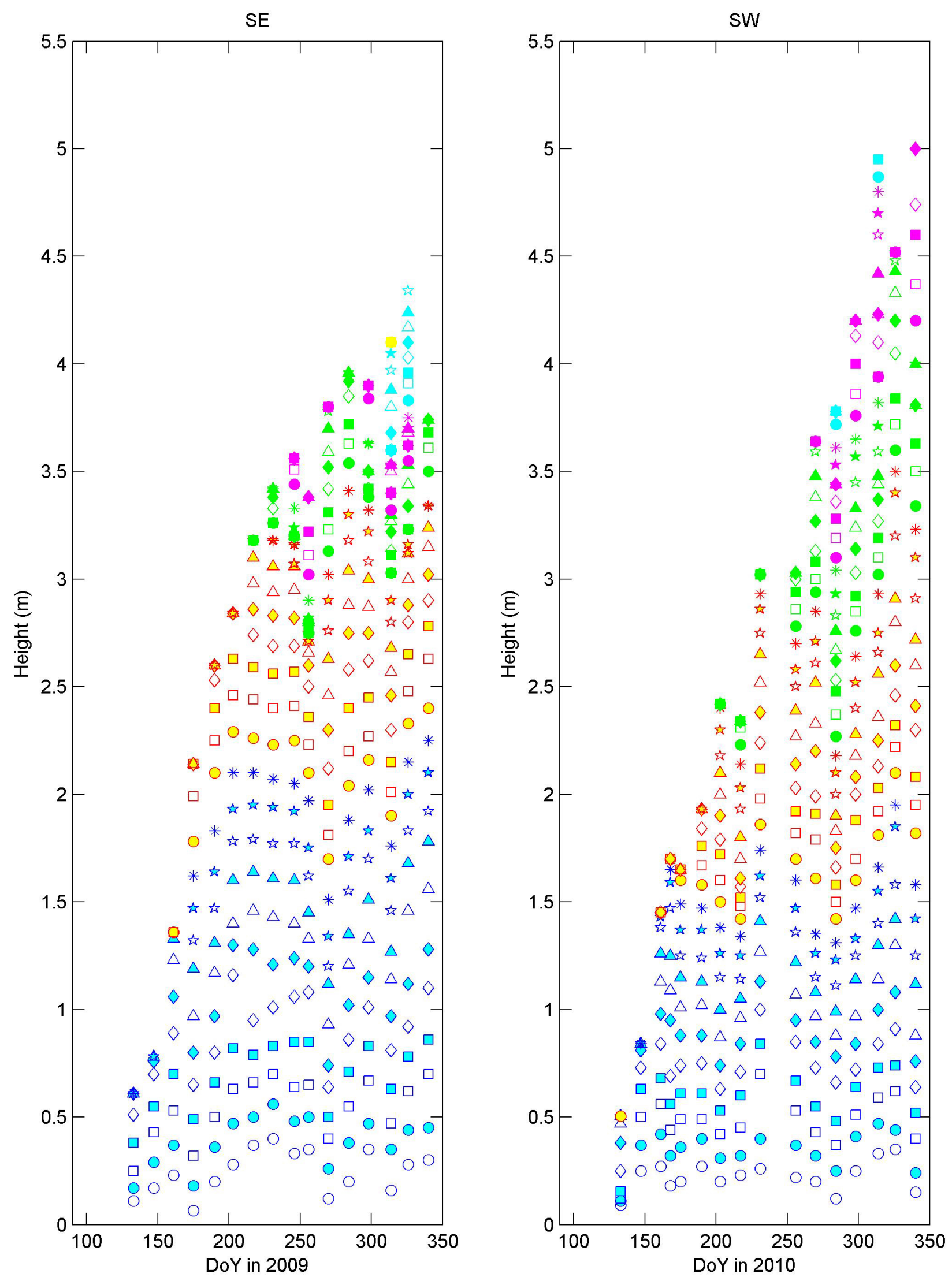

Figure A-22. (b) Leaf height. 

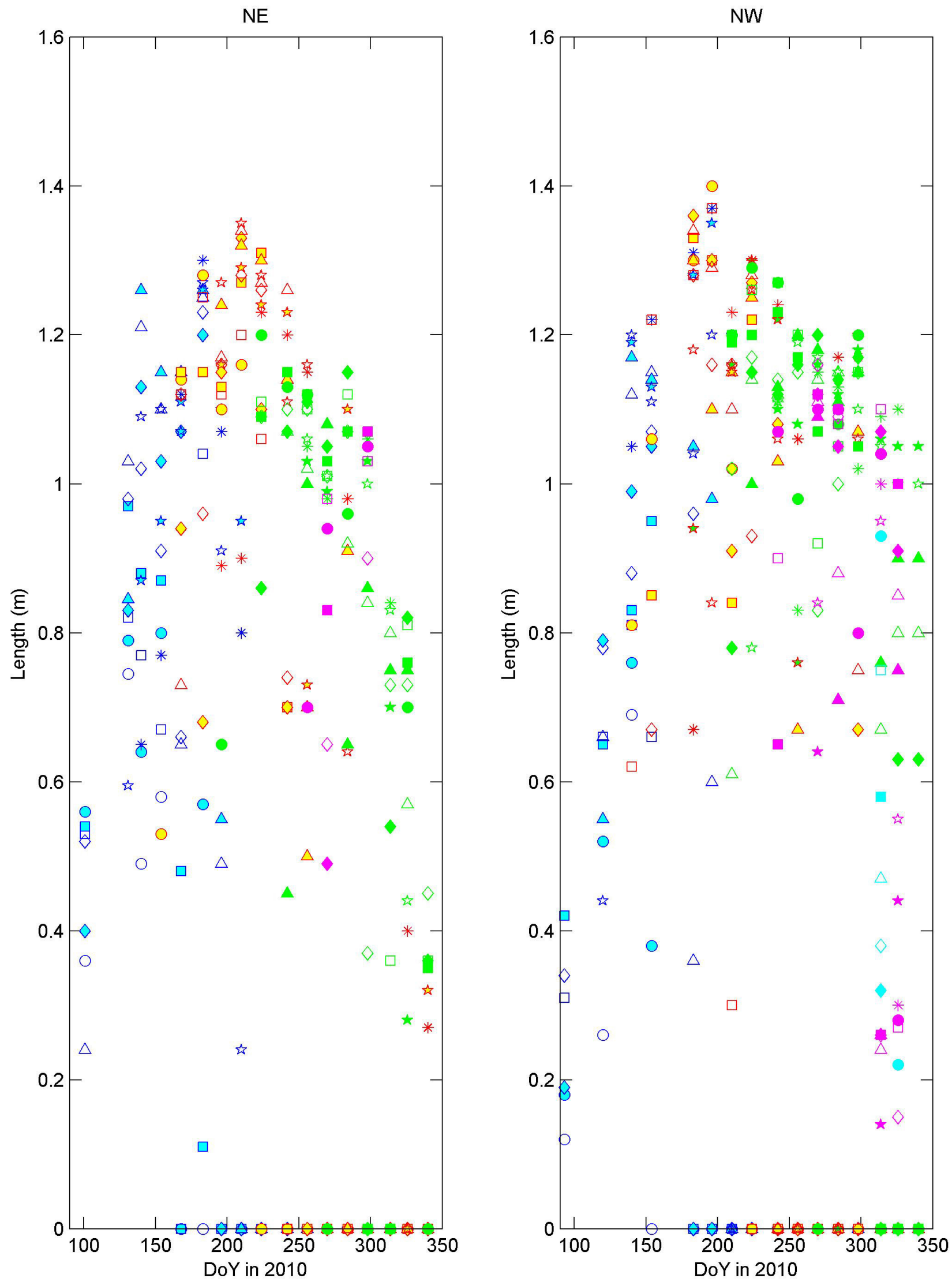

Figure A-23. (a) Leaf length. 

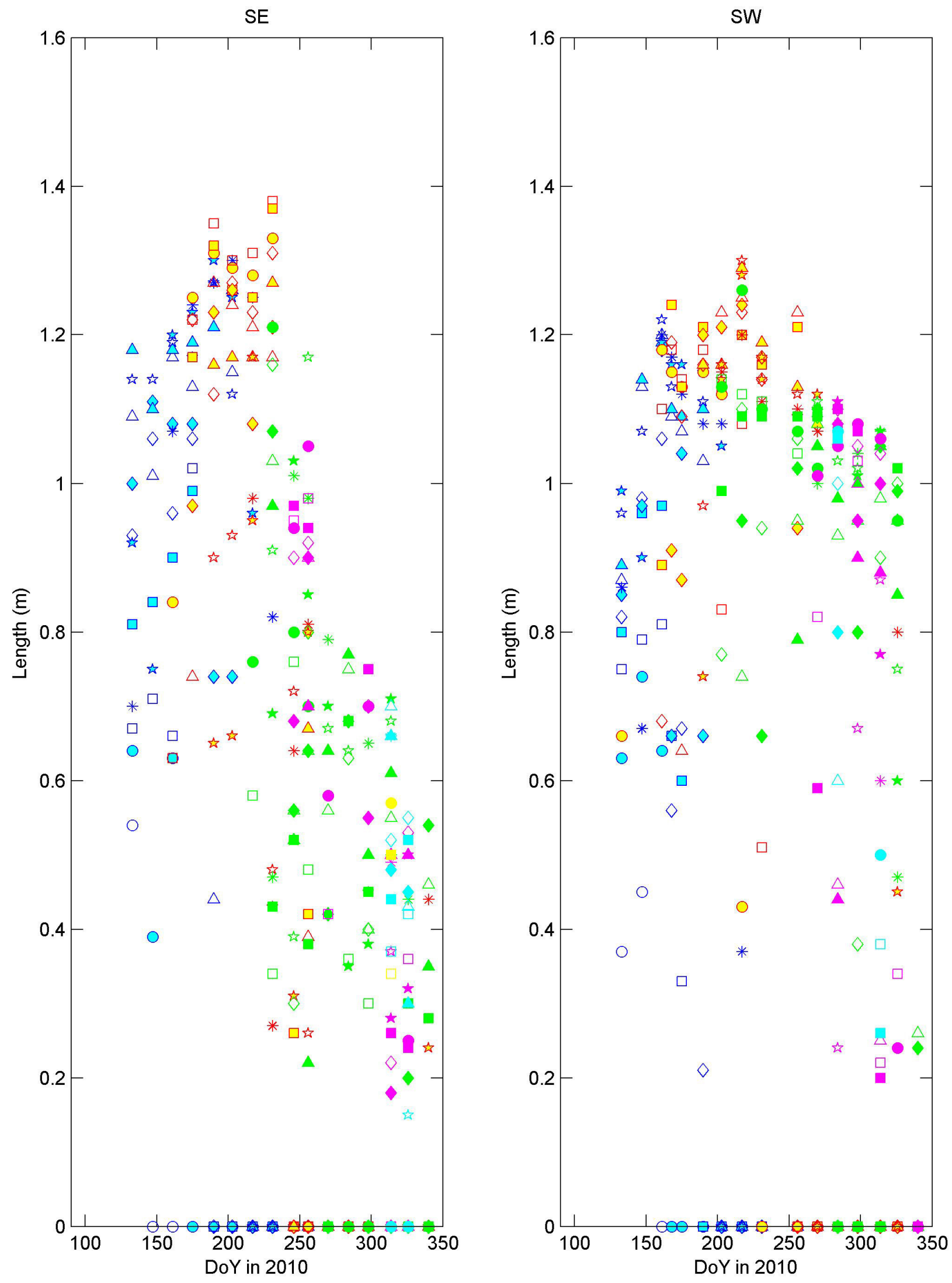

Figure A-23. (b) Leaf length. 

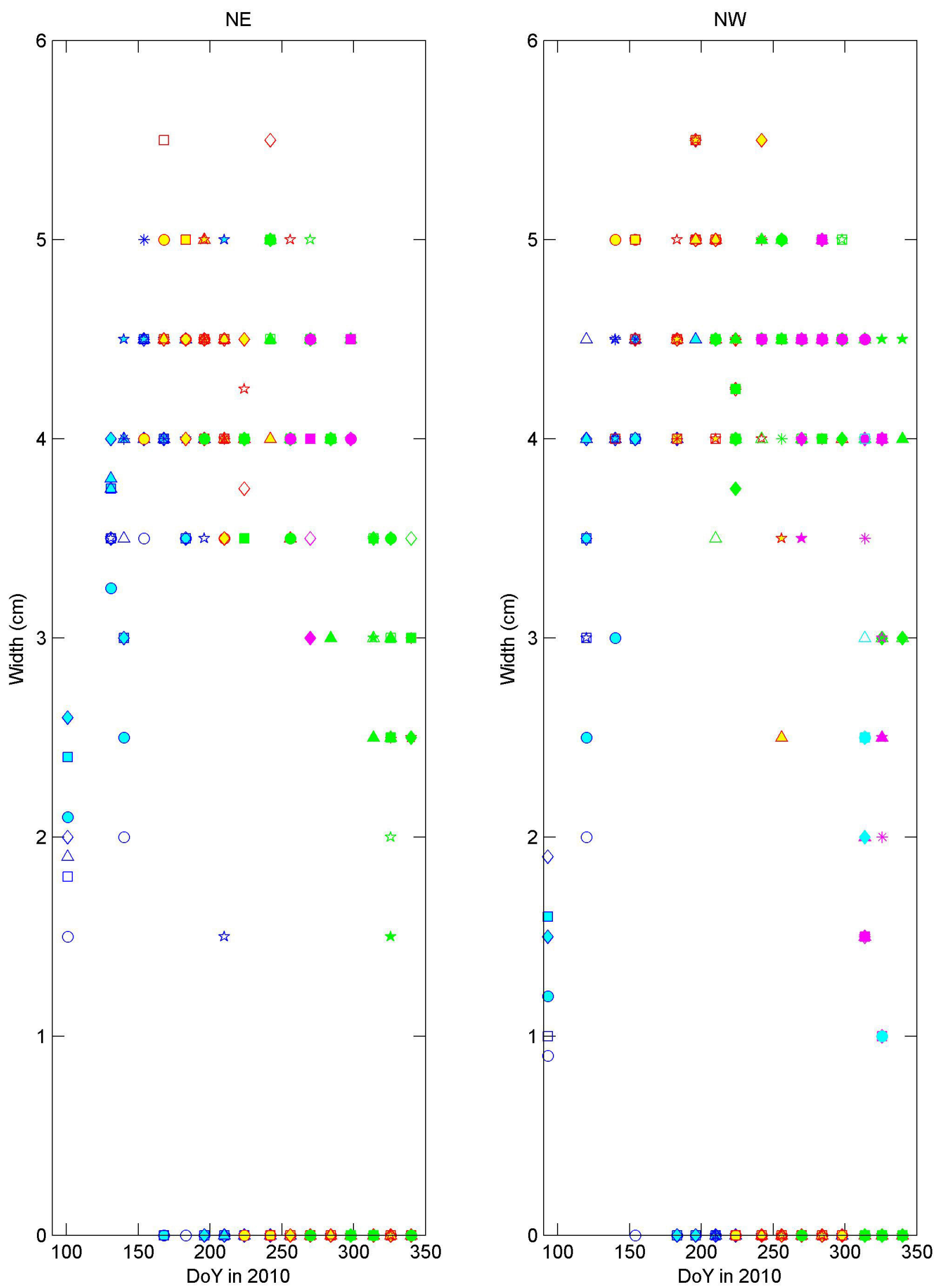

Figure A-24. (a) Leaf width. 

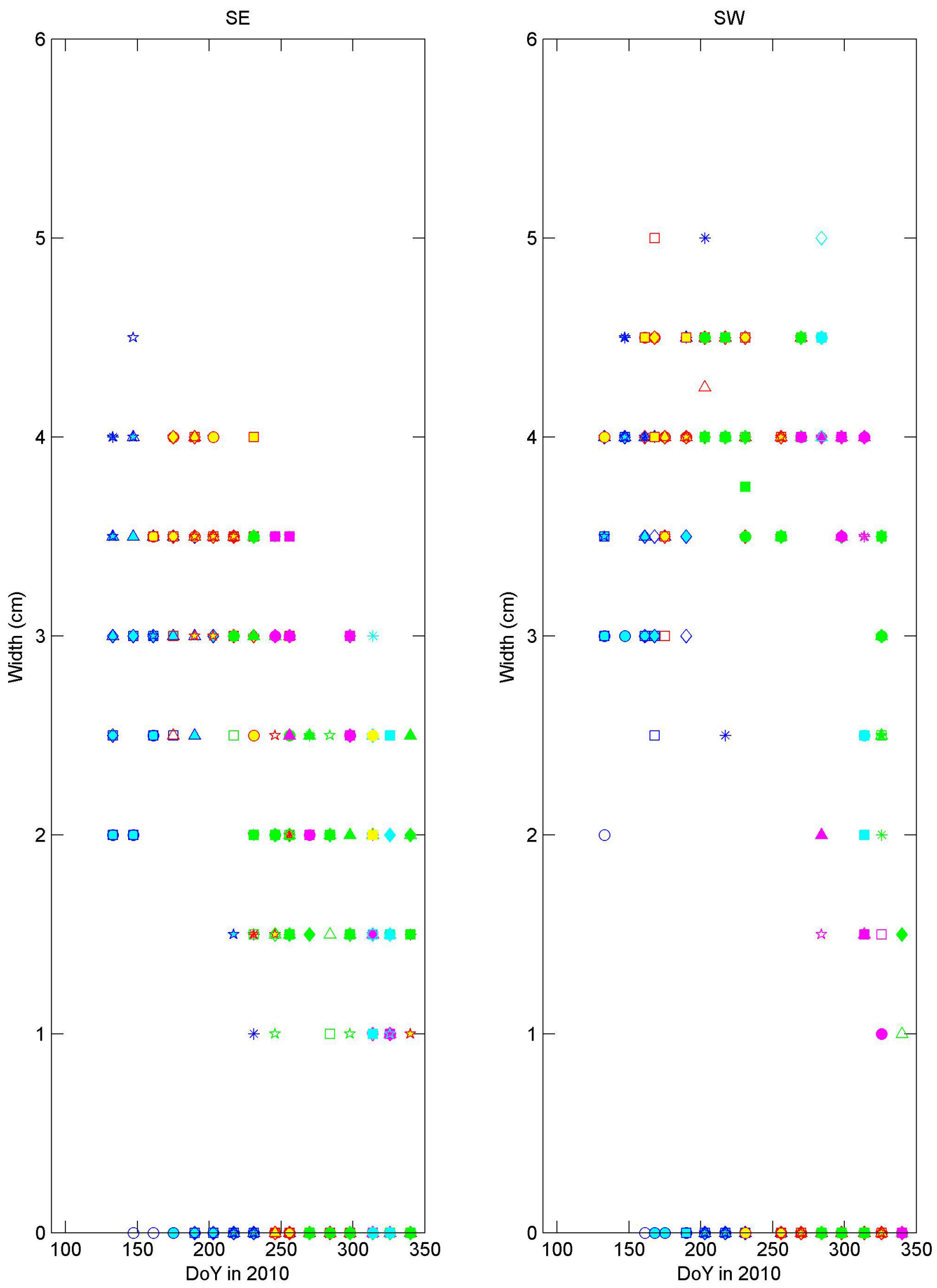

Figure A-24. (b) Leaf width. 

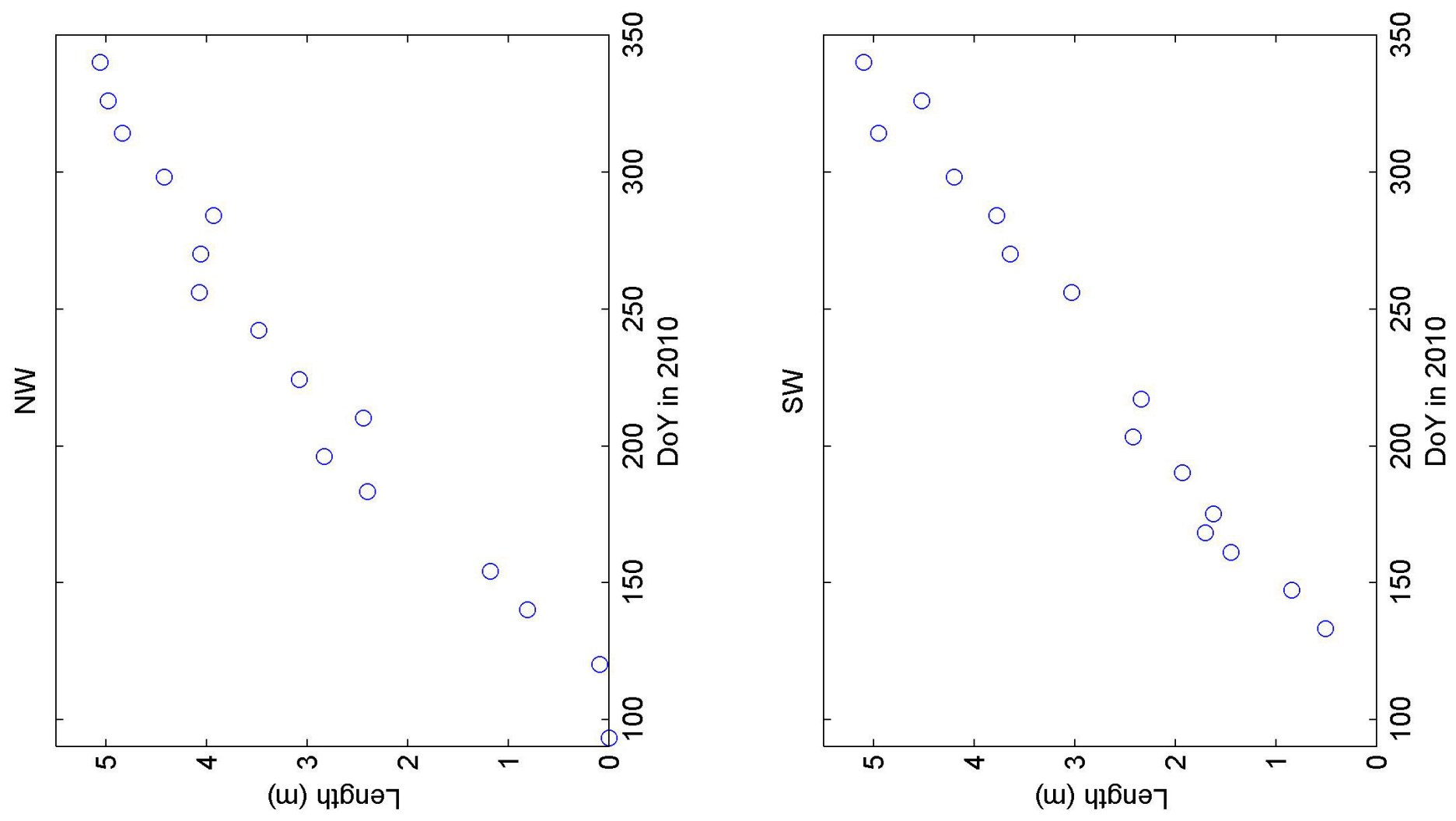

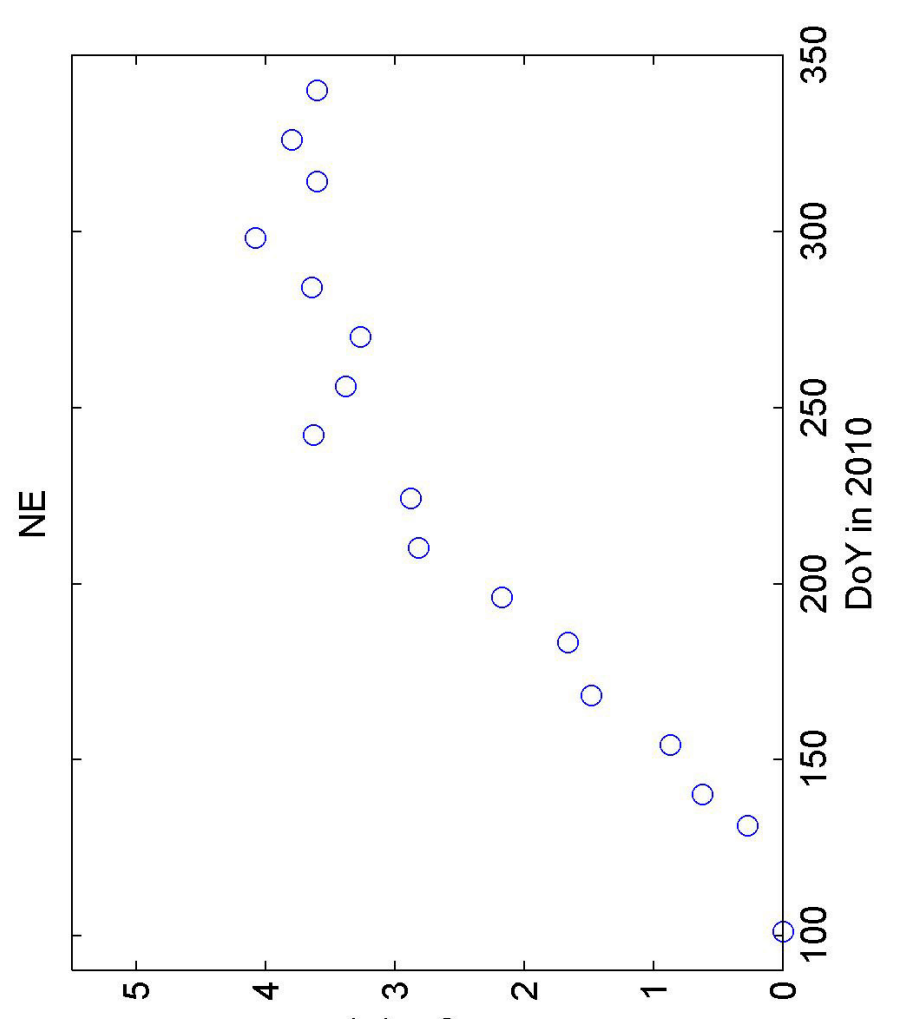

(ii) чฺ๐นәך

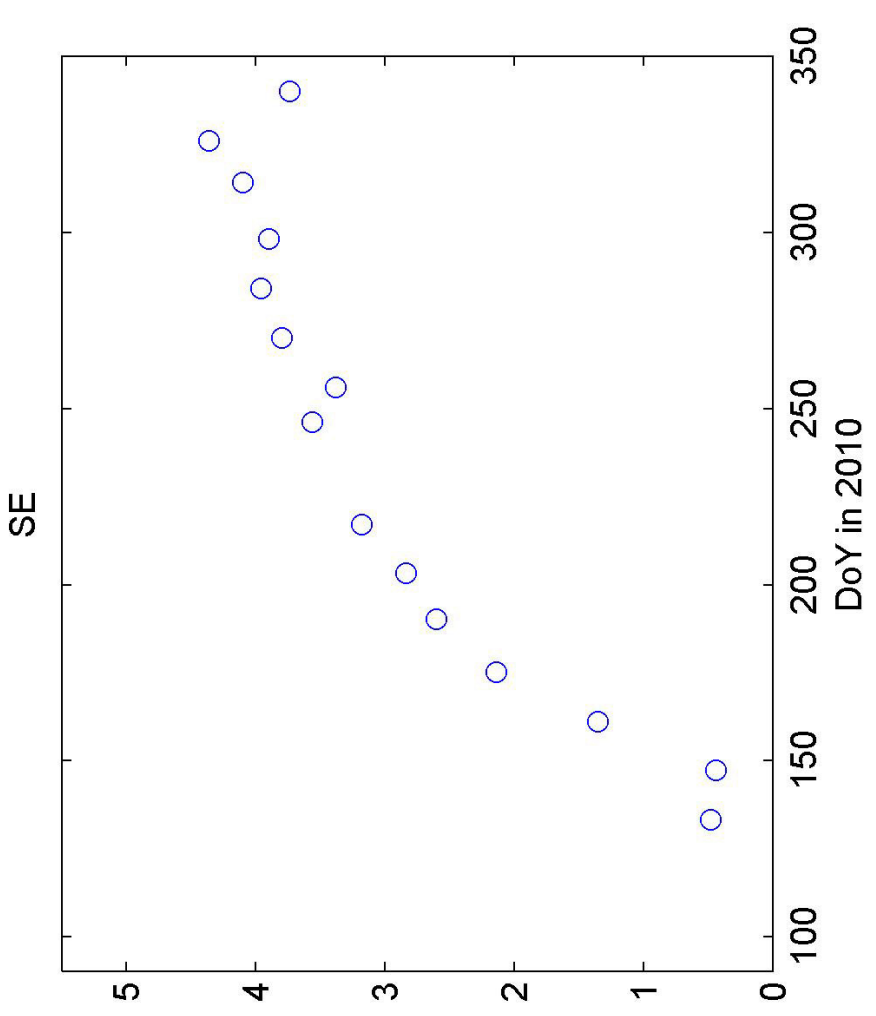

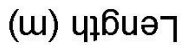

Figure A-25. Stem length. 


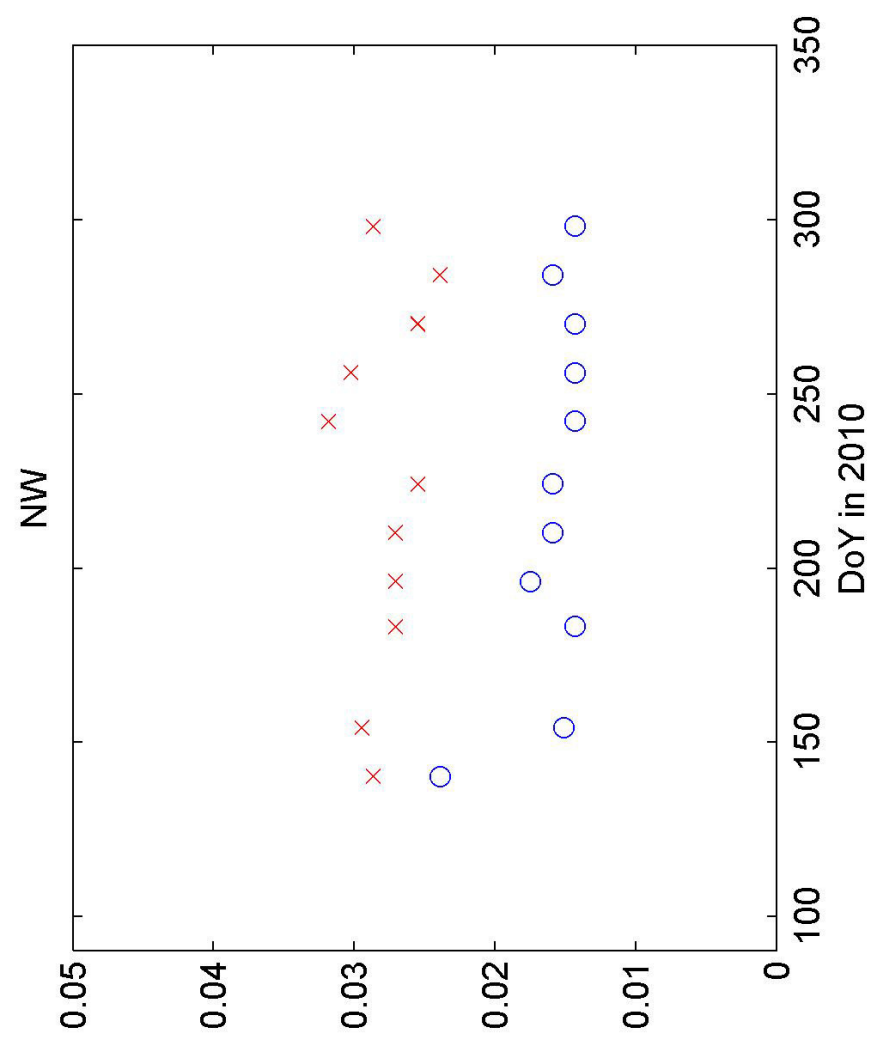

(ii) me!c

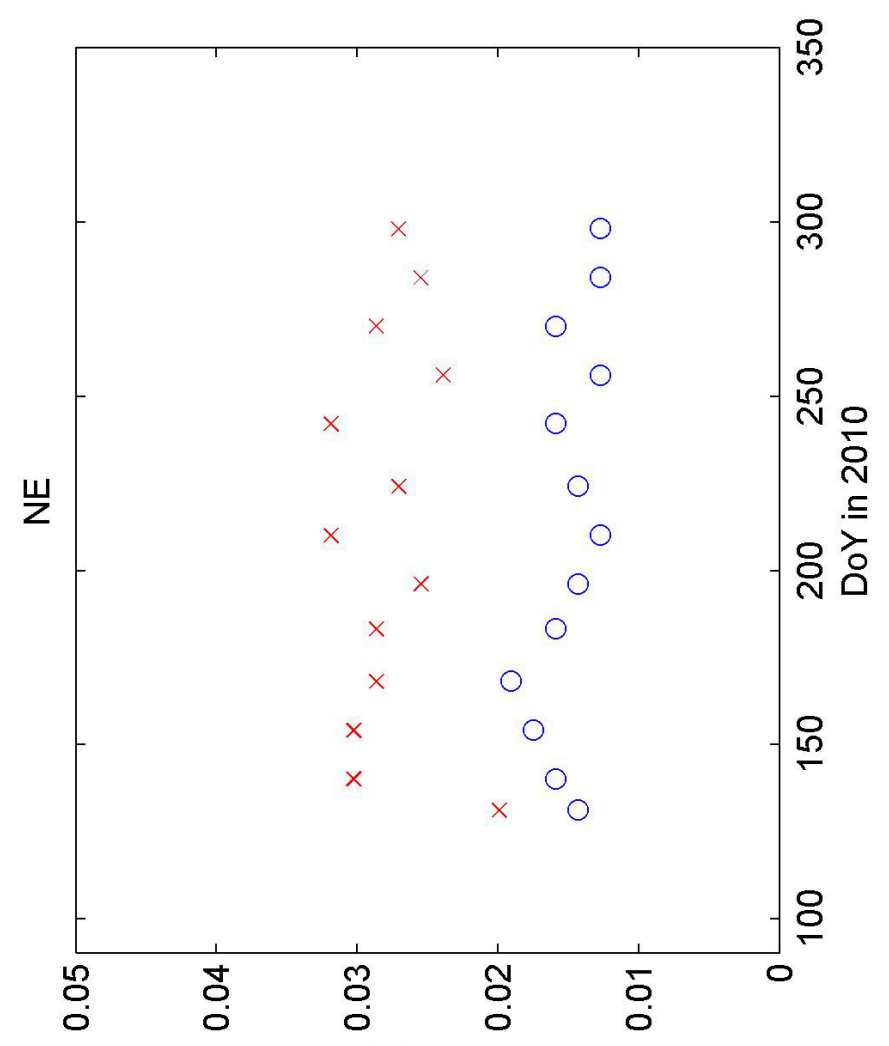

(u) me!

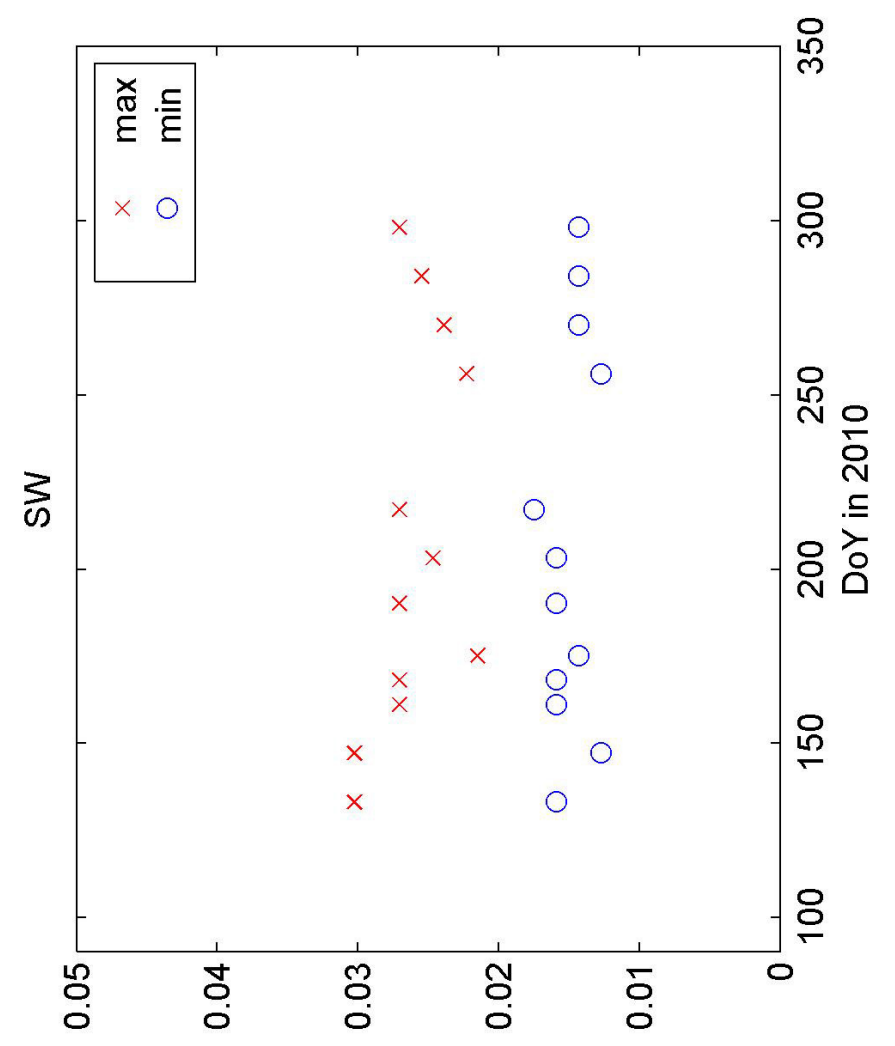

(w) me!

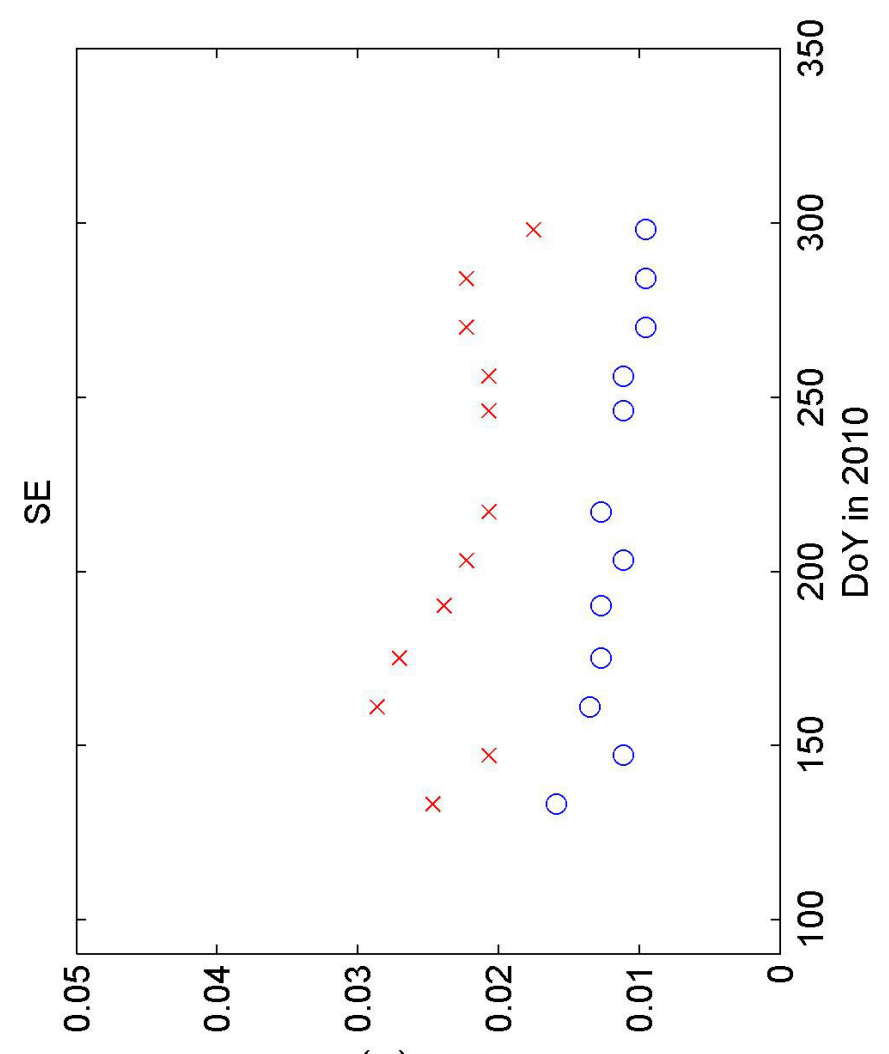

(U) me!

Figure A-26. Stem diameter. 


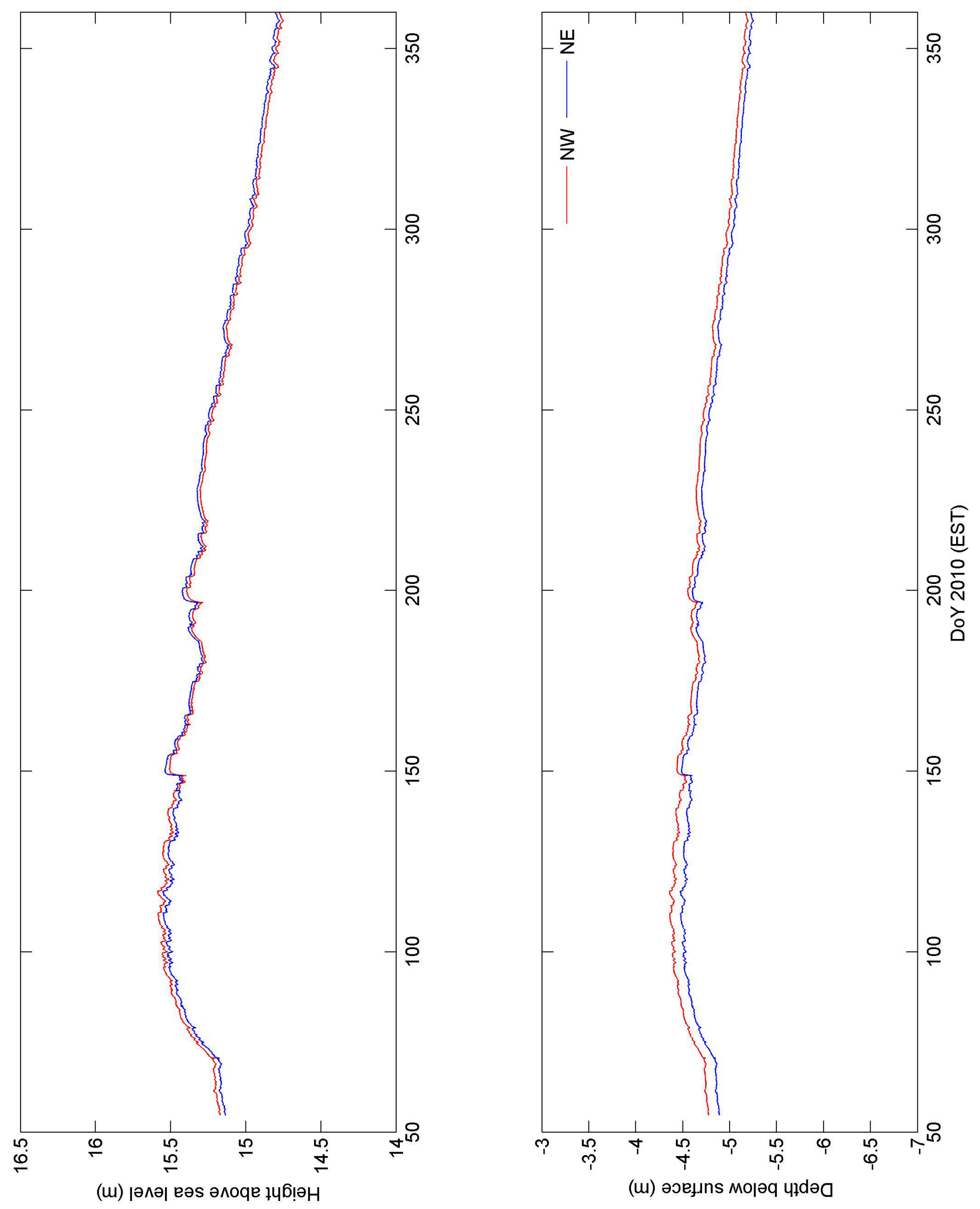

Figure A-27. Water table depth and elevation above sea level. 


\section{B. JULIAN DAY CALENDAR}

Table B-1. Julian Day Calendar for non-leap years

\begin{tabular}{|c|c|c|c|c|c|c|c|c|c|c|c|c|}
\hline & Jan & Feb & Mar & Apr & May & Jun & Jul & Aug & Sep & Oct & Nov & Dec \\
\hline 1 & 1 & 32 & 60 & 91 & 121 & 152 & 182 & 213 & 244 & 274 & 305 & 335 \\
\hline 2 & 2 & 33 & 61 & 92 & 122 & 153 & 183 & 214 & 245 & 275 & 306 & 336 \\
\hline 3 & 3 & 34 & 62 & 93 & 123 & 154 & 184 & 215 & 246 & 276 & 307 & 337 \\
\hline 4 & 4 & 35 & 63 & 94 & 124 & 155 & 185 & 216 & 247 & 277 & 308 & 338 \\
\hline 5 & 5 & 36 & 64 & 95 & 125 & 156 & 186 & 217 & 248 & 278 & 309 & 339 \\
\hline 6 & 6 & 37 & 65 & 96 & 126 & 157 & 187 & 218 & 249 & 279 & 310 & 340 \\
\hline 7 & 7 & 38 & 66 & 97 & 127 & 158 & 188 & 219 & 250 & 280 & 311 & 341 \\
\hline 8 & 8 & 39 & 67 & 98 & 128 & 159 & 189 & 220 & 251 & 281 & 312 & 342 \\
\hline 9 & 9 & 40 & 68 & 99 & 129 & 160 & 190 & 221 & 252 & 282 & 313 & 343 \\
\hline 10 & 10 & 41 & 69 & 100 & 130 & 161 & 191 & 222 & 253 & 283 & 314 & 344 \\
\hline 11 & 11 & 42 & 70 & 101 & 131 & 162 & 192 & 223 & 254 & 284 & 315 & 345 \\
\hline 12 & 12 & 43 & 71 & 102 & 132 & 163 & 193 & 224 & 255 & 285 & 316 & 346 \\
\hline 13 & 13 & 44 & 72 & 103 & 133 & 164 & 194 & 225 & 256 & 286 & 317 & 347 \\
\hline 14 & 14 & 45 & 73 & 104 & 134 & 165 & 195 & 226 & 257 & 287 & 318 & 348 \\
\hline 15 & 15 & 46 & 74 & 105 & 135 & 166 & 196 & 227 & 258 & 288 & 319 & 349 \\
\hline 16 & 16 & 47 & 75 & 106 & 136 & 167 & 197 & 228 & 259 & 289 & 320 & 350 \\
\hline 17 & 17 & 48 & 76 & 107 & 137 & 168 & 198 & 229 & 260 & 290 & 321 & 351 \\
\hline 18 & 18 & 49 & 77 & 108 & 138 & 169 & 199 & 230 & 261 & 291 & 322 & 352 \\
\hline 19 & 19 & 50 & 78 & 109 & 139 & 170 & 200 & 231 & 262 & 292 & 323 & 353 \\
\hline 20 & 20 & 51 & 79 & 110 & 140 & 171 & 201 & 232 & 263 & 293 & 324 & 354 \\
\hline 21 & 21 & 52 & 80 & 111 & 141 & 172 & 202 & 233 & 264 & 294 & 325 & 355 \\
\hline 22 & 22 & 53 & 81 & 112 & 142 & 173 & 203 & 234 & 265 & 295 & 326 & 356 \\
\hline 23 & 23 & 54 & 82 & 113 & 143 & 174 & 204 & 235 & 266 & 296 & 327 & 357 \\
\hline 24 & 24 & 55 & 83 & 114 & 144 & 175 & 205 & 236 & 267 & 297 & 328 & 358 \\
\hline 25 & 25 & 56 & 84 & 115 & 145 & 176 & 206 & 237 & 268 & 298 & 329 & 359 \\
\hline 26 & 26 & 57 & 85 & 116 & 146 & 177 & 207 & 238 & 269 & 299 & 330 & 360 \\
\hline 27 & 27 & 58 & 86 & 117 & 147 & 178 & 208 & 239 & 270 & 300 & 331 & 361 \\
\hline 28 & 28 & 59 & 87 & 118 & 148 & 179 & 209 & 240 & 271 & 301 & 332 & 362 \\
\hline 29 & 29 & & 88 & 119 & 149 & 180 & 210 & 241 & 272 & 302 & 333 & 363 \\
\hline 30 & 30 & & 89 & 120 & 150 & 181 & 211 & 242 & 273 & 303 & 334 & 364 \\
\hline 31 & 31 & & 90 & & 151 & & 212 & 243 & & 304 & & 365 \\
\hline
\end{tabular}

